UNIVERSIDADE DE SÃO PAULO

INSTITUTO DE FÍSICA DE SÃO CARLOS

\title{
CARACTERIZAÇÃO DAS PROPRIEDADES FÍSICAS DE POLIANILINAS UTILIZANDO TÉCNICAS ESPECTROSCÓPICAS
}

\author{
José Eduardo de Albuquerque
}

or

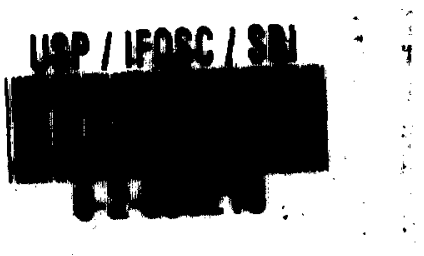

Tese apresentada ao Instituto de Física de São Carlos para a obtenção do título de Doutor em Ciências: Física Aplicada

Orientador: Prof. Dr. Roberto Mendonça Faria

Departamento de Física e Ciência dos Materiais

São Carlos - 1996

IFSC-USP 
MEMBROS DA COMISSÃO JULGADORA DA TESE DE DOUFOXX (016) 272-2218 DÉ EDUARDO DE ALBUQUEROUE APRESENTADA AO INSTITUTO DE FÍSICA DE SÃO CARLOS, UNIVERSIDADE DE SÃO PAULO, EM 04/06/1996.

\section{COMISSÃO JULGADORA:}
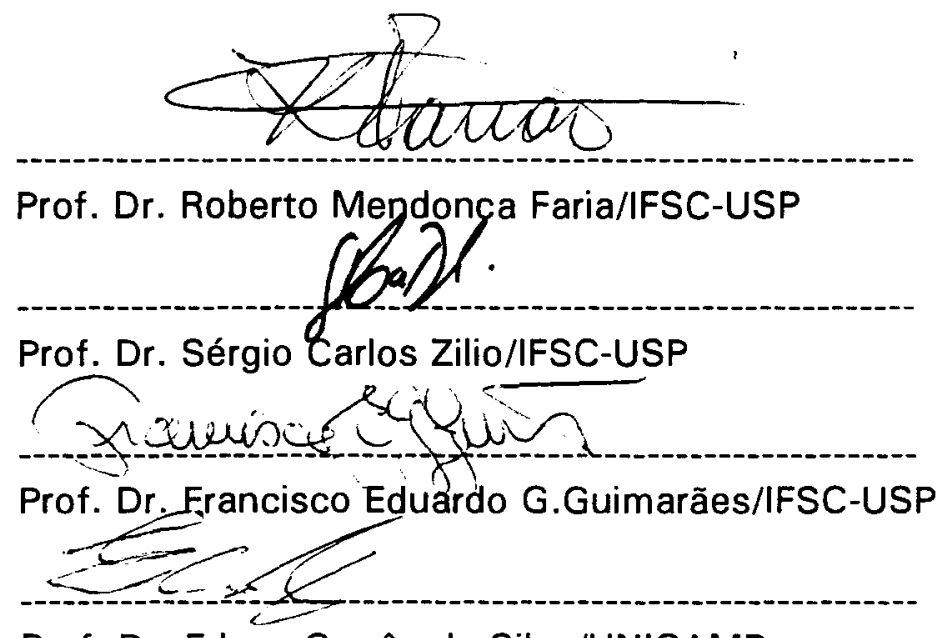

Prof. Dr. Edson Corrêa da Silva/UNICAMP

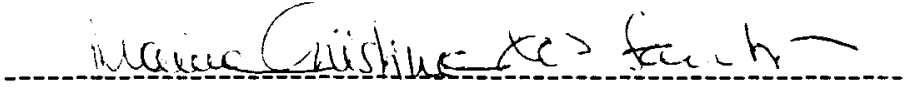

Profa. Dra. Maria Cristina dos Santos/UNICAMP

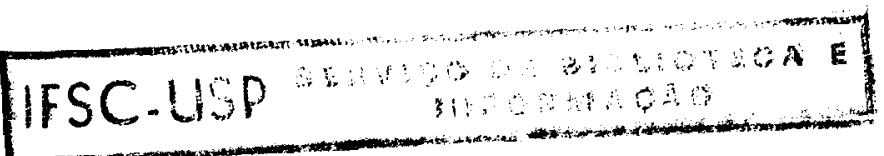




\section{AGRADECIMENTOS}

Ao prof. Roberto Mendonça Faria, pela orientação, pelo otimismo, pela força dada nos momentos mais difíceis e pela sua amizade.

Ao pesquisador Luiz Henrique C. Mattoso do CNPDIA/EMBRAPA, pela discussão e colaboração em parte deste trabalho e pela amizade.

Aos professores do Grupo de Polímeros, pela acolhida e amizade.

Aos técnicos do Grupo de Polímeros, José Bertho, Níbio e Ademir, pela ajuda técnica, e amizade.

Às secretárias do Grupo de Polímeros, Rosângela e Ivone, pela ajuda e amizade.

Aos colegas José de Souza Nogueira e Luiz Francisco Malmonge, pelo fornecimento das matérias-primas utilizadas neste trabalho, pelo companheirismo e amizade.

Aos demais colegas do Grupo de Polímeros, Sarita, Totó, Cazé, Aldo, Haroldo, José Malmonge e todos os outros, pelo companheirismo e amizade.

Ao prof. Washington Luiz B. Melo do DEE/UNESP/Ilha Solteira-SP, pela cessão do seu laboratório de Fototérmica para a realização das medidas e pela amizade. 
Ao pesquisador Ladislau Martin Neto do CNPDIA/EMBRAPA, pela cessão do seu laboratório para a realização das medidas de espectroscopia UV-visível.

Ao prof. Otaciro R. Nascimento do Grupo de Biofísica, pela cessão do espectrofotômetro para a realização das medidas espectroscópicas qualitativas.

À técnica Isabel do Grupo de Biofísica, pela ajuda e amizade.

A todos que direta ou indiretamente contribuíram para a realização deste trabalho.

Aos colegas do Departamento de Física da Universidade Federal de Viçosa, que permitiram a realização do curso de Doutorado.

À Capes, pelo suporte financeiro. 


\section{AGRADECIMENTOS ESPECIAIS}

Desejo agradecer especialmente aos meus pais, Holokx e Maria José, pelo carinho e amor dado em todos esses anos da minha vida, pela incansável e árdua luta de dar a educação aos seus dez filhos e por tudo que conseguimos até hoje.

Agradeço especialmente à minha esposa, Rozana, pelo amor e carinho e pela ajuda e compreensão em todos esses anos de estudo. Sem ela, não teria conseguido terminar esses estudos.

Agradeço também à minha filha, Julianna, pela alegria proporcionada ao longo desses anos. 
Dedico este trabalho

Aos meus pais

À minha esposa

À minha filha 


\section{SUMÁRIO}

Lista de Figuras $\quad$ iv

Lista de Tabelas $\quad$ xi

Resumo xii

Abstract xiii

INTRODUÇÃO 1

CAPÍTULO I - PROPRIEDADES DE ABSORÇÃO ÓTICA DE POLIANILINAS 8

$\begin{array}{ll}\text { I.1 - Introdução } & 10\end{array}$

I.2 - Dopagem de Polianilinas 11

I.3 - Absorção Ótica da Polianilina $\quad 12$

1.4 - Metodologia Experimental 15

$\begin{array}{ll}\text { I.5 - Resultados e Discussão } & 16\end{array}$

$\begin{array}{ll}\text { I.6 - Conclusões } & 19\end{array}$

\section{CAPÍTULO II - ESTUDO DA INTERCONVERSÃO DOS ESTADOS DE OXIDAÇÃO} DAS POLIANILINAS 21

II.1 - Introdução 23

II.2 - Estados de Oxidação das Polianilinas 24

II.3 - Pontos Isobésticos 25

II.4 - Metodologia Experimental 26

II.4.1 - Reações de Oxidação e de Redução das Polianilinas 26

II.4.2 - Cálculos Estequiométricos $\quad 27$

II.4.3 - Método para Determinação dos Estados de Oxidação 28

II.5 - Resultados e Discussão 29

II.5.1 - Obtenção de Pontos Isobésticos 29

II.5.2 - Estudo Qualitativo da Degradação da PANI em Solução 33

II.5.3 - Determinação dos Estados de Oxidação 37

II.5.3.1 - Para a PANI no Ambiente Livre 37 
II.5.3.2 - Para a PANI em Ambiente Inerte 41

II.5.3.3 - Para a POMA no Ambiente Livre 43

II.5.4 - Método da Deconvolução de Bandas 46

II.5.5 - Aplicação dos Métodos Anteriores 48

$\begin{array}{ll}\text { II. } 6 \text { - Conclusões } & 50\end{array}$

CAPÍTULO III - ESPECTROSCOPIA FOTOTÉRMICA DE POLIANILINAS 52

III.1 - Introdução 54

III. 2 - Metodologia Experimental 56

III.2.1 - O Espectrômetro Fototérmico 56

III.2.2 - As Células Fotopiroelétrica e Fotoacústica 58

III.2.3 - Preparação das Amostras 62

III.3 - Resultados e Discussão 63

III.3.1 - Filmes Espessos de PANI (PPES) 63

III.3.2 - Filme de POMA de Espessura entre 5 e $7 \mu$ m (PPES) 67

III.3.3 - Filmes Finos Transparentes de POMA (PPES) 69

III.3.4 - Espectroscopia Fotoacústica (PAS) dos Filmes Finos de POMA 79

$\begin{array}{ll}\text { III. } 4 \text { - Conclusões } & 81\end{array}$

CAPÍTULO IV - DETERMINAÇÃo DE PARÂMETROS TÉRMICOS E ÓTICOS DA POLIANILINA POR ESPECTROSCOPIA FOTOTÉRMICA 83

IV.1 - Introdução $\quad 85$

IV.2 - Modelo Teórico de Mandelis e Zver 86

IV.3 - Modelo Teórico de Rosencwaig e Gersho 90

IV.4 - Resultados e Discussão 92

IV.4.1 - Varredura de Frequiências na Espectroscopia PPES 92

IV.4.1.1 - Resultados para a PANI 94

IV.4.1.2 - Resultados para a POMA 98

IV.4.2 - Varredura de Comprimentos de Onda na Espectroscopia PPES $\quad 100$

IV.4.2.1 - Resultados para a PANI 102

IV.4.2.2 - Resultados para a POMA 105 
IV.4.2.3 - Efeitos na Fase do Sinal PPES para os Filmes Espessos de PANI 105

IV.4.3 - Resultados para a Espectroscopia PAS 108

IV.4.4 - Determinação do Coeficiente de Absorção Ótica por Espectroscopia PAS

IV.5 - Conclusões

CAPÍTULO V - CONCLUSÕES FINAIS

V.1 - Estudo da Interconversão dos Estados de Oxidação das Polianilinas

V.2 - Técnicas Fototérmicas Aplidadas às Polianilinas Não-dopadas e Dopadas

V.3 - Trabalhos Futuros 


\section{LISTA DE FIGURAS}

Figura 1 - Diagrama de evolução da estrutura de banda do $(\mathrm{CH})_{x}$ pela superposição do elétron $\pi$ desemparelhado em cada unidade $\mathrm{CH}$, com $\mathrm{x}$ crescendo de 2 até $\infty$.

Figura I.1 - Esquema da estrutura geométrica da poliesmeraldina: (a) antes da protonação e (b)-(d) depois da protonação.

Figura I.2 - Esquema mostrando as transições eletrônicas nas três bases de polianilina.

Figura I.3 - Espectros de absorção ótica de um filme de POMA em diversos estados de dopagem.

Figura I.4 - Espectros de absorção ótica de uma solução de PANI em NMP, não-dopada e dopada.

Figura I.5 - Espectros de absorção ótica de soluções de POMA em NMP, não-dopada e dopada com $\mathrm{HCl}$ e TFA.

Figura II.1 - Espectros de absorção ótica de uma solução de PANI-EB em NMP, onde foram adicionados, em etapas, quantidades pequenas de redutor.

Figura II.2 - Espectros de absorção ótica de uma solução de PANI-EB em NMP, onde foi adicionada uma pequena quantidade de oxidante $(0,1 \mathrm{mg})$, obtidos com o decorrer do tempo. 
Figura II.3 - Espectros de absorção ótica de uma solução de POMA-EB em NMP, onde foram adicionados pequenas quantidades de redutor.

Figura II.4 - Espectros de absorção ótica, obtidos com o decorrer do tempo, de uma solução de POMA-EB em NMP, onde foi inicialmente adicionada uma pequena quantidade de oxidante.

Figura II.5 - Espectros de absorção ótica de uma solução de PANI-EB em NMP, obtidos em função do tempo.

Figura II.6 - Espectros de absorção ótica de uma solução de PANI-EB em NMP, onde foi adicionado redutor, obtidos em função do tempo.

Figura II.7 - Espectros de absorção ótica de uma solução de PANI-EB em NMP, onde foi adicionado oxidante, obtidos em função do tempo.

Figura II.8 - Espectros de absorção ótica da mesma solução de PANI-EB em NMP anterior, obtidos em função do tempo.

Figura II.9 - Espectros de absorção ótica para as 11 soluções de PANI-EB em NMP, nas quais foram adicionados redutor em 4 soluções e oxidante em 6 soluções.

Figura II.10 - Gráfico da razão das absorvâncias dos máximos das duas bandas da PANI em função do estado de oxidação 1-y. O gráfico mostra as melhores retas ajustadas aos pontos experimentais (quadrados) e o ponto de interseção.

Figura II.11 - O mesmo gráfico anterior sem o ponto experimental 1-y =0,5. 
Figura II.12 - Gráficos da energia e do comprimento de onda correspondentes ao máximo da banda em torno de $2 \mathrm{eV}$ em função do estado de oxidação 1-y.

Figura II.13 - Espectros de absorção ótica para as 11 soluções de PANI-EB em NMP (em ambiente inerte), nas quais foram adicionados redutor em 4 soluções e oxidante em 6 soluções.

Figura II.14 - Gráfico da razão das absorvâncias dos máximos das duas bandas da PANI, em ambiente inerte (losângulos), em função do estado de oxidação 1-y. O gráfico mostra as melhores retas ajustadas aos pontos experimentais (losângulos) e o ponto de interseção. Os quadrados são os dados correspondentes à PANI em ambiente livre (fig.II.10).

Figura II.15 - O mesmo gráfico da figura anterior sem o ponto experimental 1-y = 0,5.

Figura II.16 - Gráficos da energia e do comprimento de onda correspondentes ao máximo da banda em torno de $2 \mathrm{eV}$ em função do estado de oxidação 1-y, para a PANI em ambiente inerte.

Figura II.17 - Espectros de absorção ótica para as 11 soluções de POMA-EB em NMP, nas quais foram adicionados redutor em 4 soluções e oxidante em 6 soluções.

Figura II.18 - Gráfico da razão das absorvâncias dos máximos das duas bandas da POMA em função do estado de oxidação 1-y. O gráfico mostra as melhores retas ajustadas aos pontos experimentais (quadrados) e o ponto de interseção.

Figura II.19 - O mesmo gráfico anterior sem o ponto experimental 1-y = 0,5. 
Figura II.20 - Gráficos da energia e do comprimento de onda correspondentes ao máximo da banda em torno de $2 \mathrm{eV}$ em função do estado de oxidação 1-y, para a POMA no ambiente livre.

46

Figura II.21 - Gráfico da área sob a banda deconvoluída em torno de $623 \mathrm{~nm}$, em função dos estados de oxidação.

Figura III.1 - Diagrama do Espectrômetro Fototérmico. Na montagem utilizando o laser como fonte de luz (para varredura de freqüências de modulação da luz), não se usa o monocromador e a fibra ótica.

Figura III.2 - Esquema da célula fotopiroelétrica [54].

60

Figura III.3 - Esquema da célula fotoacústica.

Figura III.4 - Espectros PPES de um filme de PANI não-dopado em diversas freqüências de modulação da luz.

Figura III.5 - Idem para um filme de PANI dopado em $\mathrm{HCl} 10^{-3} \mathrm{M}$.

Figura III.6 - Idem para um filme de PANI dopado em $\mathrm{HCl} 1 \mathrm{M}$.

Figura III.7 - Fase normalizada relativa aos espectros PPES da figura III.4.

Figura III.8 - Fase normalizada relativa aos espectros PPES da figura III.6.

Figura III.9 - Espectros PPES de um filme de POMA não-dopado em três frequiências de modulação da luz. 
Figura III.10 - Fase normalizada relativa aos espectros PPES da figura anterior.

Figura III.11 - Espectros PPES de um filme fino transparente de POMA não dopado, obtido por spin coating, em três frequiências de modulação da luz.

Figura III.12 - Fase normalizada relativa aos espectros PPES da figura anterior.

Figura III.13 - Espectros PPES (amostra não estando em contato com o detetor) correspondentes à mesma amostra da figura III.11.

Figura III.14 - Fase normalizada correspondente aos espectros da figura anterior.

Figura III.15 - Espectros PPES de um filme fino transparente de POMA, obtido por spin coating, dopado em $\mathrm{HCl} 10^{-2} \mathrm{M}$, em duas freqüências de modulação da luz.

Figura III.16 - Fase normalizada correspondente aos espectros da figura anterior.

Figura III.17 - Espectros PPES (amostra não estando em contato com o detetor) para a mesma amostra anterior.

Figura III.18 - Espectros PPES de um filme fino transparente de POMA, obtido por spin coating e dopado em $\mathrm{HCl} 1 \mathrm{M}$, em três frequiências de modulação.

Figura III.19 - Fase normalizada correspondente aos espectros da figura anterior.

Figura III.20 - Espectros PPES (amostra não estando em contato com o detetor) para a mesma amostra anterior. 
Figura III.21 - Espectros de absorção ótica de um filme fino transparente de POMA em dois estados de dopagem.

Figura III.22 - Diferença espectral na forma de absorvância e de transmitância (em \%) dos dois espectros da figura anterior.

Figura III.23 - Diferença dos espectros PPES do filme de POMA dopado em $\mathrm{HCl} 1 \mathrm{M}$ para o filme não-dopado.

Figura III.24 - Diferença das fases normalizadas correspondentes aos espectros da figura anterior.

Figura III.25 - Espectros fotoacústicos para dois filmes finos transparentes de POMA, obtidos na frequiência de $10 \mathrm{~Hz}$.

Figura III.26 - Fase normalizada correspondente aos espectros PAS da figura anterior.

Figura III.27 - Diferença entre os espectros PAS do filme de POMA dopado em $\mathrm{HCl} 1 \mathrm{M} \mathrm{e} \mathrm{o}$ filme não-dopado (correspondentes à figura III.25).

Figura IV.1 - Esquema da célula fotopiroelétrica utilizada para o modelo teórico.

Figura IV.2 - Esquema da célula fotoacústica utilizada para o modelo teórico.

Figura IV.3 - Pontos experimentais obtidos e melhores curvas ajustadas para a fase e a voltagem normalizadas (Filme de PANI não-dopado). As unidades para os parâmetros estão no SI. 
Figura IV.4 - Idem para o filme de PANI dopado com $\mathrm{HCl} 10^{-3} \mathrm{M}$.

Figura IV.5 - Idem para o filme de PANI dopado com $\mathrm{HCl} 1 \mathrm{M}$.

Figura IV.6 - Gráficos do termo que antecede a $\tan \left(a_{s} L_{s}\right)$ na expressão (17) em função da freqüência de modulação, usando os parâmetros de ajuste para os filmes de PANI: (a) nãodopado; (b) dopado em $\mathrm{HCl} 10^{-3} \mathrm{M}$; e (c) dopado em $\mathrm{HCl} 1 \mathrm{M}$.

96

Figura IV.7 - Pontos experimentais obtidos e melhores curvas ajustadas para a voltagem e a fase normalizadas (Filme de POMA não-dopado). As unidades para os parâmetros estão no SI.

100

Figura IV.8 - Ajuste (linha tracejada) por duas gaussianas ao espectro de absorção ótica (linha cheia) de uma solução de PANI em NMP. À direita, estão os parâmetros de ajuste: $\mathrm{Bo}=$ intensidade, $\mathrm{l} \mathrm{w}=$ largura de linha, $\mathrm{xo}=$ posição do centro da gaussiana, com os respectivos erros.

102

Figura IV.9 - Melhores curvas ajustadas pela equação de Mandelis aos espectros para o filme de PANI: (a) não-dopado; (b) dopado em $\mathrm{HCl} 10^{-3} \mathrm{M}$; e (c) dopado em $\mathrm{HCl} 1 \mathrm{M}$.

103

Figura IV.10 - Melhores curvas ajustadas pela equação de Mandelis aos espectros do filme de POMA $(5-7 \mu \mathrm{m})$.

105

Figura IV.11 - Espectro PAS do filme fino de POMA não-dopado, mostrando a melhor curva ajustada pela equação de Rosencwaig.

Figura IV.12 - Idem para o filme fino de POMA dopado em HCl $1 \mathrm{M}$. 
Figura IV.13 - Coeficiente de absorção ótica para o filme fino de POMA não-dopado.

Figura IV.14 - Coeficiente de absorção ótica para o filme fino de POMA dopado em $\mathrm{HCl} 1$ M.

Figura IV.15 - Determinação do gap ótico através do coeficiente de absorção ótica em função da energia da transição eletrônica.

\section{LISTA DE TABELAS}

Tabela IV.1 - Resultados para os parâmetros $\left(\alpha_{\mathrm{s}} \mathrm{e} \mathrm{b}_{\mathrm{ps}}\right)$ de ajuste matemático aos pontos experimentais para Fn e Vn mostrados nas figuras IV.3 a IV.5, juntamente com os parâmetros calculados a partir deles $\left(k_{s}\right.$ e $\left.c_{s}\right)$ mais os dois medidos $\left(L_{s}\right.$ e $\left.\rho_{s}\right)$.

97

Tabela IV.2 - Resultados para o comprimento de difusão térmica para os três filmes de PANI evidenciados na tabela IV.1. 


\section{RESUMO}

As polianilinas são polímeros condutores contendo elétrons $\pi$, sendo diferentes de outros membros desta classe de polímeros por apresentarem um átomo de nitrogênio entre os anéis-fenil constituintes, quebrando a conjugação da cadeia. A flexibilidade química fornecida por esse átomo de nitrogênio na cadeia permite acesso a vários estados de oxidação distintos: as bases leucoesmeraldina, esmeraldina e pernigranilina. Essas bases podem-se converter uma nas outras por reações de oxi-redução. Neste trabalho, estudamos o processo de conversão de uma base em outra, usando o oxidante peroxidissulfato de amônia ou o redutor ácido ascórbico (vitamina C). Este estudo foi realizado com o uso da espectroscopia de absorção ótica na região ultravioleta-visível. A base esmeraldina pode ser protonada em soluções ácidas, com a consequiente alteração da cadeia polimérica, tornando o polímero de isolante para condutor elétrico. A condutividade elétrica aumenta, nesse processo, em mais de dez ordens de grandeza. Por outro lado, as propriedades térmicas não se alteram muito com o estado de protonação do polímero. Estudamos as propriedades térmicas através das técnicas fototérmicas: as espectroscopias Fotopiroelétrica e Fotoacústica. Essas técnicas mostraram ser de grande utilidade no estudo das propriedades térmicas e óticas das polianilinas nãoprotonadas e protonadas com o uso de ácido clorídrico. Realizamos medidas espectroscópicas e de sinal versus frequiência de modulação da luz. Usamos o modelo de Mandelis-Zver baseado nas equações de difusão de calor na condição de detetor termicamente espesso para o ajuste teórico-experimental, na fotopiroelétrica. Para a fotoacústica, usamos o modelo Rosencwaig-Gersho. Determinamos a difusividade e a condutividade térmicas, o calor específico, o coeficiente de absorção ótica e o gap ótico (este último para o polímero nãoprotonado). 


\begin{abstract}
The polyanilines belong to the class of the conductive polymers but, differently from the conjugated polymers, they present a nitrogen atom between "phenyl rings". The presence of this $\mathrm{N}$-atom provides a major flexibility of the molecules permiting the existence of different oxidation states: leucoemeraldine, emeraldine and pernigraniline bases. These states may be converted one into another by redox reactions. In this work, we present optical spectroscopic studies of these conversions making use of ammonium peroxydisulfate or ascorbic acid (vitamine C). The emeraldine base, under protonation in acid solutions, evolutes from an insulator to a conductive material. Its conductivity increases by a factor of more than $10^{10}$. On the other hand, as it will be shown in this thesis, the thermal properties varies only slightly under protonation of the material. These thermal properties are investigated by the photothermal techniques: photoacoustic and photopyroelectric spectroscopies. Measurements of the pyroelectric voltage and the signal phase were also studied in function of the chopping frequency. The Mandelis-Zver and the Rosencwaig-Gersho models, based on the heat diffusion equations, were used to fit the experimental results. From these fittings the thermal diffusivity, the thermal conductivity, the specific heat, the optical absorption coefficient and the optical gap of the studied polyanilines were obtained.
\end{abstract}




\section{INTRODUÇÃO}

Os polímeros condutores, mais comumente chamados de "metais sintéticos", são polímeros orgânicos que possuem propriedades elétricas, eletrônicas, magnéticas e óticas semelhante às dos metais, permanecendo com as propriedades mecânicas e a processabilidade comumente associadas com os polímeros convencionais [1,2]. Eles são obtidos pela "dopagem" de polímeros orgânicos conjugados, isolantes ou semicondutores, que possuem condutividades elétricas pequenas, tipicamente na faixa de $10^{-12}$ a $10^{-8} \mathrm{~S} / \mathrm{cm}$. O método clássico de dopagem envolve a oxidação parcial química ou eletroquímica (dopagem tipo-p), ou redução parcial (dopagem tipo-n), do sistema $\pi$ polimérico [1-3]. Essa oxidação, ou redução, implica em tranferência de carga e a inserção associada de um contra-íon (para a neutralidade total da carga).

Desde a descoberta em 1977 de que o poliacetileno, $(\mathrm{CH})_{x}$, atualmente conhecido como o protótipo dos polímeros condutores, poderia ser dopado (tipo-p ou tipo-n) química ou eletroquimicamente, alcançando, assim, um estado metálico, o campo de polímeros condutores vem crescendo rapidamente. Esse crescimento rápido não é devido apenas ao caráter interdisciplinar desse campo, envolvendo a química , a eletroquímica, a física teórica e experimental e a engenharia elétrica, mas também devido às suas potencialidades tecnológicas [1,2,4]. Assim, o "sonho" em combinar as propriedades mecânicas e de processamento dos polímeros com as propriedades óticas e elétricas dos metais vem "guiando" a ciência e a tecnologia dos polímeros condutores [4]. Estima-se que, até o final desta década, o mercado mundial de plásticos condutores (polímeros conjugados dopados) movimente uma soma da ordem de dois bilhões de dólares [4]. Dentre as aplicações desses polímeros, podemos destacar: dispositivos eletrônicos como transístores FET e MOSFET; diodos emissores de luz 
(LED) flexíveis e inteiramente livres de metais; sensores químicos; displays eletrocrômicos; baterias recarregáveis e blindagens eletromagnéticas ou anti-estáticas $[1,2,4]$.

No estado dopado, a cadeia de um polímero condutor consiste de um sistema $\pi$ deslocalizado [1-5]. No estado não-dopado, o polímero pode possuir uma cadeia conjugada, como no caso do trans-poliacetileno, que pode ser mantida ou modificada depois da dopagem. A estrutura de banda do trans-poliacetileno, considerando uma molécula unidimensional idealizada, pode ser vista na figura 1 . Vê-se, diagramaticamente, como as unidades $\mathrm{CH}$ se unem, cada uma contendo um elétron $\pi$ não-emparelhado, para formar a banda preenchida $\pi$ (banda de valência) e a banda vazia $\pi^{*}$ (banda de condução). Quando x é muito grande, cada orbital molecular $\mathrm{p}$ (preenchido) possui uma energia bem próxima da dos orbitais imediatamente abaixo e acima dele. Assim, os orbitais são considerados como formando um "contínuo" de estados de energia, sendo descritos como banda de valência. Analogamente, um efeito similar acontece com os orbitais moleculares $\pi^{*}$ (vazios), formando a banda de condução.

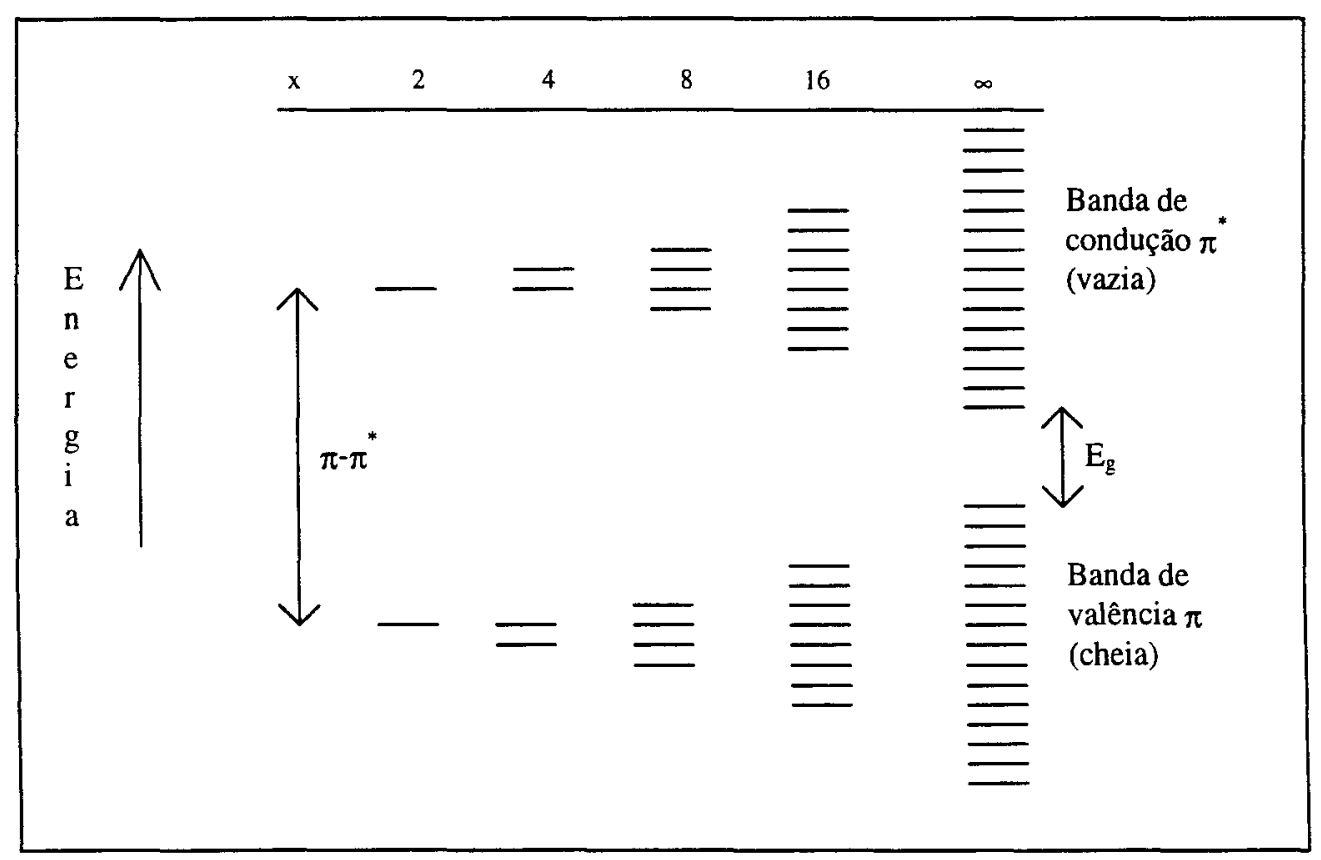

Figura 1 - Diagrama de evolução da estrutura de banda do $(\mathrm{CH})_{\mathbf{x}}$ pela superposição do elétron $\pi$ desemparelhado em cada unidade $\mathrm{CH}$, com $\mathrm{x}$ crescendo de 2 até $\infty$. 
A diferença de energia (transição $\pi-\pi^{*}$ ) entre o topo da banda de valência e a parte de baixo da banda de condução é referida como "gap de banda de energia", $\mathrm{E}_{\mathrm{g}}$. Um metal possui um gap de zero, um semicondutor tem um gap de até $\sim 2,5 \mathrm{eV}$, enquanto um isolante possui um gap > 2,5 eV. O trans- $(\mathrm{CH})_{\mathrm{x}}$ é um semicondutor com um gap de energia de 1,4 eV [1].

Seguindo a descoberta da dopagem do poliacetileno (cis- e trans-), outros polímeros, tais como o poliparafenileno, o poli(fenilenovinileno), o polipirrol, o politiofeno, o polifurano, etc., e seus derivados, também passaram por processos de dopagem tipo-p ou tipo-n. Muitos deles mostraram ser processáveis na forma condutora devido à boa solubilidade em diversos solventes orgânicos. Além disso, alguns deles mostraram boa estabilidade no ambiente, na forma dopada $[1,2]$. Essa característica não era encontrada para o poliacetileno.

O maior problema encontrado pelos polímeros condutivos é o relativo à degradação de suas propriedades físico-químicas em ambiente normal, e a conseqüente perda de condutividade. Mais recentemente, com a descoberta das propriedades de condução das polianilinas, um novo incentivo em aplicações tecnológicas foi observado, pois o monômero (anilina) é relativamente barato, a polimerização do monômero para a polianilina é direta e relativamente simples, a reação de polimerização possui alta eficiência e, principalmente, a sua processabilidade é de fácil manejo. Além disso, e talvez de importância principal, a forma condutora da polianilina possui excelente estabilidade química no ambiente, combinada com altos valores de condutividade elétrica (atingindo atualmente $\sim 10^{3} \mathrm{~S} / \mathrm{cm}$ ). Também, a polianilina possui a habilidade de alternar reversivelmente do estado de isolante para condutor por dopagem eletroquímica ou química [6].

Diferentemente de muitos outros membros da classe de polímeros condutores contendo elétrons $\pi$, como o poliacetileno, o polipirrol e o politiofeno, nas polianilinas, um hetero-átomo de nitrogênio é incorporado entre os anéis-fenil constituintes $\left(\mathrm{C}_{6} \mathrm{H}_{4}\right)$, quebrando 
a conjugação da cadeia [7]. A flexibilidade química fornecida pelo átomo de nitrogênio permite acesso a vários estados fundamentais isolantes que são distintos pelos seus estados de oxidação, caracterizados pela fração de unidades reduzidas amina (y) e unidades oxidadas imina (1-y). A unidade monomérica da cadeia compreende, portanto, anéis benzenóides e quinóides como mostra sua fórmula estrutural:

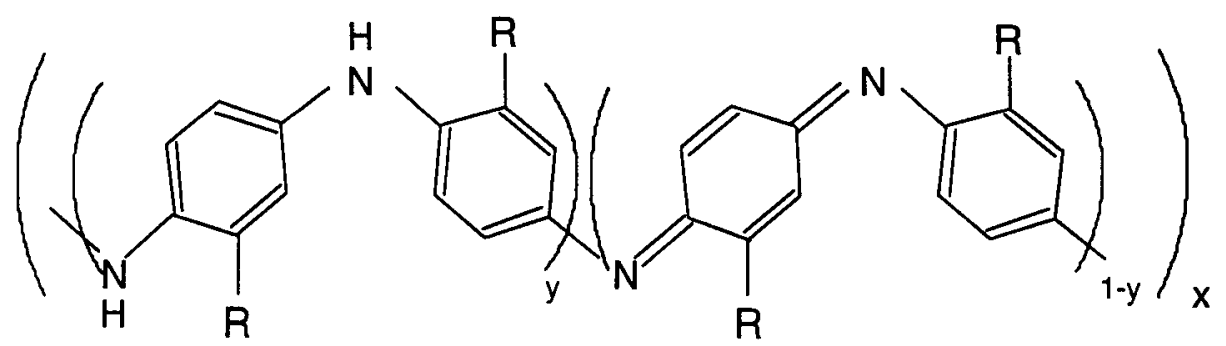

$\mathrm{R}$ é um radical, que pode ser um grupamento metil, ou etil, metoxi, etoxi, etc. A PANI é a polianilina sem o radical $\mathrm{R}$ substituído na cadeia. Se R for o grupamento metoxi na posição orto, tem-se a poli(o-metoxianilina) (POMA). Os dois anéis à esquerda são grupamentos benzenóides e o terceiro anel, a partir da esquerda, é um grupamento quinóide. Nesta configuração, $(1-\mathrm{y})=0$ corresponde à base leucoesmeraldina $(\mathrm{LB}),(1-\mathrm{y})=0,5$, à base esmeraldina $(\mathrm{EB})$, e $(1-\mathrm{y})=1$, à base pernigranilina $(\mathrm{PB})$; respectivamente, as formas totalmente reduzida, metade-oxidada e totalmente oxidada da polianilina [7-9].

O processo de dopagem da polianilina na forma de base esmeraldina envolve um outro processo que não seja a oxi-redução, isto é, não se removem e nem se adicionam elétrons à cadeia polimérica. $\mathrm{O}$ processo é feito pelo tratamento da base esmeraldina em soluções ácidas (a base se transforma no sal de esmeraldina), provocando a protonação dos átomos de nitrogênio imina do polímero. A completa protonação dos nitrogênios imina, por exemplo, em solução aquosa de ácido clorídrico de concentração $1 \mathrm{M}$, produz o cátion radical polisemiquinona em que ambos, a carga e o spin, são deslocalizados ao longo da cadeia 
polimérica. Isto provoca o aumento da condutividade elétrica em mais de dez ordens de grandeza $[1,2,10-14]$.

As propriedades físicas das polianilinas mudam com o seu estado de oxidação, isto é, as bases LB, EB e PB apresentam características próprias. Por exemplo, a completa protonação do polímero em soluções ácidas somente é obtida se ele estiver exatamente no (ou bem próximo do) estado de oxidação correspondente à base esmeraldina $(1-\mathrm{y}=0,5)$. Assim, é bastante importante a determinação do estado de oxidação em que o polímero se encontra, a fim de comparar com segurança os resultados obtidos com esses polímeros. Um dos objetivos deste trabalho é a obtenção de um método simples e prático para a determinação dos estados de oxidação das polianilinas. Os métodos existentes para esta finalidade, como a titulação volumétrica com cloreto de titânio, são complicados e bastante trabalhosos. O método a ser descrito aqui usa a espectroscopia de absorção ótica na região ultravioleta-visível como principal técnica de uso.

A primeira síntese da polianilina registrada na literatura científica tem mais de um século, mas só atualmente é que se tem dado valor a este polímero, por causa de suas potencialidades tecnológicas. O estudo de suas propriedades físicas vem aumentando desde meados da década de 1980. Esses estudos englobam vários campos da espectroscopia física, tais como a espectroscopia de absorção ótica na região ultravioleta-visível-infravermelho, a difração de raios-X, as espectroscopias de ressonância paramagnética eletrônica (EPR) e de ressonância magnética nuclear (NMR), dentre outras. Porém, o estudo de suas propriedades térmicas, como por exemplo, a difusividade e a condutividade térmicas e o calor específico, ainda não tem sido realizado. Um outro objetivo deste trabalho é o estudo dessas propriedades térmicas. 
A Espectroscopia Fotoacústica (PAS) de sólidos foi desenvolvida a partir de 1973 com os trabalhos de Allan Rosencwaig [41-43], apesar de o Efeito Fotoacústico ter sido descoberto por Alexander Graham Bell em 1880. A partir de então, o efeito foi usado por muitos anos para estudos óticos em gases. O Efeito Fotoacústico origina-se pela absorção de luz pelos materiais com a conseqüente conversão em calor por processos de transições não-radiativas. A conversão deste calor em ondas sonoras, que são detetadas por um microfone, é o princípio básico desse efeito. A Espectroscopia Fotopiroelétrica (PPES) surgiu em meados dos anos 80 com os trabalhos de H. Coufal [51] e A. Mandelis [52]. O Efeito Fotopiroelétrico origina-se também pela absorção luminosa pelos materiais seguido da conversão em calor, que é detetado como um sinal elétrico em um detetor piroelétrico. As duas técnicas fototérmicas, a PAS e a PPES, por detetarem processos de condução de calor nos materiais, são de grande utilidade para o estudo das propriedades térmicas das polianilinas. Elas serão utilizadas neste trabalho para a determinação dos parâmetros térmicos mencionados acima, assim como parâmetros óticos, como o coeficiente de absorção ótica e o gap de energia entre as bandas de valência e de condução.

Este trabalho está dividido em cinco capítulos. O capítulo I apresenta um estudo sobre as propriedades de absorção ótica das polianilinas não-dopadas e dopadas em meios ácidos. Este capítulo é introdutório e mostra o levantamento bibliográfico feito sobre os mecanismos de absorção luminosa das polianilinas. Ele mostra também resultados experimentais qualitativos da espectroscopia de absorção ótica na região ultravioleta-visível-infravermelho próximo, para amostras da base esmeraldina não-dopadas e dopadas, na forma de filmes finos e em solução. Esses resultados não são inéditos, apresentando similares na literatura científica. Os dados mostrados têm como objetivo a identificação dos diversos tipos de transições eletrônicas envolvidos na base e no sal de esmeraldina. O capítulo II é o estudo da 
interconversão dos estados de oxidação das polianilinas. Este estudo usa principalmente a técnica de espectroscopia de absorção ótica na região UV-visível. Já existem dados na literatura para a PANI, porém, para a POMA, os resultados são inéditos. Os capítulos III e IV são relacionados com as técnicas fototérmicas mencionadas acima, aplicadas ao estudo das propriedades térmicas e óticas das polianilinas. Os parâmetros térmicos obtidos para as polianilinas com essas técnicas são inéditos. O último capítulo fornece as conclusões finais deste trabalho, juntamente com as sugestões para trabalhos futuros. 


\section{CAPÍTULO I \\ PROPRIEDADES DE ABSORÇÃO ÓTICA DE POLIANILINAS}




\section{CAP. I - PROPRIEDADES DE ABSORÇÃO ÓTICA DE POLIANILINAS}

\section{I.1 - INTRODUÇÃO}

As polianilinas, apesar de pertencerem à classe dos polímeros condutores contendo elétrons $\pi$, apresentam algumas características de absorção ótica particulares que os distinguem dos outros polímeros dessa classe. Essas características advêm dos seus diferentes estados de oxidação: a base leucoesmeraldina $(1-y=0)$, totalmente reduzida, a esmeraldina $(1-y=0,5)$, metade-oxidada, e a pernigranilina $(1-y=1)$, totalmente oxidada. A base leucoesmeraldina apresenta somente a transição $\pi-\pi^{*}$ (na região do ultravioleta), enquanto as outras duas apresentam, além dessa, transições intermediárias de energias inferiores à transição $\pi-\pi^{*}[7]$. As energias dessas transições intermediárias estão na região do visível. Assim, a base leucoesmeraldina apresenta-se praticamente incolor, quando em solução diluída de N-metilpirrolidona (NMP). A esmeraldina apresenta-se na cor azul e a pernigranilina, violeta-púrpura.

Neste capítulo, apresentaremos o estudo feito sobre as propriedades de absorção ótica das polianilinas não-dopadas e dopadas em meios ácidos. Este estudo engloba o levantamento bibliográfico feito nessa área e mais uma parte experimental, onde mostraremos qualitativamente, através da espectroscopia de absorção ótica na região ultravioleta-visível e infravermelho próximo, o processo de dopagem de polianilinas em meios ácidos e o de desdopagem em meios básicos. Esses resultados experimentais não são inéditos na literatura científica, sendo que objetivo é dar suporte principalmente à aplicação de outras técnicas espectroscópicas ao estudo de polianilinas dopadas e não-dopadas. 


\section{I.2 - DOPAGEM DE POLIANILINAS}

$\mathrm{O}$ aumento extremamente grande da condutividade elétrica, de $<10^{-10} \mathrm{a} \sim 5 \mathrm{~S} / \mathrm{cm}$ [10-12] (atualmente alcançando $6000 \mathrm{~S} / \mathrm{cm}$ para filmes orientados uniaxialmente [13]), conseguido pelo tratamento da base esmeraldina com solução ácida, envolve um novo tipo de dopagem de um polímero condutor. Isto ocorre pela adição de próton à cadeia do polímero e não pela oxidação parcial do sistema $\pi$ polimérico, como na dopagem tipo $\mathrm{p}$ de outros polímeros condutores. Sob protonação dos sítios $-\mathrm{N}=$ inicialmente não-protonados, a condutividade aumenta apesar de a concentração eletrônica não ser alterada [10-14]. A partir de estudos de EPR e susceptibilidade magnética, um modelo bastante aceito para a transição isolante-condutor se baseia nos seguintes fenômenos $[11,15,16]$ : (i) depois da protonação da base esmeraldina com o meio ácido, há formação de bipólarons (figura I.1.b); (ii) o bipólaron é instável na cadeia da poliesmeraldina e por uma reação interna redox eles se transformam em dois pólarons (fig.I.1.c); (iii) por repulsão coulombiana, os pólarons se separam, dando origem à formação da rede de pólarons (fig.I.1.d), que é o estado metálico. Há controvérsias em relação a este modelo, onde a formação de bipólarons é a mais aceita [17]. O aumento da condutividade com a taxa de dopagem está relacionada a efeitos de desordem da cadeia polimérica, provocando o abaixamento do nível de Fermi para dentro da banda de valência $[17,18]$ 
(a)

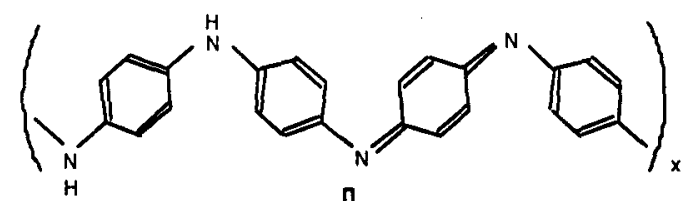

protonação: $2 \mathrm{H}^{+}$

(b)

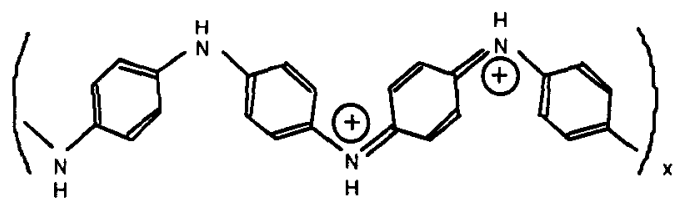

(c)

(d)

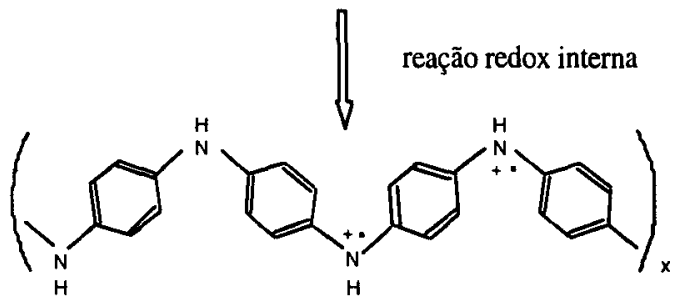
separação dos pólarons

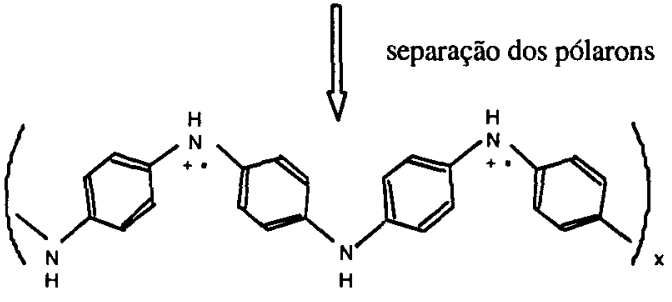

Figura I.1 - Esquema da estrutura geométrica da poliesmeraldina: (a) antes da protonação e (b)-(d) depois da protonação.

\section{I.3 - ABSORÇÃO ÓTICA DA POLIANILINA}

A forma totalmente reduzida da polianilina, a base leucoesmeraldina, exibe uma transição eletrônica centrada em $343 \mathrm{~nm}(3,61 \mathrm{eV})$ associada a uma transição $\pi-\pi^{*}$, isto é, à transição de gap de banda, situada nos anéis benzenóides do polímero [7,19,26,27], como mostra a figura I.2. Como a leucoesmeraldina possui dois elétrons $\mathrm{p}_{z}$ do nitrogênio por unidade de repetição de comprimento $a$ da cadeia, a banda de valência ( $\pi$ ) é totalmente ocupada, e a transição da banda de valência para a de condução $\pi^{*}$ se dá em um vetor de onda 
$\mathrm{k} \sim \pi / a[7]$. Por outro lado, na base pernigranilina, a forma completamente oxidada, cada átomo de nitrogênio possui um elétron $\mathrm{p}_{z} \mathrm{e}$, assim, a banda de valência é metade preenchida. $\mathrm{A}$ dimerização de Peierls resultante da cadeia polimérica induz a um gap de energia no centro da banda de valência [7]. Como resultado, uma transição eletrônica de $\sim 2,3$ eV (540 nm) no espectro ótico da pernigranilina é observada (figura I.2), juntamente com duas transições, em energia mais alta, que resultam de transições $\pi-\pi^{*}$ centradas no anel benzenóide ( $324 \mathrm{~nm}, 3,86$ eV) e no quinóide (287 nm, 4,32 eV) [19].

A base esmeraldina, a forma metade-oxidada da polianilina, exibe duas transições eletrônicas na região UV-Vis [7,8,16,19-27]. A transição de energia mais alta centrada em 327 nm $(3,79 \mathrm{eV})$ tem sido atribuída a um gap de banda, isto é, a uma transição $\pi-\pi^{*}$ (figura 1.2). A energia desta transição é deslocada para menores comprimentos de onda em comparação à transição $\pi-\pi^{*}$ da base leucoesmeraldina. Este deslocamento para maiores energias e a natureza assimétrica desta transição resulta da presença de duas transições $\pi-\pi^{*}$ muito próximas, resultantes de uma combinação de duas transições eletrônicas, uma centrada nos anéis benzenóides $(342 \mathrm{~nm}, 3,62 \mathrm{eV})$ e outra, nos anéis quinóides (327 nm, 3,79 eV) [19]. A proporção relativa dos anéis benzenóide para quinóide na base esmeraldina pura $(1-y=0,5)$ é de 3:1. Como consequiência, a absorção de mais alta energia relacionada com a transição $\pi-\pi^{*}$ localizada nos anéis quinóides não é tão intensa (ou bem definida), levando a uma superposição larga das duas transições $\pi-\pi^{*}$ na base esmeraldina [19]. A transição de mais baixa energia centrada em $637 \mathrm{~nm}(1,94 \mathrm{eV})$ é característica de uma banda de transferência de carga entre três anéis localizados (dois benzenóides e um quinóide), sendo referida como um éxciton molecular $[19,23,28,29]$. Este complexo é criado sob a ação da luz por uma transferência de carga parcial de dois anéis benzenóides (adjacentes a um quinóide) para dentro do anel quinóide, deficiente de elétron. Esta transição eletrônica é estruturalmente 
consistente com uma unidade oxidada circundada por duas unidades reduzidas adjacentes, correspondendo, em média, à doação de metade de um elétron de cada um desses anéis benzenóides adjacentes, ricos em elétrons, para dentro do anel quinóide deficiente de elétrons, levando a um anel quinóide carregado negativamente e dois anéis benzenóides carregados positivamente [19]. O modelo de éxciton molecular é mais aceito atualmente, embora já ter sido relatado na literatura [30,31] que essa transição de mais baixa energia na base esmeraldina é devido a uma transição $n-\pi^{*}$ de um par desemparelhado do nitrogênio para a banda de condução $\pi^{*}$. Contudo, tal interpretação está em conflito com a descrição de orbitais da base esmeraldina (ou seus equivalentes oligoméricos) [29].

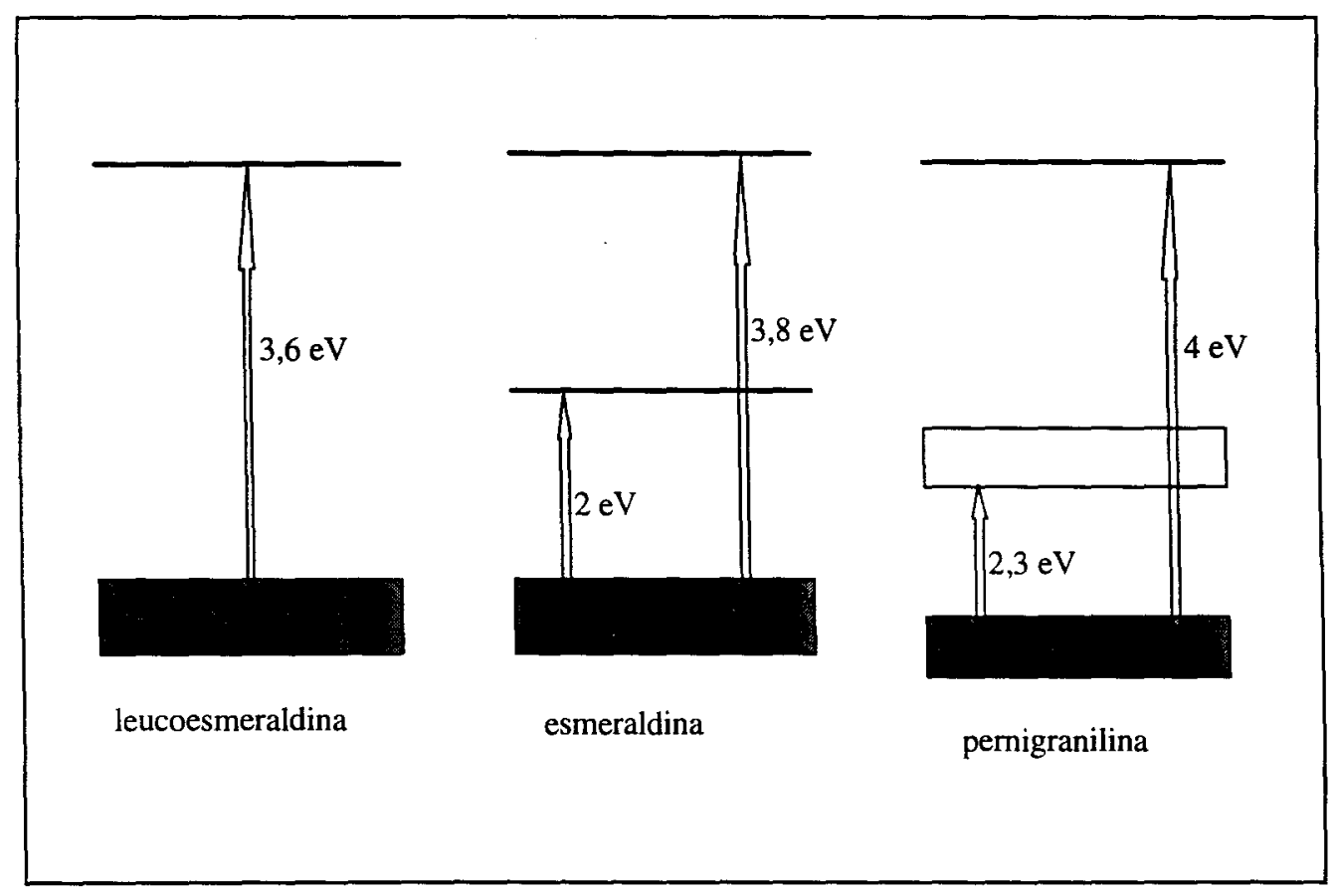

Figura I.2 - Esquema mostrando as transições eletrônicas nas três bases de polianilina.

A forma da polianilina condutora, sal de esmeraldina, é alcançada pela protonação da base esmeraldina com a exposição em ácidos protônicos, ou pela dopagem oxidativa da base 
leucoesmeraldina [6,12]. O sal de esmeraldina apresenta picos de absorção em $\sim 360 \mathrm{~nm}$ (3,5eV), em $\sim 439 \mathrm{~nm}(2,9 \mathrm{eV})$ e em $-860 \mathrm{~nm}(1,5 \mathrm{eV})$ [12,15,16,19-21,23,24]. As posições dos picos dependem do tipo de dopante e se a PANI está nos estados líquido, sólido ou na forma de dispersão colóidal [25]. A absorção em 3,5 eV corresponde à transição $\pi-\pi^{*}$ dos grupamentos benzenóides. Os picos em 2,9 e $1,5 \mathrm{eV}$ correspondem às bandas que são interpretadas como excitações para a banda de pólaron $[11,12,15,16,19,20,23,24,26,27]$.

\section{I.4 - METODOLOGIA EXPERIMENTAL}

A síntese química da polianilina (PANI) foi feita pelo doutorando José de Souza Nogueira e da poli(o-metoxianilina) (POMA), pelo doutorando Luiz Francisco Malmonge. A síntese é realizada a partir da oxidação do monômero em um meio aquoso de $\mathrm{HCl} 1 \mathrm{M}(\mathrm{pH}$ 0 ), em temperaturas entre 0 e $5{ }^{\circ} \mathrm{C}$. O oxidante utilizado é o peroxidissulfato de amônia. A razão molar de agente oxidante por monômero utilizada na síntese é 0,25 , isto é, usa-se anilina em excesso [32,33]. Este método de síntese química produz um precipitado na forma de um pó verde escuro, que é o sal de esmeraldina. Este polímero pode ser desprotonado em solução aquosa de hidróxido de amônia $(0,1$ a $0,5 \mathrm{M})$, resultando na base esmeraldina, que é um pó azul escuro com brilho metálico [32,33].

Obtivemos espectros de absorção ótica da polianilina em um espectrofotômetro comercial marca Varian, modelo Cary 2315, do grupo de Biofísica do IFSC/USP/São CarlosSP. Fizemos um filme de POMA, usando a técnica de spin-coating, em uma placa de quartzo de $2 \mathrm{~mm}$ de espessura. Este filme foi dopado em uma solução de ácido clorídrico $1 \mathrm{M} \mathrm{e}$ desdopado em soluções de hidróxido de amônia, em diversos pH's. Obtivemos espectros 
também de soluções de PANI em NMP (N-metilpirrolidona), onde as dopagens foram feitas adicionando soluções ácidas de $\mathrm{HCl}$ e TFA (ácido trifluoroacético).

\section{I.5 - RESULTADOS E DISCUSSÃO}

A figura I.3 mostra os espectros obtidos, à temperatura ambiente, para um filme de POMA não-dopado, depois dopado com $\mathrm{HCl} 1 \mathrm{M}$ (uma imersão de $30 \mathrm{~s}$ do filme na solução) e depois desdopado com $\mathrm{NH}_{4} \mathrm{OH}$ em dois pH's (duas imersões rápidas do filme nas soluções). Depois de cada imersão do filme nas soluções, ele era secado ao ar livre. Como pode ser visto, os espectros mostram a alteração nas bandas de absorção com o estado de dopagem dos filmes. Quanto mais dopado, maior é a absorção no infravermelho próximo, representando maior condutividade do polímero. Esta absorção no infravermelho próximo representa transições intrabanda polarônica. A formação da banda polarônica corresponde ao estado metálico do polímero [16]. Nota-se que, com a dopagem do polímero, há um desaparecimento da banda correspondente ao éxciton molecular, uma diminuição da intensidade da banda correspondente à transição $\pi-\pi^{*}$, e o surgimento de um "ombro" à direita desta banda. Com a desdopagem do polímero já dopado, em pH's básicos, volta a surgir a transição correspondente ao éxciton molecular e ocorre uma diminuição das bandas devido à formação de pólarons. Tanto a banda com pico em torno de $850 \mathrm{~nm}$, quanto a transição que corresponde a esse "ombro" (em torno de $450 \mathrm{~nm}$ ), correspondem à formação de pólarons na cadeia polimérica. Quanto mais o filme é desdopado em $\mathrm{pH}$ básico, maior é o desaparecimento das bandas polarônicas, maior é o ressurgimento da banda de éxciton molecular e maior é a intensidade da banda correspondente à transição $\pi-\pi^{*}$. Assim, é mais evidente o retorno do 
polímero ao seu estado isolante. Desta forma, podemos concluir que o processo de dopagem e desdopagem do polímero, isto é, o processo de torná-lo condutor e isolante é reversível.

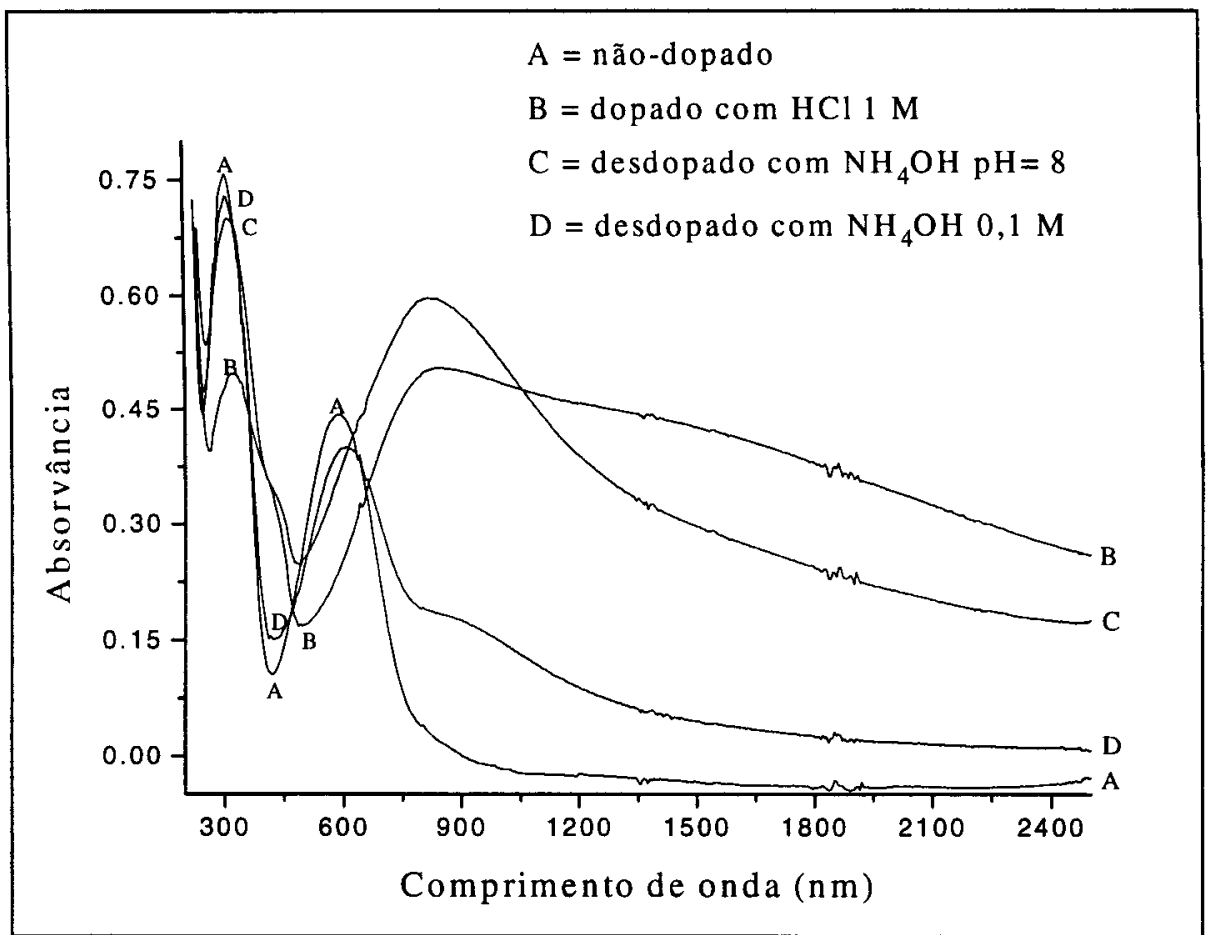

Figura I.3 - Espectros de absorção ótica de um filme de POMA em diversos estados de dopagem.

A figura I.4 mostra os espectros obtidos para uma solução de polianilina (PANI) em NMP (N-metilpirrolidona), sendo dopada com uma e duas gotas de $\mathrm{HCl} 1 \mathrm{M}$. O espectro para a PANI não-dopada é análogo ao da POMA não-dopada, apresentando as duas bandas características na região do ultravioleta e do visível: a transição $\pi-\pi^{*}$ em torno de $325 \mathrm{~nm}$ e a transição de éxciton molecular em torno de $625 \mathrm{~nm}$. Os espectros para a PANI dopada mostram as três bandas características : a transição $\pi-\pi^{*}$ um pouco deslocada para o vermelho, e as duas transições para a banda polarônica, a primeira em torno de $425 \mathrm{~nm}$, que agora está bem resolvida, e a segunda em torno de $860 \mathrm{~nm}$. Nota-se que, quando se adiciona mais uma 
gota de $\mathrm{HCl} 1 \mathrm{M}$ à solução, o espectro como um todo se desloca para baixo, indicando, provavelmente, uma degradação do polímero. A banda polarônica em torno de $860 \mathrm{~nm}$, mais larga, sofre um pequeno deslocamento para maiores comprimentos de onda. Podemos notar também que a banda polarônica é mais localizada em solução do que em filme (comparando a figura I.4 com a I.3), porque as absorções no infravermelho próximo são menos pronunciadas.

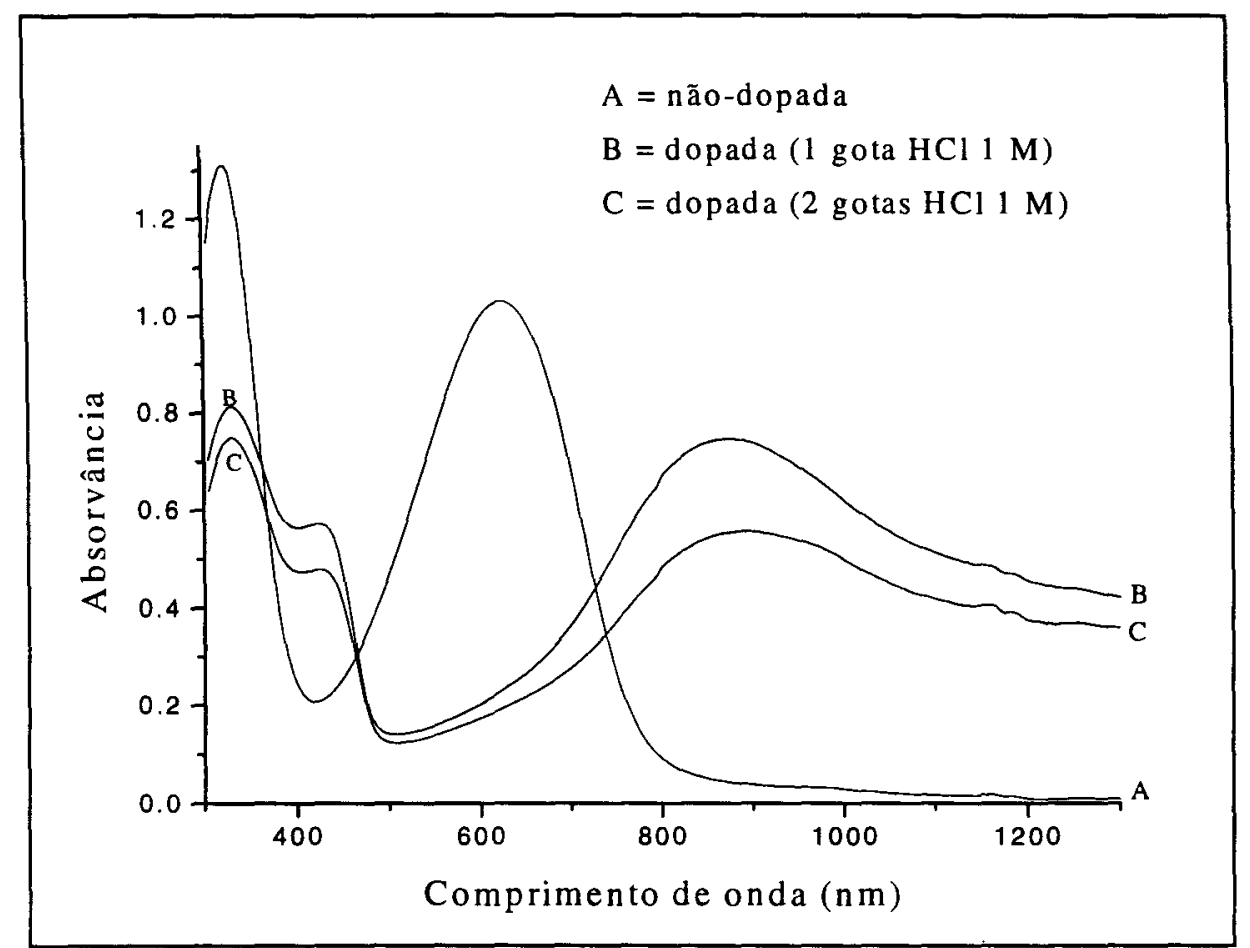

Figura I.4 - Espectros de absorção ótica de uma solução de PANI em NMP, não-dopada e dopada.

A figura I.5 mostra os espectros obtidos para soluções de POMA, em NMP, nãodopada, dopada com $\mathrm{HCl}$ 1M (1 gota adicionada à solução) e dopada com TFA (5 gotas adicionadas à solução). Podemos notar que, para a solução não-dopada, aparece um vestígio da banda polarônica em torno de $840 \mathrm{~nm}$, indicando que, depois da síntese do polímero, este não ficou completamente desdopado com a utilização de $\mathrm{NH}_{4} \mathrm{OH}$. Verifica-se que a segunda 
banda polarônica (em torno de $840 \mathrm{~nm}$ ) é deslocada para menores comprimentos de onda para a POMA dopada com TFA. A intensidade da primeira banda polarônica (em torno de $425 \mathrm{~nm}$ ) relativa à da segunda é menor para a POMA dopada com TFA.

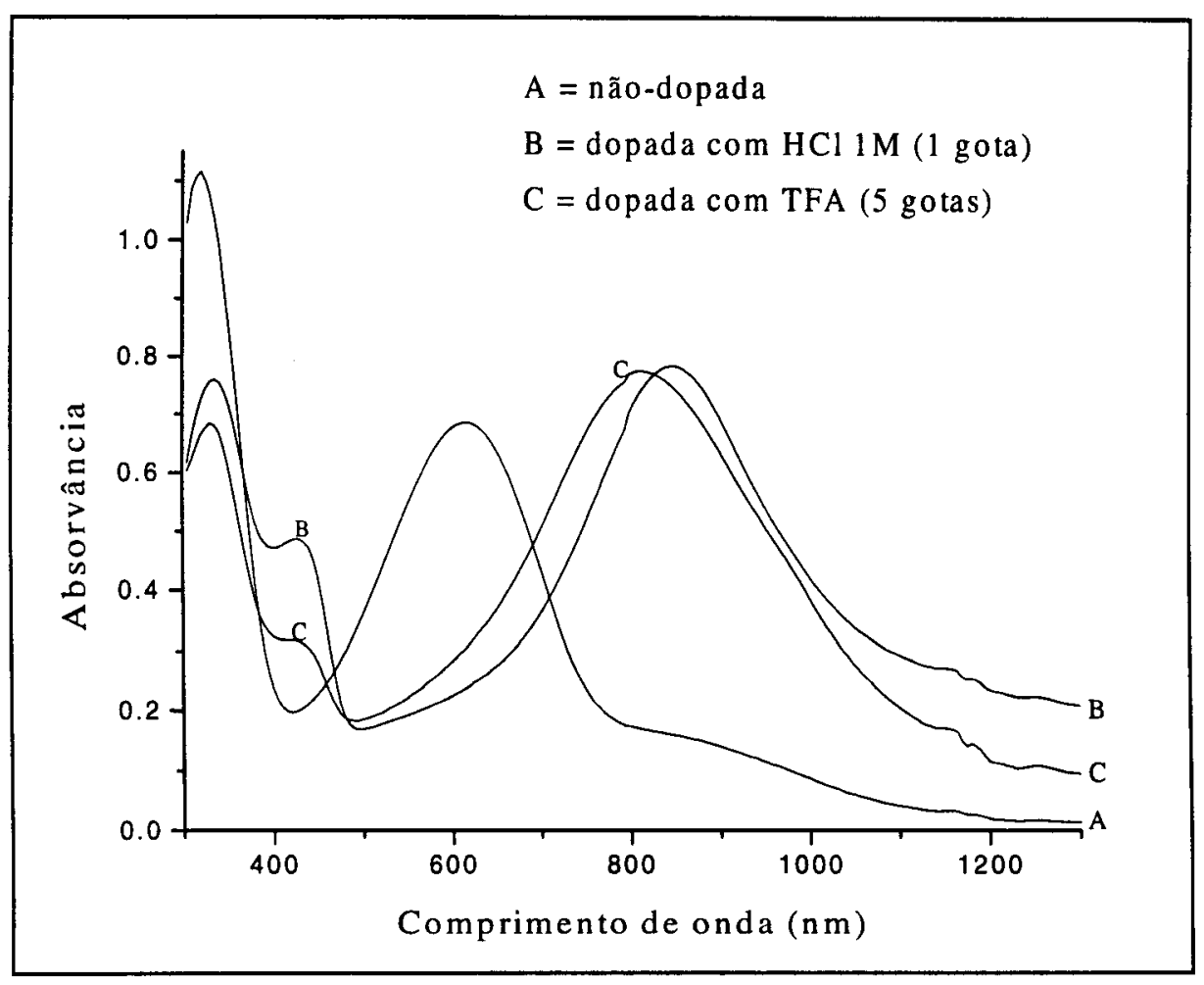

Figura 1.5 - Espectros de absorção ótica de soluções de POMA em NMP, não-dopada e dopada com $\mathrm{HCl}$ e TFA.

\section{I.6 - CONCLUSÕES}

O processo de dopagem das polianilinas é bastante simples e pode ser feito utilizandose diferentes soluções ácidas. $\mathrm{O}$ processo de desdopagem em meios básicos pode não ser eficiente o suficiente para tornar o polímero $100 \%$ não-dopado. Filmes finos do polímero, feitos por spin coating, dopam-se facilmente com simples mergulhos nas soluções ácidas — em questão de alguns segundos. Se deixarmos os filmes muito tempo na solução, eles 
degradam-se por completo e se soltam das placas de quartzo. Notamos que os filmes de POMA degradam-se mais rapidamente que os de PANI, nas dopagens em soluções de $\mathrm{HCl}$. 


\section{CAPÍtULLO II}

\section{ESTUDO DA INTERCONVERSÃO DOS ESTADOS DE OXIDAÇÃO DAS POLIANILINAS}




\section{CAP. II - ESTUDO DA INTERCONVERSÃO DOS ESTADOS DE OXIDAÇÃO DAS POLIANILINAS}

\section{II.1 - INTRODUÇÃO}

Este capítulo apresenta um estudo sobre os estados de oxidação das polianilinas, mais especificamente da PANI e da POMA. O objetivo principal é obter um método para determinar o estado de oxidação em que o polímero se encontra através de uma análise rápida. A importância desse trabalho reside no fato de que as propriedades físicas das polianilinas mudam com o seu estado de oxidação. Assim, é importante a sua determinação para se poder comparar com segurança resultados de pesquisa sobre esses polímeros - deve-se evitar comparar resultados de estudos de polianilinas que não estejam no mesmo estado de oxidação. A princípio, o polímero é sintetizável no estado esmeraldina (teoricamente $1-\mathrm{y}=0,5$ ), mas ele pode ser obtido em um estado de oxidação entre 0,4 (quando sintetizado sob ambiente inerte de argônio, fora do oxigênio do ar) e 0,6 (quando sintetizado ao ar livre) [12,34].

Os métodos existentes para a determinação dos estados de oxidação das polianilinas, como a titulação volumétrica com $\mathrm{TiCl}_{3}$, são complicados e bastante trabalhosos [34]. $\mathrm{O}$ método a ser descrito aqui utiliza a espectroscopia de absorção ótica UV-Visível como a principal técnica de uso. Para tanto, foram realizadas reações de oxidação e de redução das bases de polianilinas, e, através da estequiometria dessas reações, curvas empíricas foram levantadas a fim de se caracterizar o estado de oxidação médio do polímero, acompanhandose a evolução da curva de absorção UV-Visível.

As reações de oxi-redução das bases de polianilina acontecem de tal forma que uma base se transforma diretamente na outra, sem passar por algum composto intermediário (em nível molecular). Em termos espectrais (UV-Visível), isto se dá com o surgimento de pontos 
isobésticos, que são pontos onde os espectros se cruzam. A obtenção desses pontos é de fundamental importância para a aplicação do método mencionado acima.

\section{II.2 - ESTADOS DE OXIDAÇÃO DAS POLIANILINAS}

Vimos anteriormente que os estados de oxidação das polianilinas são caracterizados pela fração y de unidades reduzidas (amina) e pela fração (1-y) de unidades oxidadas (imina), formando a cadeia polimérica:

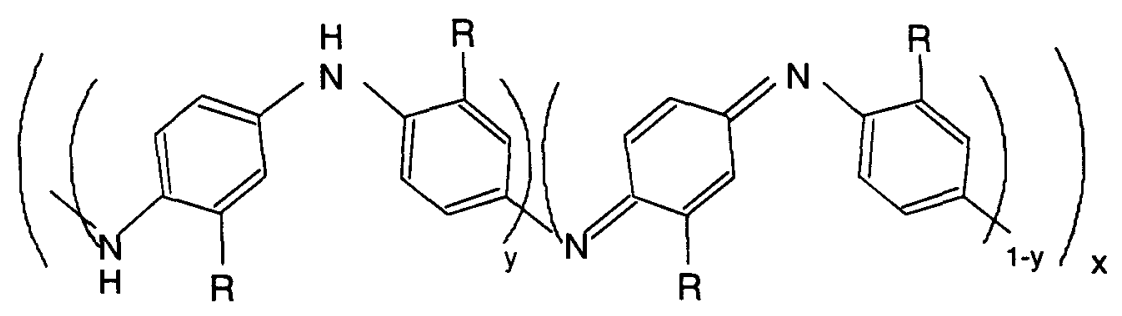

onde $(1-y)=0$ corresponde à base leucoesmeraldina $(\mathrm{LB}),(1-\mathrm{y})=0,5$, à base esmeraldina (EB) e $(1-y)=1$, à base pernigranilina $(\mathrm{PB})$; respectivamente, as formas totalmente reduzida, metade-oxidada e totalmente oxidada da polianilina [7-9,40]. Essas três formas podem transformar-se uma nas outras através de uma reação de oxi-redução [10] :

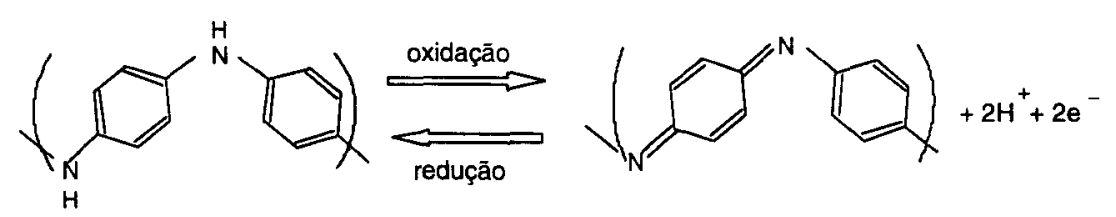

Dados experimentais [8] mostram que a base leucoesmeraldina é oxidada para a esmeraldina e a pernigranilina é reduzida para a esmeraldina em uma única etapa, sem passar por qualquer estado de oxidação discreto intermediário. O mesmo ocorre na oxidação da base 
esmeraldina para a pernigranilina e na redução da esmeraldina para a leucoesmeraldina. $O$ estado de oxidação médio das espécies de polianilina varia continuamente com a adição de oxidante ou redutor.

\section{II.3 - PONTOS ISOBÉSTICOS}

Quando somente dois compostos em equilíbrio químico são responsáveis por toda a absorção ótica em uma dada região, pode ser mostrado que existe no mínimo um ponto no espectro em que a absorvância independe da razão das duas concentrações. Se as bandas não se superpõem, esse ponto incluirá a região onde a absortividade (coeficiente de extinção) é nula entre elas. Se as bandas se superpõem e se a estequiometria é um para um, a freqüência será aquela em que as absortividades das duas espécies são iguais [35,36]. Em outras palavras, os espectros das duas espécies se cruzam em um ponto, chamado ponto isobéstico. A existência de tal ponto não é uma prova da ausência de um terceiro composto, uma vez que este poderia apresentar absortividade nula nessa frequiência particular. Mas a ausência de um ponto isobéstico é uma prova definitiva da presença de mais de dois constituintes [35].

A afirmação feita antes, de que existem somente três estados discretos de oxidação das polianilinas, advém dos resultados experimentais que demonstram pontos isobésticos nos espectros obtidos que monitoram as reações de oxi-redução. Mais adiante, na parte experimental, mostraremos a obtenção de pontos isobésticos nos espectros obtidos para as reações de redução e de oxidação das polianilinas. 


\section{II.4 - METODOLOGIA EXPERIMENTAL}

\section{II.4.1 - Reações de Oxidação e de Redução das Polianilinas}

As reações de oxi-redução foram feitas a partir da base esmeraldina (EB), como foi sintetizada em laboratório. Supomos que o seu estado de oxidação é originalmente 0,5. Utilizamos o ácido ascórbico como agente redutor e o peroxidissulfato de amônia como oxidante. As reações para oxidar a leucoesmeraldina (LB) até atingir a pernigranilina (PB), com o peroxidissulfato de amônia, são as seguintes [19]:
a. $\mathrm{LB}+\left(\mathrm{NH}_{4}\right)_{2} \mathrm{~S}_{2} \mathrm{O}_{8} \rightarrow \mathrm{EB}+2 \times\left(\mathrm{NH}_{4}\right)\left(\mathrm{HSO}_{4}\right)$
b. $\mathrm{EB}+\left(\mathrm{NH}_{4}\right)_{2} \mathrm{~S}_{2} \mathrm{O}_{8} \rightarrow \mathrm{PB}+2 \times\left(\mathrm{NH}_{4}\right)\left(\mathrm{HSO}_{4}\right)$

Nas reações acima, tanto a $\mathrm{LB}$ quanto a $\mathrm{EB}$ perdem $2 \mathrm{H}^{+}+2 \mathrm{e}^{-}$. As reações para reduzir a pernigranilina até a leucoesmeraldina, com o ácido ascórbico, são:
c. $\mathrm{PB}+\mathrm{C}_{6} \mathrm{H}_{8} \mathrm{O}_{6} \rightarrow \mathrm{EB}+\mathrm{C}_{6} \mathrm{H}_{6} \mathrm{O}_{6}$
d. $\mathrm{EB}+\mathrm{C}_{6} \mathrm{H}_{8} \mathrm{O}_{6} \rightarrow \mathrm{LB}+\mathrm{C}_{6} \mathrm{H}_{6} \mathrm{O}_{6}$

Nas reações c e d acima, tanto a $\mathrm{PB}$ quanto a $\mathrm{EB}$ ganham $2 \mathrm{H}^{+}+2 \mathrm{e}^{-}$. Para os nossos propósitos, utilizamos as reações b e d, assumindo que a $E B$, no estado de oxidação 0,5 , é exatamente obtida na síntese do polímero. Usamos a espectroscopia de absorção ótica na região UV-Visível para monitorar as reações de oxidação e de redução. Fazendo os cálculos estequiométricos, de acordo com as equações acima, determinamos as massas de oxidante e de redutor necessárias para obter o valor exato do estado de oxidação médio (1-y) requerido. Utilizamos $10 \mathrm{mg}$ da base esmeraldina diluídos em $10 \mathrm{~m} \ell$ de NMP, em frascos separados para adicionar o oxidante e o redutor. Os cálculos foram feitos de tal forma que o oxidante e o 
redutor eram adicionados em pequenas porções aos frascos respectivos, a fim de obtermos vários estados de oxidação distintos. Os frascos eram tampados logo após a adição de oxidante ou de redutor. Os espectros foram obtidos tirando uma pequena parte $(10 \mu \ell)$ da solução com uma pipeta e fazendo uma diluição com o NMP (1 m $\ell)$, a fim de podermos obter os espectros. As soluções nas quais eram adicionados o redutor e o oxidante ficavam em constante agitação, utilizando-se um agitador magnético. Os espectros foram obtidos no espectrofotômetro Shimadzu, modelo 1601, do CNPDIA/EMBRAPA e no Varian, modelo Cary 2315, do grupo de Biofísica do DFI/IFSC/USP (para os espectros qualitativos).

\section{II.4.2 - Cálculos Estequiométricos}

Observando a reação (b) acima, verificamos que um mol de peroxidissulfato de amônia produz quatro moles de átomos de nitrogênio imina no produto. De acordo com a referência [19]:

$$
1-\mathrm{y}=\frac{\text { numero de atomos } \mathrm{N}-\text { imina no produto }}{\text { numero total de atomos no produto }}
$$

o que implica que:

$$
1-\mathrm{y}=\frac{\mathrm{n}_{\mathrm{ox}}}{\mathrm{n}_{\mathrm{EB}}}
$$

onde $\mathrm{n}_{\mathrm{ox}}=$ número de moles do oxidante e $\mathrm{n}_{\mathrm{EB}}=$ número de moles da base esmeraldina. Esta equação fornece a massa do oxidante em função do estado de oxidação médio 1-y. Analogamente, observando a reação (d) acima, temos que:

$$
\mathrm{y}=\frac{\mathrm{n}_{\mathrm{red}}}{\mathrm{n}_{\mathrm{EB}}}
$$


onde $\mathrm{n}_{\mathrm{red}}=$ número de moles do redutor. Esta equação fornece a massa do redutor em função do estado de redução médio y. Para a PANI (10 mg), a massa de peroxidissulfato de amônia em função do estado de oxidação é dada por $\mathrm{m}_{\mathrm{ox}}=(1-\mathrm{y}) \times 2,759 \times 10^{-5} \times 228,2 \mathrm{~g}$, e a massa de ácido ascórbico em função do estado de redução é $\mathrm{m}_{\mathrm{red}}=\mathrm{y} \times 2,759 \times 10^{-5} \times 176,1 \mathrm{~g}$. Para a POMA (10 mg), $\mathrm{m}_{\mathrm{ox}}=(1-\mathrm{y}) \times 2,073 \times 10^{-5} \times 228,2 \mathrm{~g}$, e $\mathrm{m}_{\mathrm{red}}=\mathrm{y} \times 2,073 \times 10^{-5} \times 176,1 \mathrm{~g}$. As medidas dessas massas foram feitas em uma balança da marca Mettler Toledo, modelo AG 245 , com precisão de $10^{-5} \mathrm{~g}$.

\section{II.4.3 - Método para Determinação dos Estados de Oxidação}

O método consiste em obter gráficos da razão das absorvâncias dos máximos das duas bandas da polianilina, em função dos estados de oxidação médios 1-y, que são obtidos a partir da estequiometria das reações de oxi-redução. Desse gráfico, obtém-se uma curva empírica, a partir da qual pode-se determinar posteriormente o estado de oxidação desconhecido de um polímero, simplesmente tomando-se a razão das absorções dos máximos das duas bandas da polianilina. Obtêm-se também gráficos da energia correspondente ao máximo da banda em $2 \mathrm{eV}$ em função de $1-\mathrm{y}$, podendo auxiliar na determinação do estado de oxidação desconhecido.

As reações de oxidação e de redução eram realizadas por um período de 12 a 15 horas antes de serem obtidos os espectros. Para cada estado de oxidação 1-y, havia um frasco de reação correspondente. Para a PANI, realizamos as reações no ambiente livre e, também, em uma câmara fechada onde fizemos fluir gás argônio. Para a POMA, fizemos somente as reações no ambiente livre. 
A fim de compararmos esse método com um outro, fizemos a deconvolução das bandas dos espectros de absorção ótica, obtidos em função dos estados de oxidação. Este método usa processos matemáticos para separar as bandas dos espectros, fazendo ajustes com funções gaussianas. Utilizamos o programa "LABCALC" para fazer estes ajustes.

\section{II.5 - RESULTADOS E DISCUSSÃO}

\section{II.5.1 - Obtenção de Pontos Isobésticos}

A figura II.1 mostra os espectros obtidos para uma solução em NMP da PANI-EB, que foi reduzida com a adição de pequenas quantidades de ácido ascórbico. O ácido ascórbico foi adicionado aos poucos na solução, sem haver pesagem das quantidades usadas (como a solução foi obtida bem diluída, para se poderem obter os espectros sem necessitar de diluição, a quantidade de ácido ascórbico adicionada aos poucos na solução não foi quantitativamente controlada). Logo depois de adicionado o redutor, os espectros eram medidos. Dois pontos isobésticos, um perto de $310 \mathrm{~nm}$ e outro em torno de $390 \mathrm{~nm}$, foram registrados, estando de bom acordo com a literatura $[8,19]$. O ponto isobéstico que surge em $310 \mathrm{~nm}$ é devido à transformação da banda da EB na da LB. A banda de éxciton molecular da EB vai desaparecendo à medida que ela vai-se transformando na LB. Devido a esses pontos isobésticos, podemos afirmar que a EB vai-se transformando diretamente na LB, sem passar por algum composto intermediário. $\mathrm{O}$ espectro para a $\mathrm{EB}$ apresenta-se alterado, porque a solução foi preparada (e guardada em geladeira) uma semana antes de serem medidos os espectros. Como não foi feito pesagem alguma dos componentes da reação, os espectros da figura II.1 servem apenas para apresentar qualitativamente a obtenção dos pontos isobésticos. 


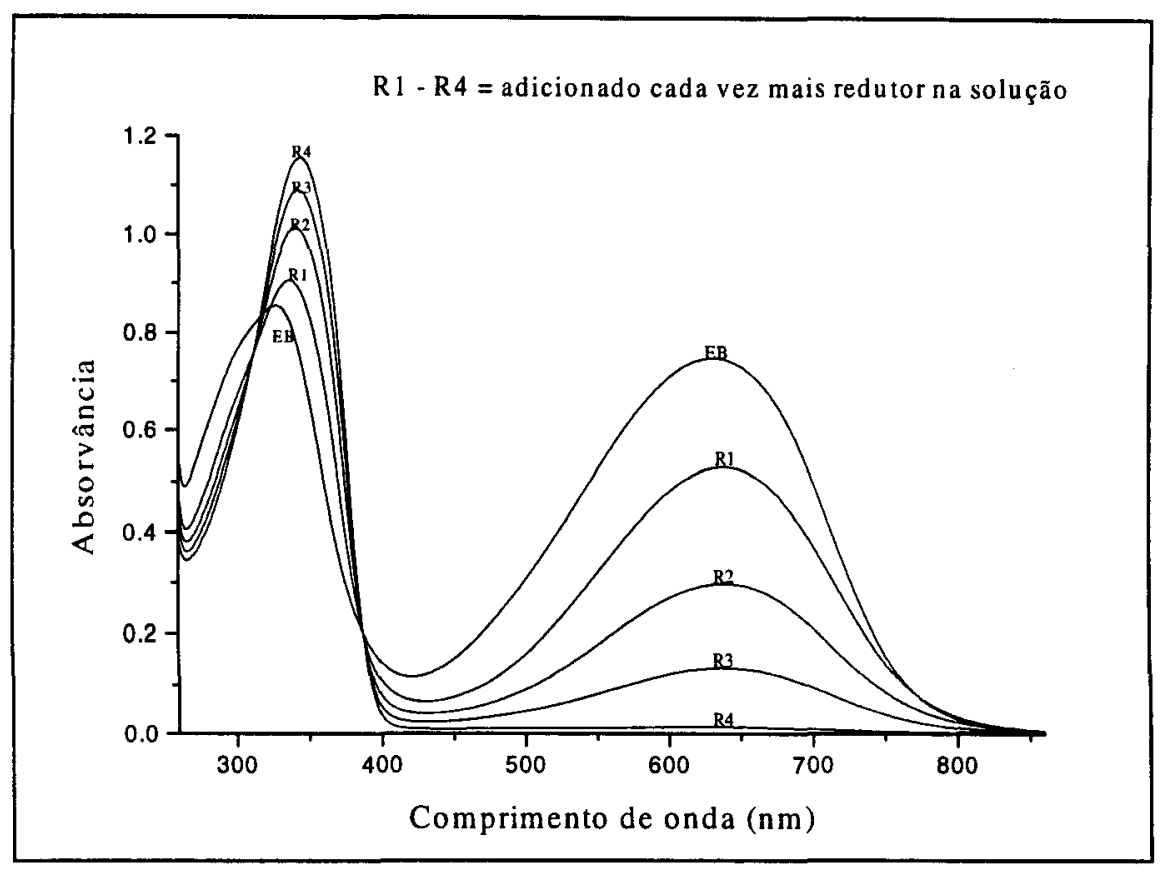

Figura II.1 - Espectros de absorção ótica de uma solução de PANI-EB em NMP, onde foram adicionados, em etapas, quantidades pequenas de redutor.

A figura П. 2 mostra o estudo da cinética da reação de conversão da base esmeraldina na pernigranilina. Os espectros foram obtidos para uma solução de PANI-EB em NMP (0,2 mg de PANI em $20 \mathrm{~m} \ell$ de NMP), onde foi adicionado aproximadamente $0,1 \mathrm{mg}$ de peroxidissulfato de amônia (quantidade suficiente para transformar toda a EB na $\mathrm{PB}$ ). Os espectros foram medidos para os tempos: logo depois de adicionado o oxidante, e aproximadamente depois de 1 h, 3 h, 5 h e 6 h. Pode-se notar a alteração gradativa dos espectros, onde as bandas da EB vão-se transformando nas da PB. Na região das transições $\pi$ $\pi^{*}$, surgem as duas transições características da pernigranilina, devido aos anéis benzenóides e quinóides (a proporção dos anéis quinóides para os benzenóides aumenta na pernigranilina). $\mathrm{Na}$ região de $2 \mathrm{eV}$, a banda de éxciton molecular da $\mathrm{EB}$ vai-se transformando na banda devido à desestabilização de Peierls da $\mathrm{PB}$, em direção a menores comprimentos de onda. Como pode ser verificado, há obtenção de três pontos isobésticos, um em torno de $310 \mathrm{~nm}$, outro perto de 
$390 \mathrm{~nm}$ e o último perto de $570 \mathrm{~nm}$, sendo consistentes com os dados da literatura $[8,19]$. Estes pontos nos mostram que a $\mathrm{EB}$ vai-se transformando diretamente na $\mathrm{PB}$, sem passar por algum composto intermediário.

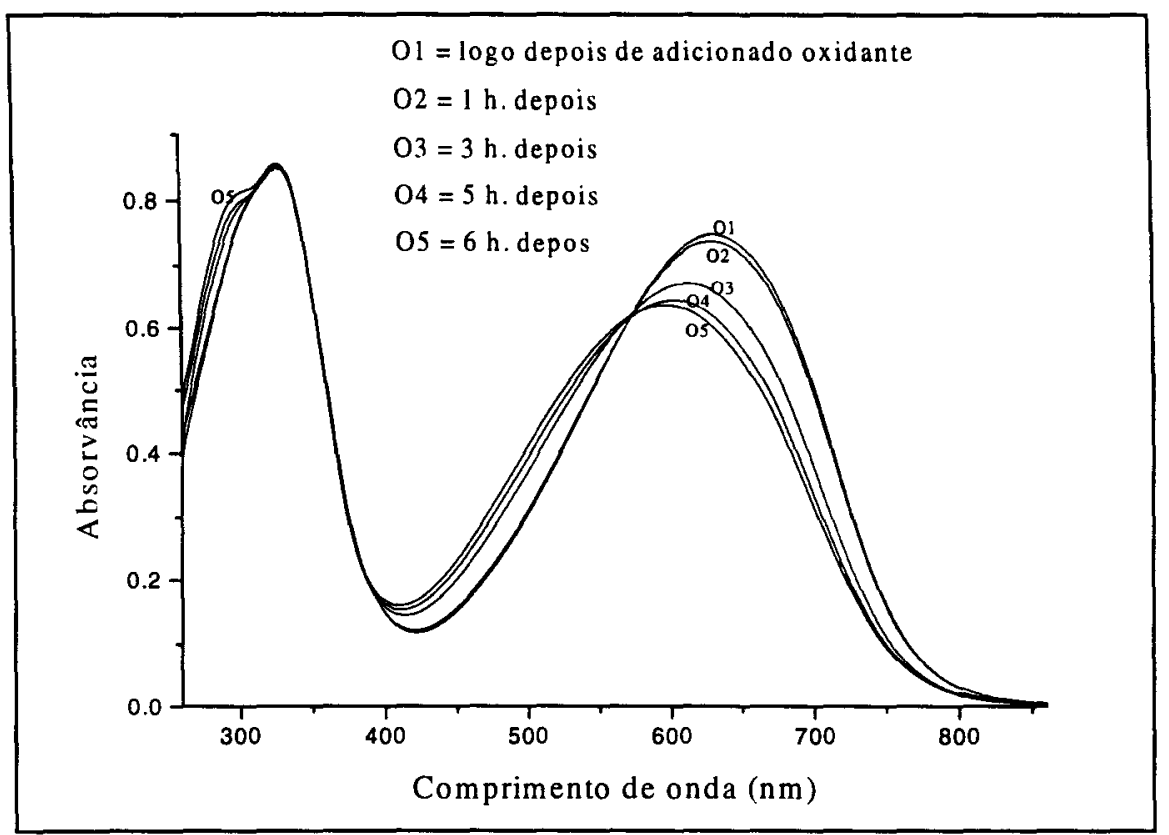

Figura II.2 - Espectros de absorção ótica de uma solução de PANI-EB em NMP, onde foi adicionada uma pequena quantidade de oxidante $(0,1 \mathrm{mg})$, obtidos com o decorrer do tempo.

A figura II.3 mostra os espectros obtidos para uma solução de POMA-EB em NMP (estudo qualitativo), onde foram adicionados, em pequenas quantidades, o ácido ascórbico. Cada espectro foi medido logo após a adição do redutor. Analogamente ao caso da PANI, os espectros mostram a alteração das bandas da EB, com a adição de redutor, tranformando-se na banda da leucoesmeraldina. Pode-se verificar que surge um "ombro" à direita da banda da leucoesmeraldina, que não tem um análogo no caso da PANI. Não encontramos dados na literatura que mencione alguma transição que dá origem a esse "ombro". Pode-se verificar um ponto isobéstico em torno de $390 \mathrm{~nm}$, como no caso da PANI. Parece que surge também o 
ponto isobéstico (apesar de não estar bem resolvido) na região da transição $\pi-\pi^{*}$, em torno de $300 \mathrm{~nm}$, na transformação da banda da EB para a da LB. Esses pontos isobésticos são consistentes com os dados da literatura para o caso da PANI $[8,19]$.

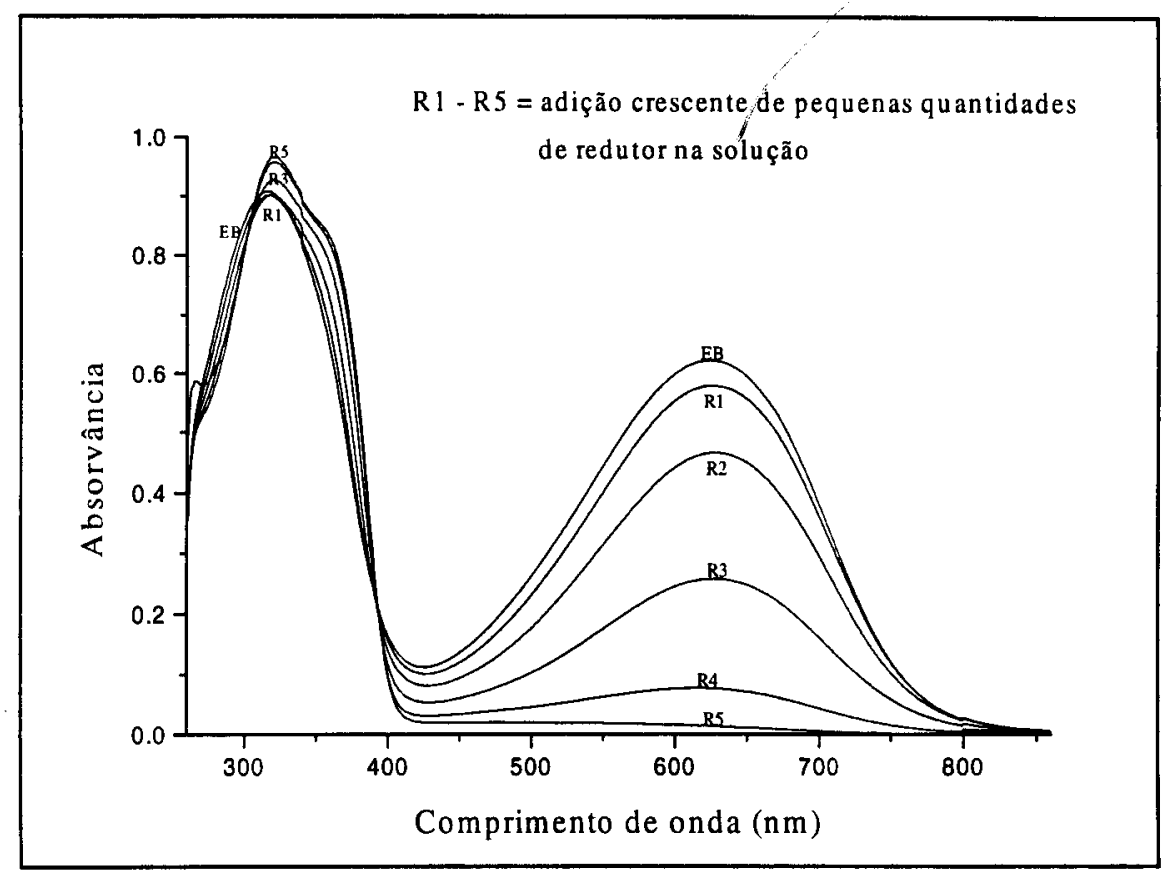

Figura II.3 - Espectros de absorção ótica de uma solução de POMA-EB em NMP, onde foram adicionados pequenas quantidades de redutor.

A figura II.4 mostra um estudo também qualitativo dos espectros obtidos para uma solução de POMA-EB em NMP, onde foi adicionado um pouco de peroxidissulfato de amônia. Os espectros foram obtidos com o decorrer do tempo, aproximadamente depois de 35 min (O1), 1h 27min, 2h 25min, 3h 17min, 4h 20min, 5h 25min, 6h 35min e 9h 30min (O8). Na região da transição $\pi-\pi^{*}$, à medida que a POMA vai-se oxidando, a banda se desloca para menores comprimentos de onda, surgindo um ponto isobéstico (difuso) em torno de $330 \mathrm{~nm}$. Na região de $2 \mathrm{eV}$, a banda da $\mathrm{EB}$ vai-se transformando na da $\mathrm{PB}$, sem passar por um ponto isobéstico. Parece que a base esmeraldina, como foi sintetizada, não está no estado de 
oxidação exato $(1-y)=0,5$, porque a posição do pico da banda de éxciton molecular, no início, mantém-se aproximadamente constante, e o pico aumenta de intensidade até um máximo para, então, depois se deslocar em direção a comprimentos de onda menores. Observando os espectros da figura II.3, vemos que este comportamento inicial corresponde ao dos estados reduzidos, para $(1-\mathrm{y})<0,5$. No entanto, para todos os espectros, surge o ponto isobéstico perto de $390 \mathrm{~nm}$, como no caso da PANI.

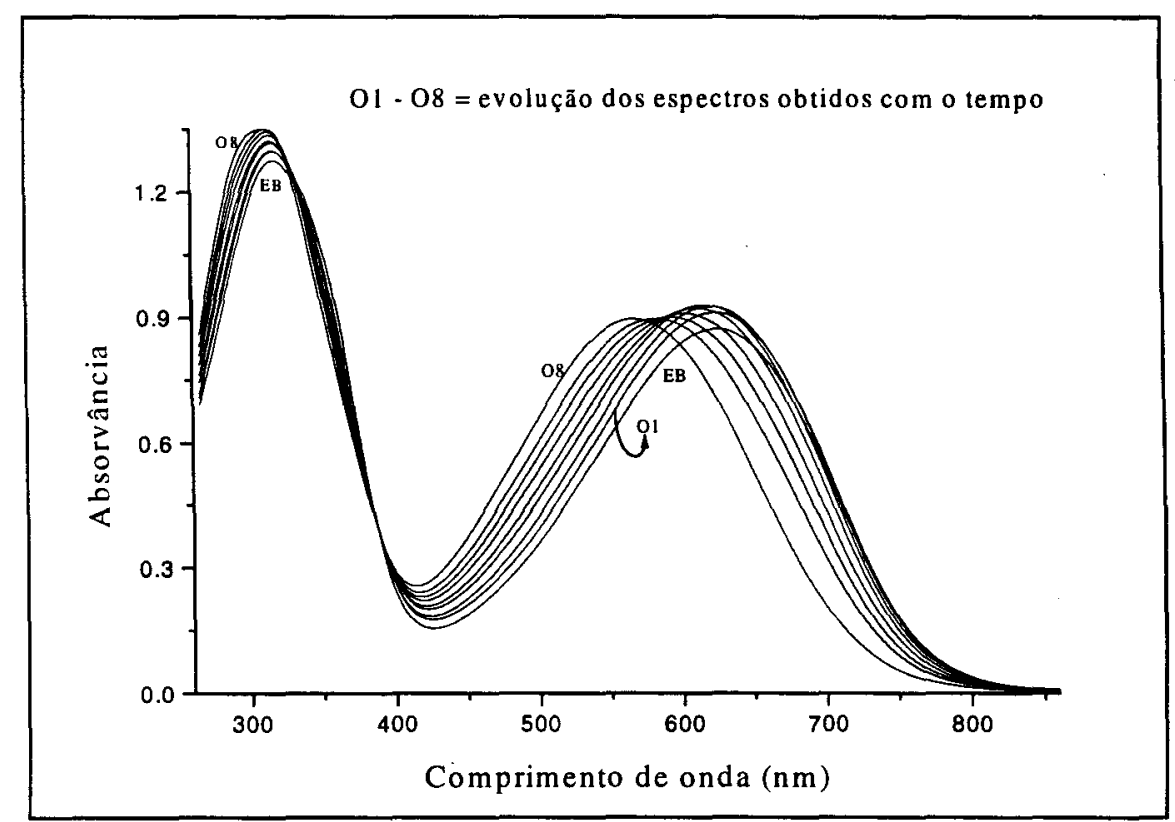

Figura II.4 - Espectros de absorção ótica, obtidos com o decorrer do tempo, de uma solução de POMA-EB em NMP, onde foi inicialmente adicionada uma pequena quantidade de oxidante.

\section{II.5.2 - Estudo Qualitativo da Degradação da PANI em Solução}

Fizemos um estudo qualitativo, através da espectroscopia UV-visível, do envelhecimento da PANI em solução de NMP, em função do tempo. A figura II.5 mostra o que acontece com os espectros da PANI-EB, obtidos logo após o preparo da solução, após uma semana do preparo da solução e 2,5 meses depois, sendo a solução guardada em geladeira 
nesses períodos. Nota-se pouca alteração na banda de éxciton molecular, mas surge uma banda intensa e aguda perto de $300 \mathrm{~nm}$, que provavelmente deve estar relacionada com subprodutos devido à oxidação do polímero pelo oxigênio do ar. Não encontramos dados da literatura a respeito da degradação da polianilina com o tempo.

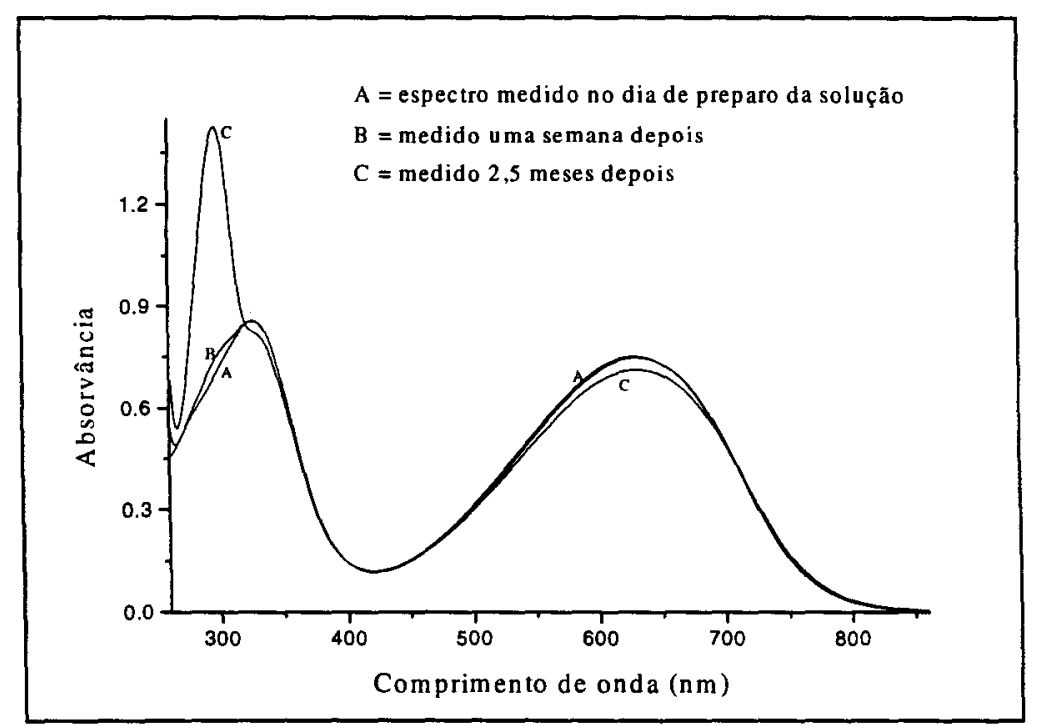

Figura II.5 - Espectros de absorção ótica de uma solução de PANI-EB em NMP, obtidos em função do tempo.

A figura II.6 mostra os espectros de uma solução de PANI-EB, que foi reduzida com o ácido ascórbico (espectro A), e depois guardada em geladeira por um pouco mais de 2 meses (espectro B). Verifica-se que a solução volta a oxidar, porque surge a banda de éxciton molecular. Este fato se justifica, porque o oxigênio do ar pode oxidar as unidades amina, transformando-as em unidades imina [12], principalmente se o ambiente for aquoso, sendo que a água atua como catalisador no processo de retirada dos hidrogênios das unidades amina [37]. Surge também a banda perto de $300 \mathrm{~nm}$, que provavelmente demonstra a degradação do polímero. 


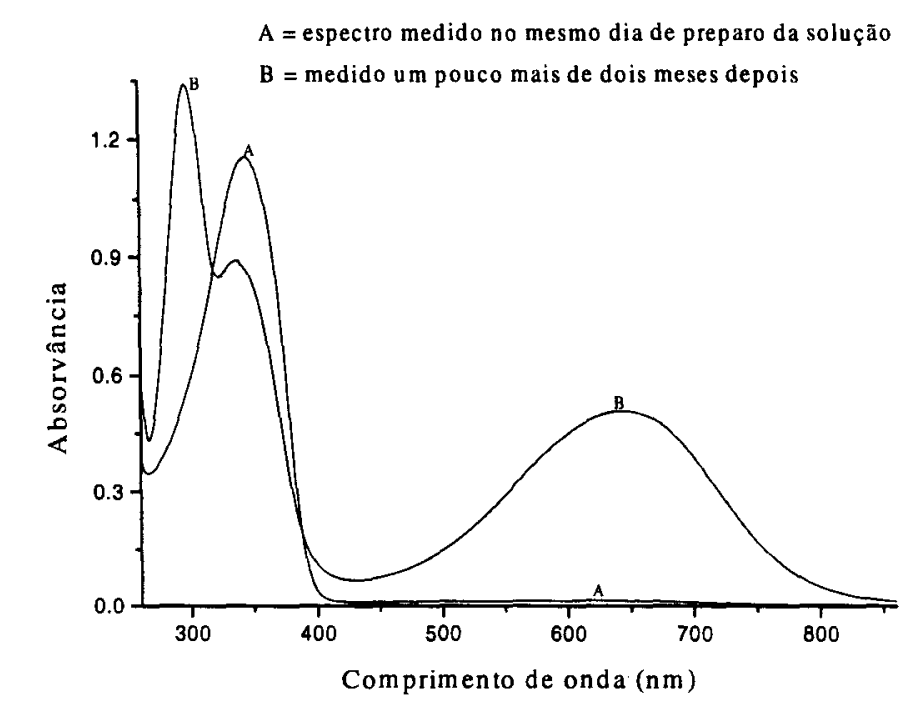

Figura II.6 - Espectros de absorção ótica de uma solução de PANI-EB em NMP, onde foi adicionado redutor, obtidos em função do tempo.

A figura II.7 mostra espectros apresentados na figura II.2 (solução de PANI-EB, 0,2 mg de PANI em $20 \mathrm{~m} \ell$ de NMP, onde foi adicionado aproximadamente $0,1 \mathrm{mg}$ de peroxidissulfato de amônia), acrescentados de mais dois espectros, obtidos $21,5 \mathrm{~h}$ e $24,5 \mathrm{~h}$ depois de adicionado o oxidante. Nota-se que a obtenção do ponto isobéstico perto de $570 \mathrm{~nm}$, na transformação da banda da esmeraldina para a da pernigranilina, ocorre somente até $6 \mathrm{~h}$ depois de adicionado o oxidante. A partir daí, os espectros começam a se cruzar em outros pontos, significando que não há somente dois compostos na solução (que absorvem nesta região). Isto demonstra o surgimento de subprodutos da reação, com a diminuição das quantidades das bases esmeraldina e pernigranilina. Nos dois últimos espectros, O6 e O7, observa-se uma banda intensa em torno de $290 \mathrm{~nm}$, parecida com as que aparecem nas figuras anteriores, demonstrando possivelmente a degradação do polímero. 


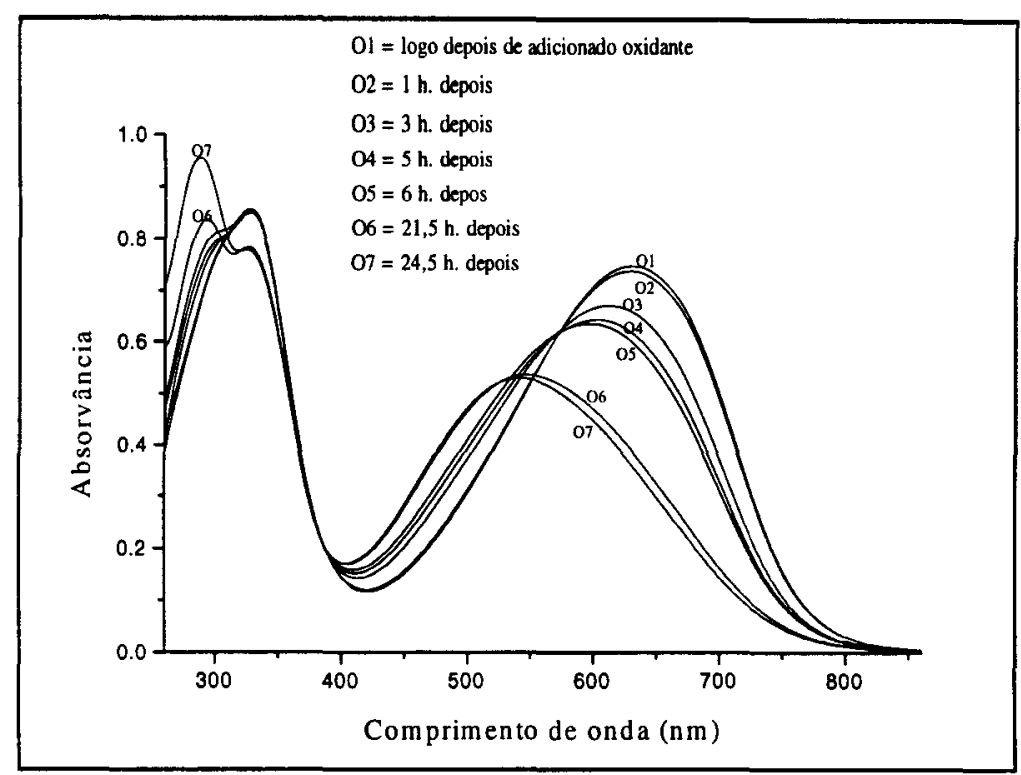

Figura II.7 - Espectros de absorção ótica de uma solução de PANI-EB em NMP, onde foi adicionado oxidante, obtidos em função do tempo.

A figura II.8 mostra os espectros obtidos para a solução de PANI-EB já mostrada na figura anterior, que foi oxidada com o peroxidissulfato de amônia (espectro A corresponde ao espectro $\mathrm{O} 7 \mathrm{da}$ figura anterior). A solução foi guardada na geladeira por um período de um pouco mais de dois meses (espectro B). Verifica-se que a banda perto de $300 \mathrm{~nm}$ aumenta muito de intensidade, efeito que deve estar relacionado com a degradação do polímero.

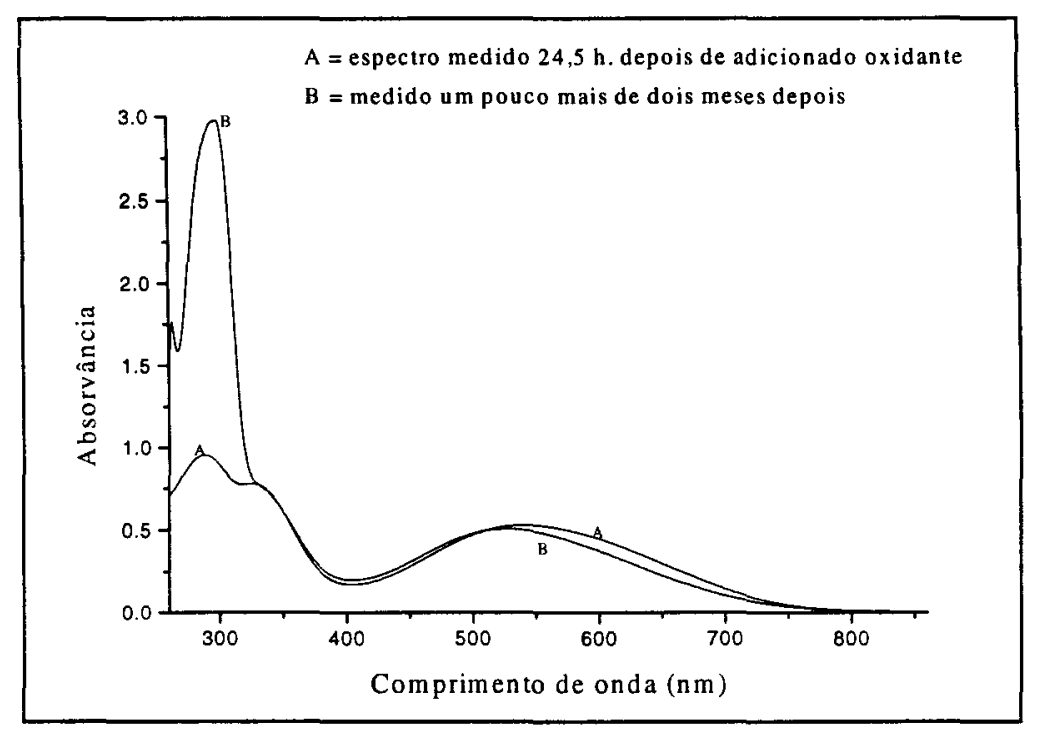

Figura II.8 - Espectros de absorção ótica da mesma solução de PANI-EB em NMP anterior, obtidos em função do tempo. 


\section{II.5.3 - Determinação dos Estados de Oxidação}

\section{II.5.3.1 - Para a PANI no Ambiente Livre}

A figura II.9 mostra os espectros de absorção ótica obtidos para monitorar as reações de oxidação e de redução para a PANI no ambiente livre. Foram utilizados onze frascos, cada um contendo $10 \mathrm{mg}$ de PANI diluídos em $10 \mathrm{~m} \ell$ de NMP. Quatro frascos foram utilizados para os estados reduzidos, onde foram adicionadas as quantidades calculadas de ácido ascórbico e seis frascos, para os estados oxidados, onde foram adicionadas as quantidades calculadas de peroxidissulfato de amônia. Não se observam pontos isobésticos bem definidos devido ao fato de que nas soluções oxidadas (e também nas reduzidas) havia formação de precipitado, que ficava em suspensão. Isto provocava uma diminuição da concentração do soluto, que é responsável pela absorção. Assim, os espectros aparecem deslocados, uns em relação aos outros, provocando a não obtenção dos pontos isobésticos. Esse efeito ocorreu principalmente para o estado de oxidação $1-y=0,9$, onde visivelmente o espectro aparece deslocado como um todo para baixo.

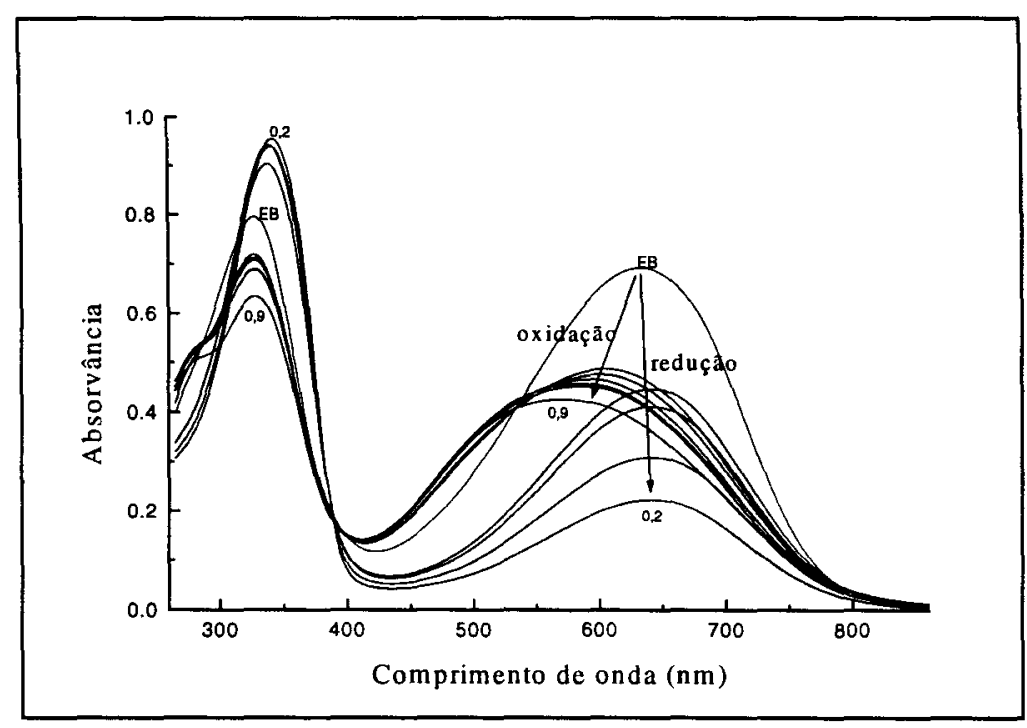

Figura II.9 - Espectros de absorção ótica para as 11 soluções de PANI-EB em NMP, nas quais foram adicionados redutor em 4 soluções e oxidante em 6 soluções. 
A figura II.10 mostra o gráfico (razão das absorvâncias dos picos das duas bandas versus estado de oxidação 1-y) obtido para os onze frascos de reação da PANI, na região UVvisível. No gráfico, o símbolo quadrado representa os pontos para os espectros obtidos quinze horas depois de preparadas as soluções, e o símbolo triângulo para os espectros obtidos uma semana depois. Observa-se que os pontos obedecem aproximadamente a duas retas, uma para os estados reduzidos e a outra para os oxidados. O gráfico mostra as retas ajustadas aos pontos experimentais (quadrados). As duas retas se interceptam em um ponto bem próximo do estado de oxidação correspondente à base esmeraldina $(1-\mathrm{y}=0,5)$, estando de bom acordo com dados da literatura [19]. Mesmo retirando o ponto $1-y=0,5$, que corresponde ao frasco contendo somente a base esmeraldina, as duas retas se interceptam em um ponto que fornece a mesma abscissa próxima de 0,5. A figura II.11 mostra esta situação. A escolha de se retirar o ponto correspondente a $1-y=0,5$ é somente para comparação, a fim de verificar se ocorre um deslocamento significativo do ponto de interseção das retas. Isto não ocorreu como pode ser verificado. De posse de gráficos deste tipo, podemos obter com boa precisão o estado de oxidação desconhecido da PANI. Para isto, toma-se a razão das absorções correspondentes aos máximos das duas bandas da polianilina na região UV-visível e, por intermédio da curva obtida no gráfico, obtém-se o ponto correspondente a esta razão no eixo das abscissas (1-y).

Para os pontos obtidos uma semana depois (triângulos), verifica-se que ocorre uma sensível alteração para os estados reduzidos, quase não afetando os estados oxidados. Isto significa que os estados reduzidos sofrem maior influência do envelhecimento pelo ambiente. Para o estado $1-y=0,5$ (base esmeraldina), também quase não há alteração decorridos uma semana. 


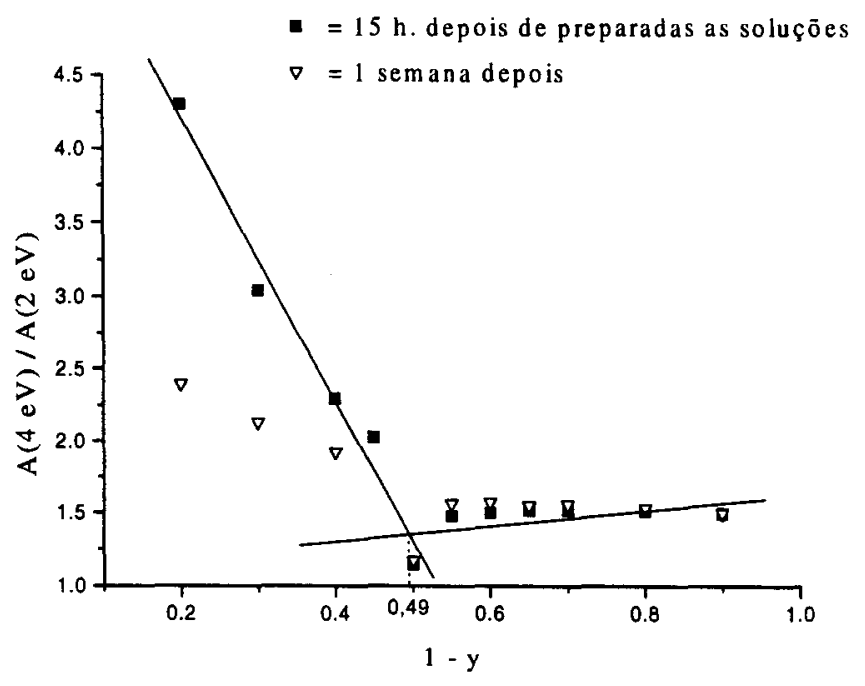

Figura II.10 - Gráfico da razão das absorvâncias dos máximos das duas bandas da PANI em função do estado de oxidação 1-y. O gráfico mostra as melhores retas ajustadas aos pontos experimentais (quadrados) e o ponto de interseção.

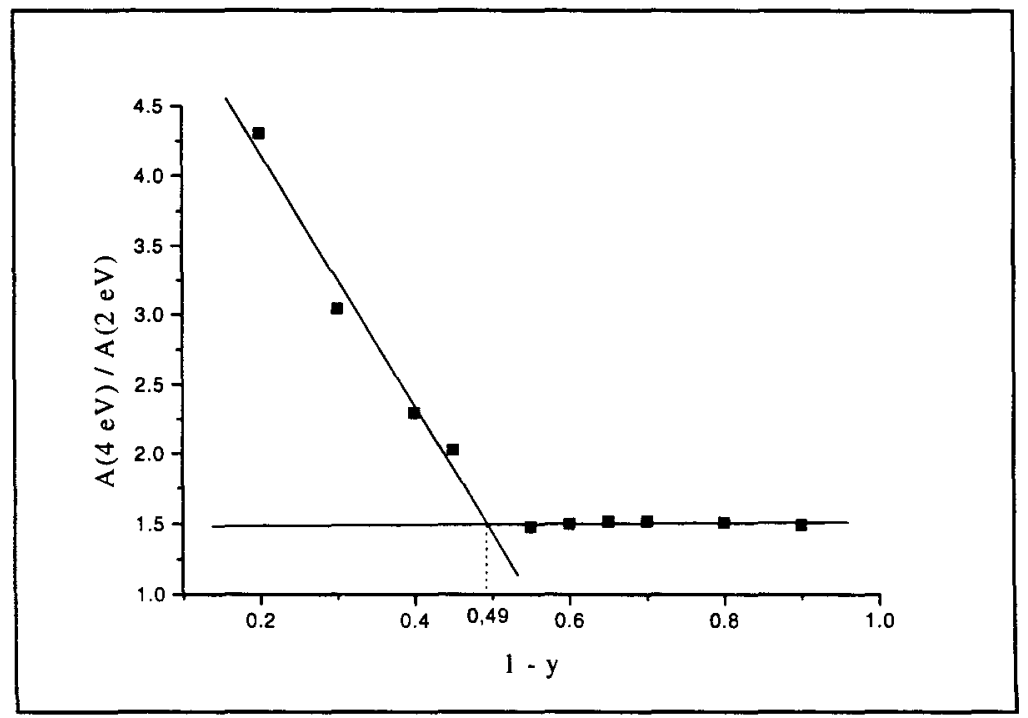

Figura II.11 - O mesmo gráfico anterior sem o ponto experimental $1-y=0,5$.

A figura $\Pi 1.12$ mostra os gráficos da energia (e do correspondente comprimento de onda) do máximo da banda em torno de $2 \mathrm{eV}$, em função do estado de oxidação 1-y (correspondentes ao mesmo material anterior). Verifica-se que a energia e o comprimento de 
onda praticamente não se alteram para os estados reduzidos. Isto é consistente com o fato de que as unidades de base esmeraldina são reduzidas diretamente para as unidades leucoesmeraldina, sem passar por quaisquer espécies intermediárias detectáveis. É observado um grande aumento na energia (correspondendo à diminuição no comprimento de onda) para os estados de oxidação acima de $1-y=0,5$. Isto é consistente com a idéia de que a banda em 2 eV seja composta por duas transições eletrônicas superpostas, uma devido à base esmeraldina, que absorve em torno de $634 \mathrm{~nm}$, e a outra devido à base pernigranilina, que absorve em torno de $536 \mathrm{~nm}$, gerando a banda com máximo em $570 \mathrm{~nm}$ para $1-\mathrm{y}=0,9$. A banda da pernigranilina em torno de $536 \mathrm{~nm}$ aumenta de intensidade com o aumento do estado de oxidação. Verifica-se uma inflexão em torno de $1-y=0,5$, sendo consistente com a literatura [19]. Esses dados experimentais, razão das absorvâncias e energia da banda em torno de $2 \mathrm{eV}$, definem claramente o estado de oxidação correspondente à base esmeraldina, que é o estado que atinge os maiores valores de condutividade elétrica após a dopagem.

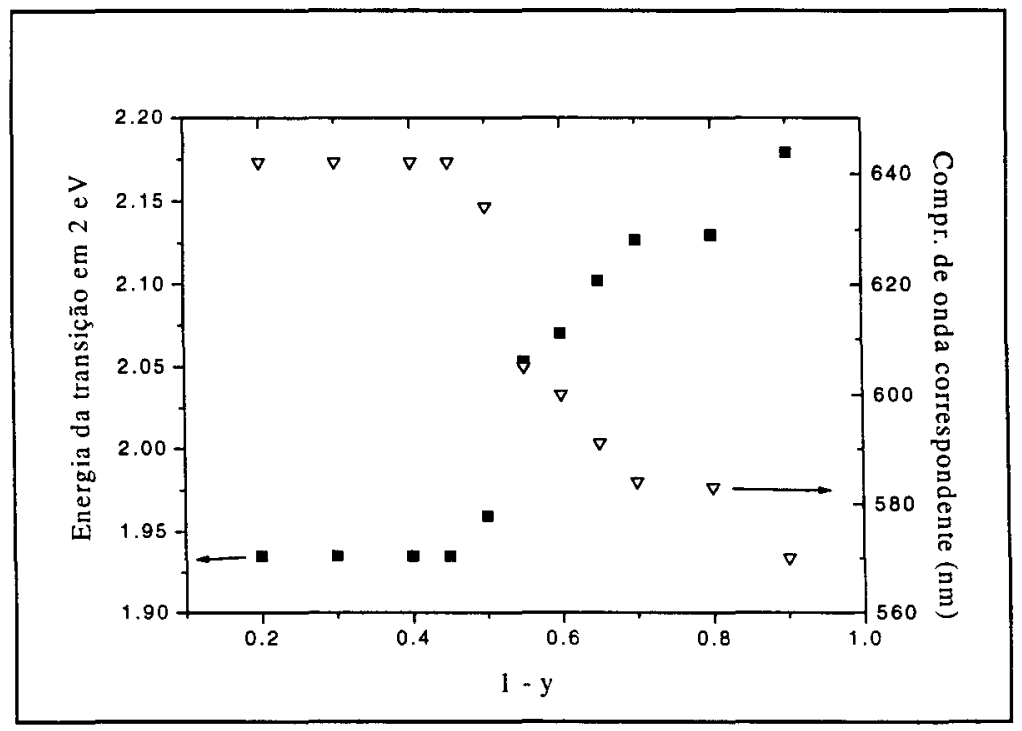

Figura II.12 - Gráficos da energia e do comprimento de onda correspondentes ao máximo da banda em torno de $2 \mathrm{eV}$ em função do estado de oxidação 1-y. 


\section{II.5.3.2 - Para a PANI em Ambiente Inerte}

A figura II.13 mostra os espectros de absorção ótica obtidos para monitorar as reações de oxidação e de redução para a PANI em ambiente inerte de gás argônio. Seguiu-se a mesma metodologia do item anterior, onde os espectros foram obtidos em torno de quinze horas depois de preparadas as soluções. A queda nos espectros como um todo, para os estados oxidados, pode ser explicada devido à formação de precipitado, observado nos frascos, diminuindo a quantidade de soluto que é responsável pela absorção de luz, conforme explicado anteriormente.

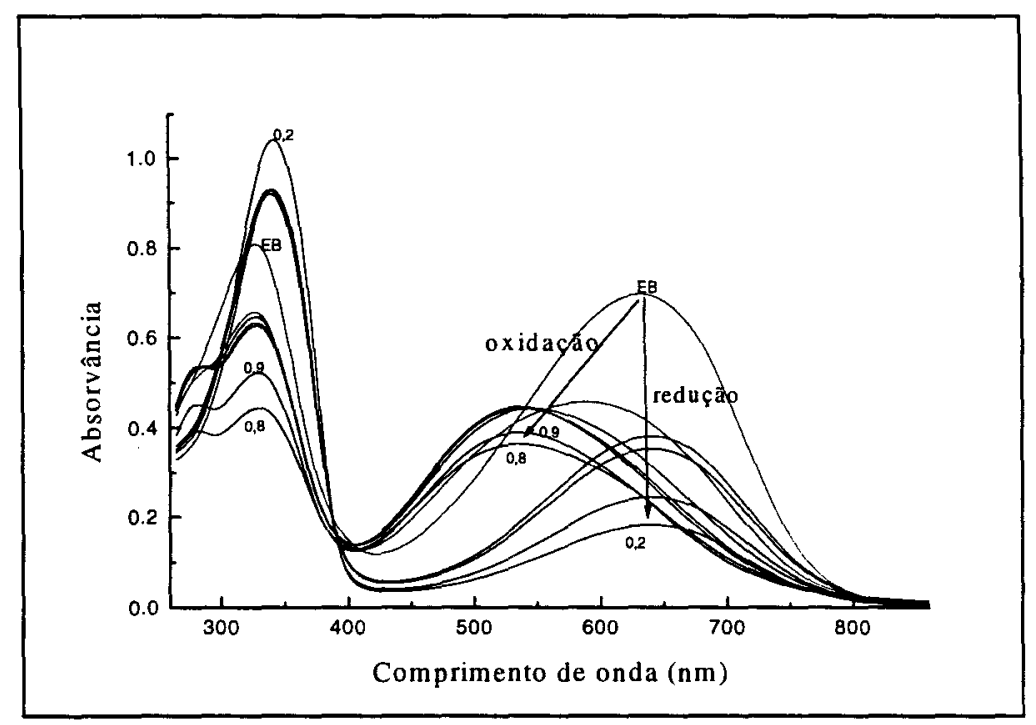

Figura II.13 - Espectros de absorção ótica para as 11 soluções de PANI-EB em NMP (em ambiente inerte), nas quais foram adicionados redutor em 4 soluções e oxidante em 6 soluções.

A figura II.14 mostra o gráfico (razão das absorvâncias dos picos das duas bandas versus estado de oxidação 1-y) obtido para a PANI em ambiente de gás argônio. Nela estão indicados também os pontos correspondentes aos da figura II.10 (os quadrados), que são os dados obtidos para a PANI no ambiente livre. Verifica-se que, em relação aos dados para a PANI no ambiente livre, há uma maior alteração dos pontos para os estados reduzidos do que 
para os estados oxidados. Isto é consistente com a conclusão de que a maior influência do ambiente ocorre sobre os estados reduzidos. Observa-se que a interseção das duas retas ajustadas aos pontos experimentais se dá em um ponto igual ao do estado $1-\mathrm{y}=0,5$ (base esmeraldina). Se retirarmos o ponto correspondente a $1-y=0,5$, que corresponde ao frasco sem adição de oxidante ou de redutor, as duas retas ajustadas aos pontos se interceptam também em $1-y=0,5$, como mostrado na figura II.15. Novamente, a interseção das duas retas define o estado de oxidação da base esmeraldina.

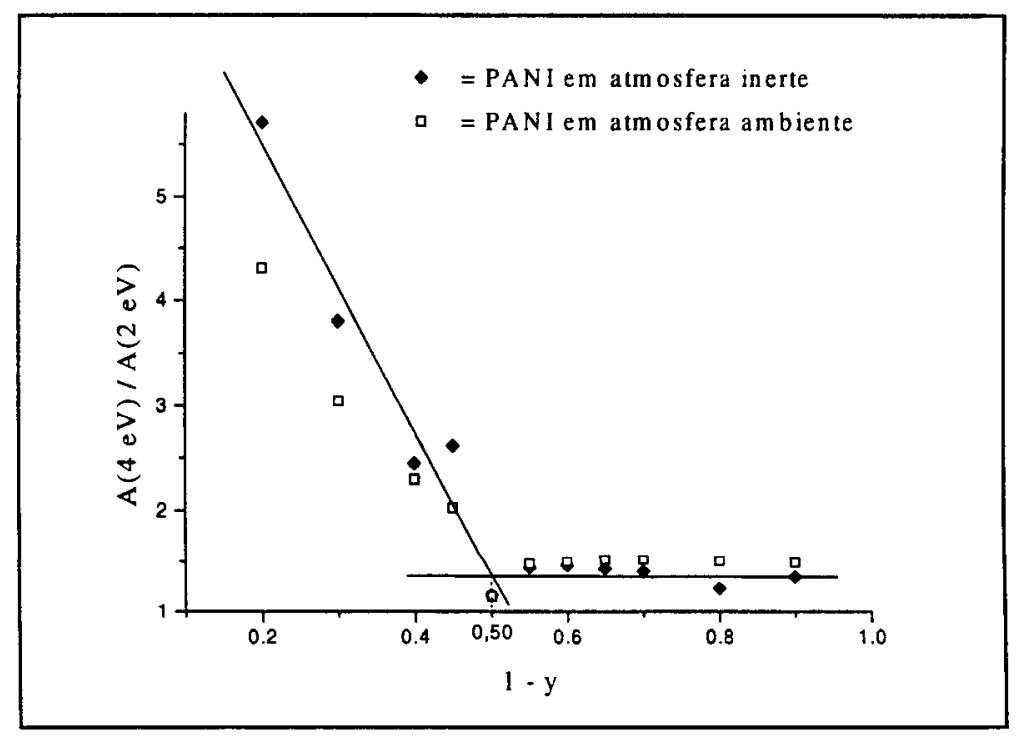

Figura II.14 - Gráfico da razão das absorvâncias dos máximos das duas bandas da PANI, em ambiente inerte (losângulos), em função do estado de oxidação 1-y. O gráfico mostra as melhores retas ajustadas aos pontos experimentais (losângulos) e o ponto de interseção. Os quadrados são os dados correspondentes à PANI em ambiente livre (fig.II.10).

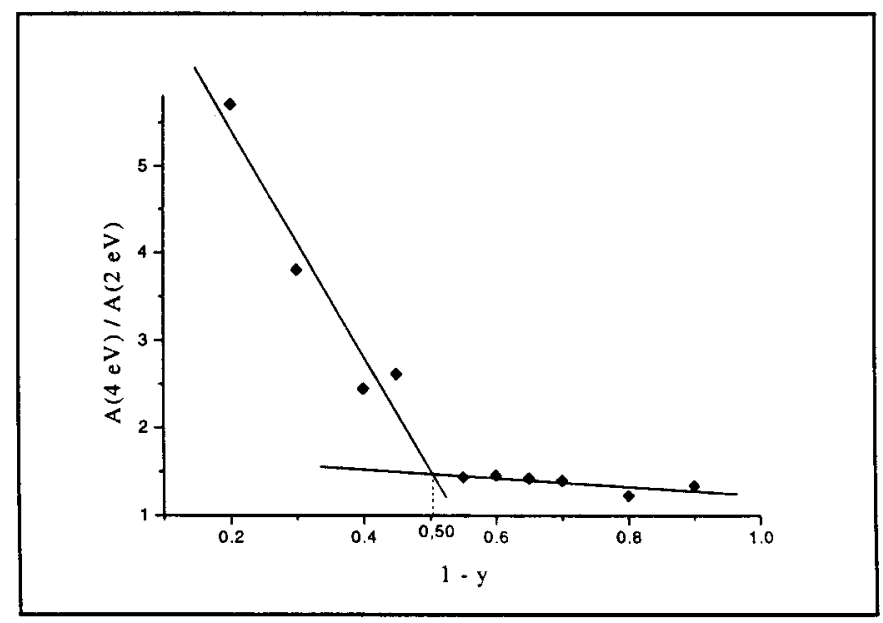

Figura II.15 - O mesmo gráfico da figura anterior sem o ponto experimental $1-y=0,5$. 
A figura II.16 mostra os gráficos da energia e do comprimento de onda correspondentes ao máximo da banda em torno de $2 \mathrm{eV}$, em função do estado de oxidação 1-y, para a PANI em ambiente inerte. Nota-se que a energia e o comprimento de onda não se alteram para os estados reduzidos, como no caso da PANI em ambiente livre. O comportamento para os estados oxidados, distintamente do que ocorreu no ambiente livre, mostra que a energia fica constante para $1-y \geq 0,7$; isto é, a partir de $1-y=0,7$ a banda já chegou ao estágio final da pernigranilina (em $536 \mathrm{~nm}$ ).

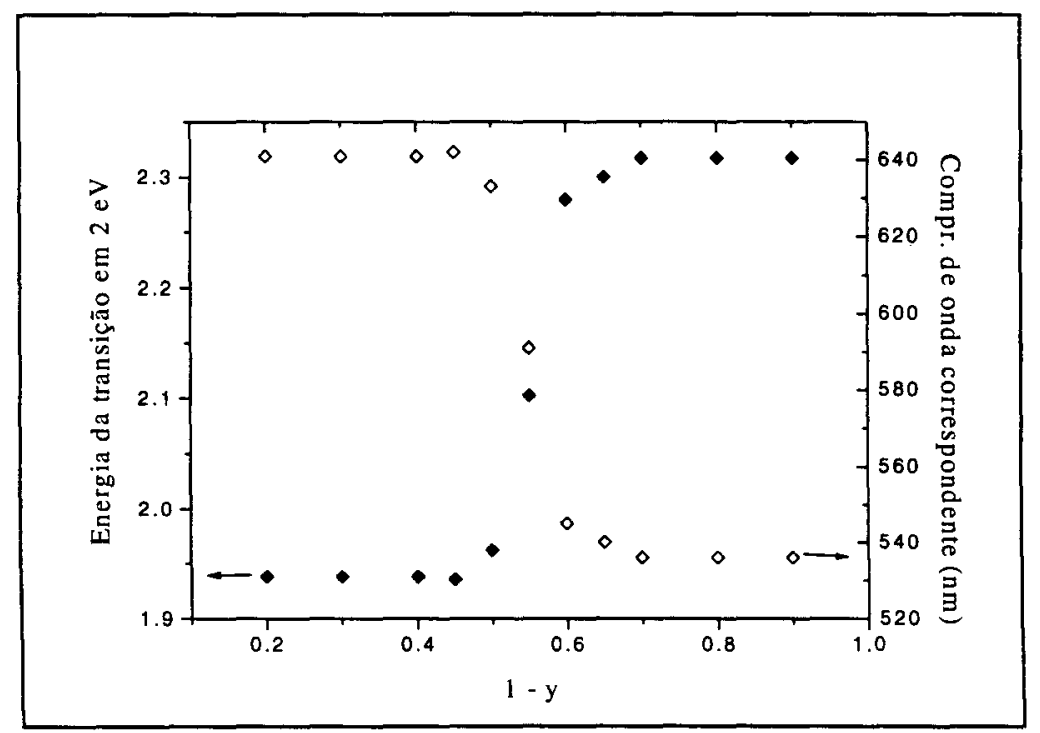

Figura II.16 - Gráficos da energia e do comprimento de onda correspondentes ao máximo da banda em torno de $2 \mathrm{eV}$ em função do estado de oxidação 1-y, para a PANI em ambiente inerte.

\section{II.5.3.3 - Para a POMA no Ambiente Livre}

A figura II.17 mostra os espectros obtidos para monitorar as reações de oxidação e de redução para a POMA no ambiente livre. Seguiu-se a mesma metodologia que no caso da PANI no ambiente livre. Pode-se verificar a existência de pontos isobésticos em torno de 300 nm e $390 \mathrm{~nm}$, sendo consistente com os espectros das figuras II.3 e II.4. Verifica-se também 
um ponto isobéstico (difuso) em torno de $570 \mathrm{~nm}$ na transformação da banda de éxciton molecular da base esmeraldina para a banda da pernigranilina. Este ponto não foi obtido na figura II.4. A não-obtenção de pontos isobésticos está muito relacionada com a formação de precipitado nas soluções, conforme mencionado anteriormente. Para este caso da POMA, houve pouca formação de precipitado nos frascos de reação. Devido a este fato, os pontos isobésticos estão melhor resolvidos. Estes pontos para a POMA são consistentes com os obtidos para a PANI mencionados na literatura $[8,19]$.

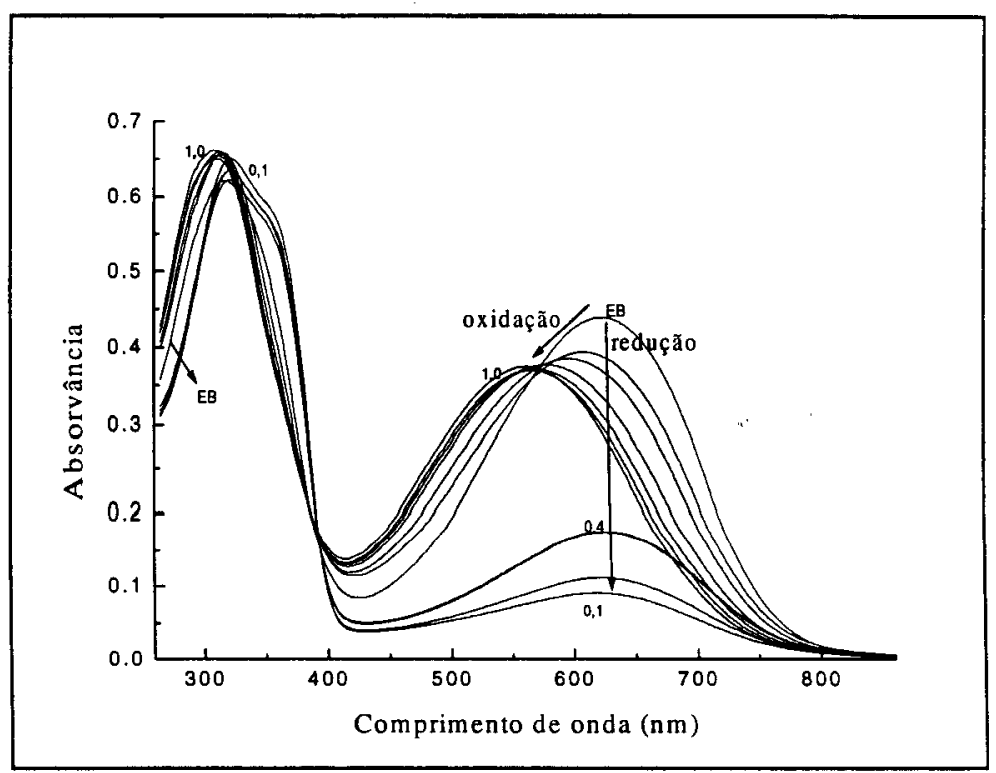

Figura 11.17 - Espectros de absorção ótica para as 11 soluções de POMA-EB em NMP, nos quais foram adicionados redutor em 4 soluções e oxidante em 6 soluções.

A figura II.18 mostra o gráfico razão das absorvâncias versus estados de oxidação obtido para a POMA. No gráfico, o símbolo quadrado representa os pontos para os espectros obtidos quinze horas depois de preparadas as soluções e o símbolo triângulo, para os espectros obtidos uma semana depois. O comportamento é bem semelhante ao caso da PANI no ambiente livre, com uma pequena diferença para os dados obtidos uma semana depois, onde a 
influência do meio ambiente é maior tanto para os estados reduzidos quanto para os oxidados. Como pode ser verificado, a interseção das duas retas ajustadas aos pontos experimentais define o estado de oxidação da base esmeraldina. A figura II.19 mostra o mesmo gráfico sem o ponto experimental correspondente a $1-y=0,5$. Neste caso, o ponto de interseção das retas fornece também a abscissa correspondente à base esmeraldina.

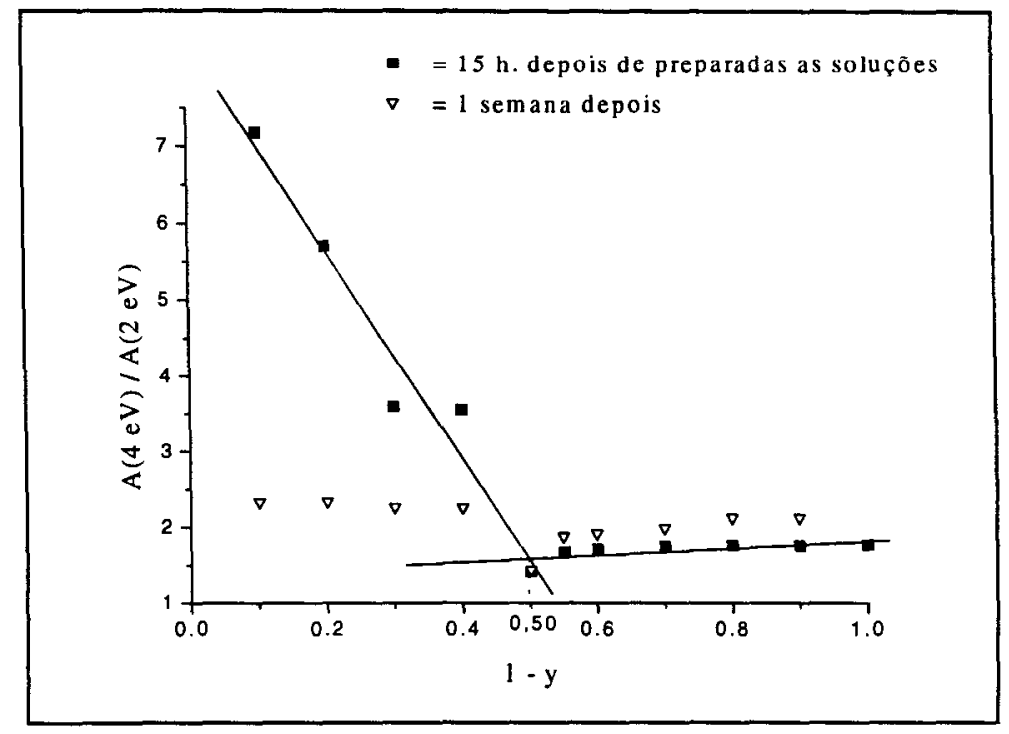

Figura II.18 - Gráfico da razão das absorvâncias dos máximos das duas bandas da POMA em função do estado de oxidação 1-y. O gráfico mostra as melhores retas ajustadas aos pontos experimentais (quadrados) e o ponto de interseção.

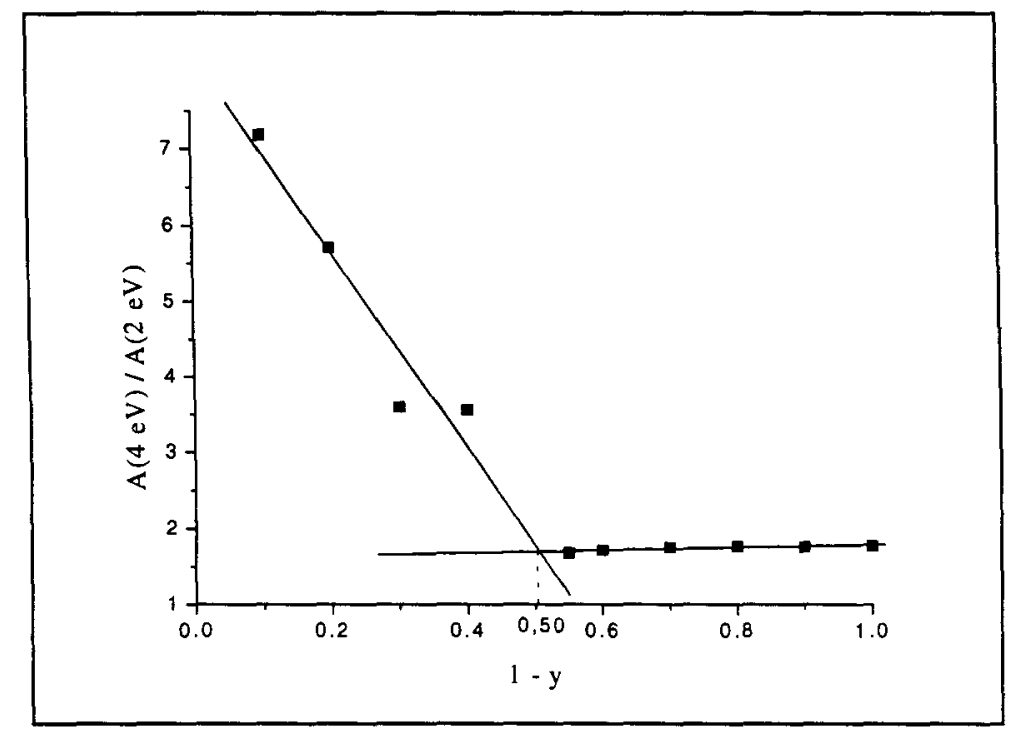

Figura II.19 - O mesmo gráfico anterior sem o ponto experimental 1-y =0,5. 
A figura II.20 mostra os gráficos da energia e do comprimento de onda correspondentes ao máximo da banda em torno de $2 \mathrm{eV}$, em função do estado de oxidação 1-y, para o mesmo material anterior. Aqui, novamente o comportamento é semelhante ao caso da PANI em ambiente livre, onde verifica-se que a energia e o comprimento de onda praticamente não se alteram para os estados reduzidos, e, para os pontos acima de $1-\mathrm{y}=0,5$, é observado um grande aumento na energia (correspondendo à diminuição no comprimento de onda). Daí vem a definição do estado de oxidação correspondente à base esmeraldina.

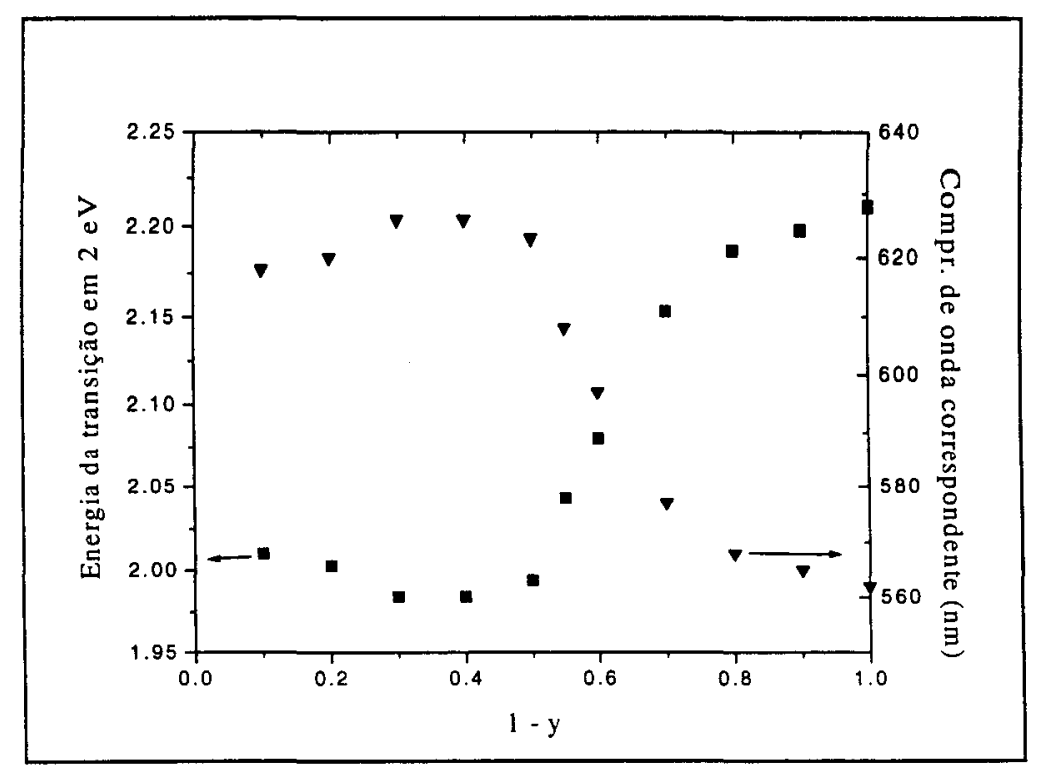

Figura II.20 - Gráficos da energia e do comprimento de onda correspondentes ao máximo da banda em torno de $2 \mathrm{eV}$ em função do estado de oxidação 1-y, para a POMA no ambiente livre.

\section{II.5.4 - Método da Deconvolução de Bandas}

Fazendo a deconvolução (separação) das bandas dos espectros, obtemos a área sob as bandas deconvoluídas (considerando que são gaussianas). Esta área é uma grandeza física proporcional ao coeficiente de extinção. Este fornece a absorção em um determinado 
comprimento de onda, enquanto a área sob a banda fornece a absorção ao longo de toda a banda do espectro $[38,39]$.

Na reação de redução da base esmeraldina para a leucoesmeraldina, na região dos $4 \mathrm{eV}$ sempre há duas bandas de absorção se superpondo, enquanto na região dos $2 \mathrm{eV}$, a banda de éxciton molecular da esmeraldina vai desaparecendo. Neste caso, só há uma banda, porque, nesta região, a leucoesmeraldina não apresenta absorção. $\mathrm{Na}$ reação de oxidação da esmeraldina para a pernigranilina, há sempre duas bandas de absorção superpostas em cada região (duas na região dos $4 \mathrm{eV}$ e duas na região dos $2 \mathrm{eV}$ ). A banda característica de cada espécie vai-se transformando na da outra, dando origem aos pontos isobésticos. Com a deconvolução das bandas, pode-se somar a área sob as duas bandas na região dos $4 \mathrm{eV}$ (para qualquer estado de oxidação) e usar esse valor para a normalização da área sob a banda de éxciton molecular da base esmeraldina situada em $623 \mathrm{~nm}$.

A figura II.21 mostra a área sob a banda deconvoluída em torno de $623 \mathrm{~nm}$ da POMA (banda de éxciton molecular da base esmeraldina), em função dos estados de oxidação 1-y. A área foi normalizada em relação ao valor médio da soma das áreas das bandas situadas na região dos $4 \mathrm{eV}$ (que sempre são duas), para todos os estados de oxidação. Vê-se claramente uma descontinuidade em $1-\mathrm{y}=0,5$, onde a área da banda em $623 \mathrm{~nm}$ é máxima, definindo o estado de oxidação correspondente à base esmeraldina. A área é máxima neste ponto, porque a banda em $623 \mathrm{~nm}$ é máxima para a base esmeraldina $(1-\mathrm{y}=0,5)$.

O processo de deconvolução mostrou que a soma da área das duas bandas que se situam na região dos $4 \mathrm{eV}$ é praticamente constante para todos os estados de oxidação $1-\mathrm{y}$. $\mathrm{O}$ mesmo ocorre para a soma da área das bandas que se situam na região dos $2 \mathrm{eV}$, para os estados entre $1-y=0,5$ e 1,0 . Isto comprova o fato de que um composto se transforma diretamente em outro, sem passar por algum composto intermediário, em nível molecular. Ou 
seja, uma banda se transforma diretamente em outra, de tal forma que a soma delas permanece constante para os estados de oxidação envolvidos.

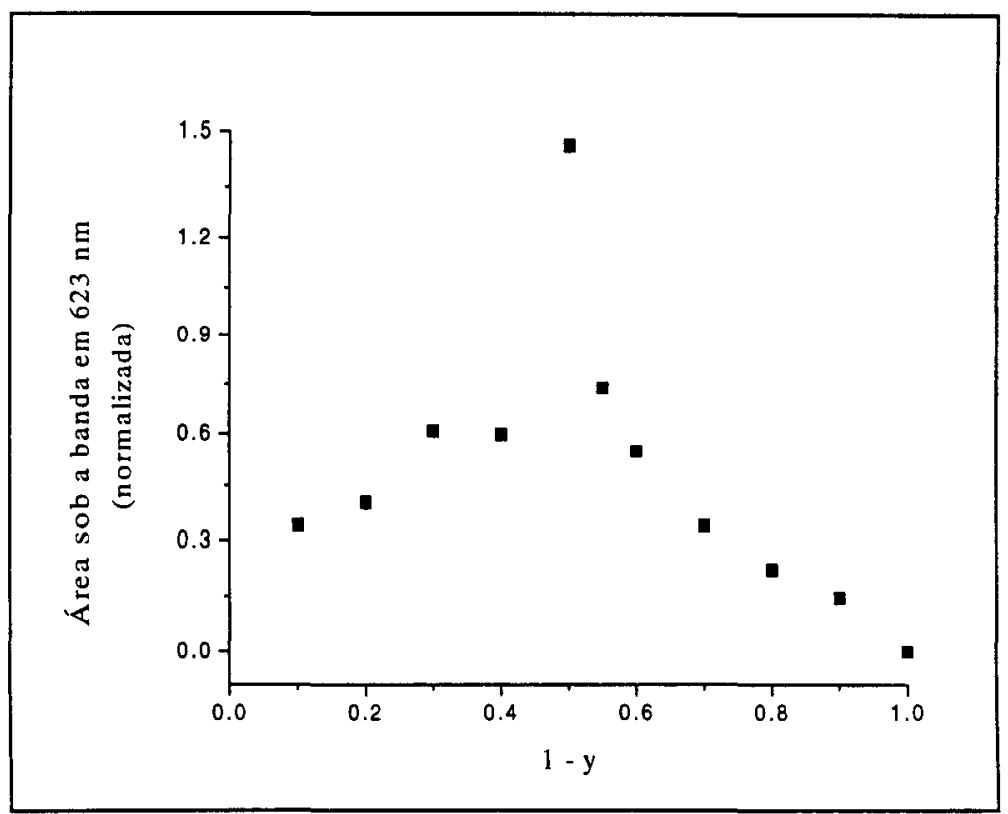

Figura II.21 - Gráfico da área sob a banda deconvoluída em torno de $623 \mathrm{~nm}$, em função dos estados de oxidação.

\section{II.5.5 - Aplicação dos Métodos Anteriores}

Vamos aplicar agora os dois métodos para a determinação dos estados de oxidação das polianilinas. A figura II.4 anterior mostra os espectros obtidos qualitativamente para uma solução de POMA em NMP, onde foi adicionado uma pequena quantidade de oxidante. Os espectros foram obtidos com o decorrer do tempo. Conforme explicado antes, parece que o polímero, como foi sintetizado, não está no estado de oxidação exato da base esmeraldina, porque a banda em torno de $623 \mathrm{~nm}$ aumenta inicialmente de intensidade. Em seguida, começa a deslocar-se consideravelmente para menores comprimentos de onda. Vamos determinar o estado de oxidação do polímero correspondente ao primeiro espectro, que é o da 
base esmeraldina (como foi sintetizada) e o correspondente ao último espectro (O8), que é o estado mais oxidado, depois de decorridos $9,5 \mathrm{~h}$ de reação com o oxidante. A posição do máximo da banda em $2 \mathrm{eV}$ para a base esmeraldina (EB) é $625 \mathrm{~nm}$. Observando a figura II.20, vemos que este valor corresponde a um estado reduzido do polímero. Porém, o valor exato do estado de oxidação é ainda impossível de ser determinado. A razão das absorvâncias dos máximos das duas bandas, em 4 e $2 \mathrm{eV}$, para a base esmeraldina dá um valor igual a 1,46. Observando a figura $\Pi$.18, podemos ver que o estado de oxidação correspondente a essa razão é muito próxima de 0,5 , tomando-se a reta correspondente aos estados reduzidos. Vamos utilizar então o método da deconvolução de bandas. Fazendo a deconvolução das bandas correspondentes ao espectro EB da figura II.4, obtemos o valor 1,43 como a área sob a banda em $623 \mathrm{~nm}$, normalizada pela soma das áreas sob as bandas em $4 \mathrm{eV}$. Observando a figura II.21, vemos que o estado de oxidação correspondente a esse valor, pelo lado dos estados reduzidos, é também muito próximo de 0,5. Assim, os dois métodos fornecem aproximadamente os mesmos valores para os estados de oxidação. Assim, podemos afirmar que o estado de oxidação do polímero, como foi sintetizado, está um pouco reduzido, mas com um estado de oxidação muito próximo de 0,5 .

Para o último espectro da figura II.4 (O8), o máximo da banda na região dos 2 eV é $566 \mathrm{~nm}$. De acordo com a figura II.20, o estado de oxidação do polímero para esse valor já pode ser determinado, ficando em torno de 0,85 . Vamos ver se esse valor coincide com os fornecidos pelos gráficos correspondentes às figuras II.18 e II.21. A razão das absorvâncias dos máximos das bandas em 4 e $2 \mathrm{eV}$ é 1,51, de acordo com a figura II.4. Assim, este número está abaixo dos valores das razões para os estados oxidados, como pode ser verificado na figura II.18. Esse fato provavelmente ocorreu, porque os pontos do gráfico da figura II.18 podem apresentar uma margem de erro de tal forma que esse valor para a razão das

IFSC-USP 
absorvâncias esteja dentro dessa margem. Conseqüentemente, de acordo com essa figura, não há como determinar o estado de oxidação. Mas, utilizando o método da deconvolução de bandas, obtemos o valor 0,191 para a área normalizada sob a banda em $623 \mathrm{~nm}$ (depois de deconvoluída). De acordo com a figura П.21, este valor fornece o estado de oxidação igual a 0,8 para o polímero, que está próximo do valor fornecido pela posição do máximo da banda.

\section{II.6 - CONCLUSÕES}

A espectroscopia de absorção ótica mostrou ser uma técnica de grande utilidade na determinação dos estados de oxidação das polianilinas. Através de espetros de absorção ótica, pode-se usar as curvas obtidas nas figuras II.10 e II.12 para a PANI (ou II.18 e II.20 para a POMA), a fim de avaliar o estado de oxidação desconhecido de uma amostra do polímero. Por exemplo, se a razão das absorções dos máximos das duas bandas da PANI, no ambiente livre, der um valor igual a 3,0, então, de acordo com a figura II.10, o estado de oxidação do polímero é igual a aproximadamente 0,32. Assim, essas curvas experimentais podem ser muito úteis para a avaliação do estado de oxidação. Porém, vimos que, em determinadas situações, este método apresenta limitações e, desta forma, deve-se recorrer a outros, para a determinação dos estados de oxidação. Fizemos isto utilizando o processo de deconvolução de bandas, conforme mencionado. Assim, um método complementa o outro. Porém, o processo é mais trabalhoso, pois há a necessidade do tratamento matemático sobre o espectro para fazer a deconvolução das bandas. Isto pode ser feito por meio de programas matemáticos em microcomputador. De posse de um espectro de absorção ótica de uma polianilina (POMA), de estado de oxidação desconhecido, com a deconvolução das bandas e com a conseqüente 
determinação de suas áreas, pode-se utilizar o gráfico da figura II.21 para determinar o seu estado de oxidação. Assim, essa curva é útil também na determinação do estado de oxidação.

O processo de obtenção dos estados de oxidação descrito aqui pode ser usado como um método de síntese de amostras em um estado de oxidação pretendido. Por exemplo, se queremos obter a polianilina em um estado de oxidação igual a 0,7 , então temos somente que determinar a quantidade de oxidante (peroxidissulfato de amônia) necessário para converter a base esmeraldina até este valor, usando a estequiometria da reação de oxidação (b). Feita a reação, pode-se isolar o polímero, no estado de oxidação desejado, por um processo simples de precipitação e filtração, seguido de lavagens do pó assim obtido [33]. 


\section{CAPÍTULO III \\ ESPECTROSCOPIA FOTOTÉRMICA DE POLIANILINAS}




\section{CAP. III - ESPECTROSCOPIA FOTOTÉRMICA DE POLIANILINAS}

\section{III.1 - INTRODUÇÃO}

A Espectroscopia Fotoacústica (PAS) é uma técnica relativamente recente e tem usado como detetores do sinal fotoacústico microfones convencionais e transdutores piezoelétricos. Os transdutores piezoelétricos mais comuns são feitos usualmente de cerâmicas piezoelétricas, como por exemplo, o titanato zirconato de chumbo (PZT). Os piezoelétricos cerâmicos exibem uma resposta de freqüência muito maior que os microfones, e assim são dominantes em aplicações de espectroscopia fotoacústica, onde são requeridas respostas rápidas do detetor, como na PAS com laser pulsado. Recentemente, A. C. Tam e H. Coufal usaram filmes finos de fluoreto de polivinilideno (PVDF) como transdutores piezoelétricos para espectroscopia fotoacústica modulada e pulsada [51,52]. Esses filmes possuem vantagens sobre os detetores de PZT, sendo a principal a sua resposta em freqüência, que é muito mais alta e plana. Adicionalmente a este comportamento piezoelétrico, os filmes finos de PVDF exibem fortes propriedades piroelétricas, e assim eles podem ser usados como detetores de radiação térmica. O efeito piroelétrico consiste na indução de uma polarização espontânea e rápida em um cristal piezoelétrico não centro-simétrico, como um resultado de uma mudança da temperatura no cristal. Coufal utilizou a resposta piroelétrica de filmes finos de PVDF para obter espectros, para freqüências de modulação baixas, de filmes de poli(metil metacrilato) dopado com $\mathrm{Nd}_{2} \mathrm{O}_{3}$ [51]. Esta aplicação abriu caminho para a possibilidade de uma nova técnica espectroscópica, usando filmes finos piroelétricos como detetores, para obter absorção ótica e detetar processos de conversão de energia não-radiativo em matéria condensada $[51,52]$. 
A comparação entre a deteção PAS piezoelétrica e a piroelétrica mostrou que ambas as técnicas possuem tempos de resposta e sensibilidade similares [51,53]. Coufal observou que a deteção piroelétrica tem vantagens adicionais sobre a PAS piezoelétrica, tais como simplicidade de calibração, insensibilidade a ressonâncias mecânicas e ruídos acústicos, um alto potencial para melhoria da relação sinal/ruído e uma excelente resposta plana na faixa utilizável de temperatura [51,53]. Experimentos realizados por A. Mandelis, para caracterizar a resposta de uma célula fotopiroelétrica, com relação a um feixe de luz de excitação de comprimento de onda e frequêencia de modulação variáveis, mostraram que ela possui uma resposta linear de freqüência entre $10 \mathrm{~Hz}$ e $2 \mathrm{kHz}$; uma distinta vantagem sobre as nãolinearidades devido à ressonância de Helmholtz presentes nas células PAS de microfone comerciais [53].

Em estudos espectroscópicos fotopiroelétricos em pós de $\mathrm{Ho}_{2} \mathrm{O}_{3}$, Mandelis observou a inversão das características espectrais da amplitude do sinal piroelétrico, ao passar de 11 para $50 \mathrm{~Hz}$, sem mudança respectiva da fase fotopiroelétrica [52,53]. Para explicar essa característica surpreendente, que não era encontrada na PAS, e, também, para dar suporte à nova técnica espectroscópica, chamada usualmente de Espectroscopia Fotopiroelétrica (PPES), Mandelis e M. M. Zver [53] criaram um modelo teórico para um sistema unidimensional, constituído por uma amostra sólida em contato íntimo com um filme fino piroelétrico e suportada por um material não-absorvente (de luz), em uma célula aberta. Este modelo será discutido no próximo capítulo.

As técnicas PAS e PPES, que juntamente com outras constituem a Espectroscopia Fototérmica, serão utilizadas aqui na caracterização das propriedades óticas e térmicas de polianilinas. No próximo capítulo, veremos que as equações básicas (desenvolvidas a partir da eficiência de conversão não-radiativa e do transporte de calor), quando ajustadas aos pontos 
experimentais, fornecem parâmetros físicos importantes, como por exemplo: a difusividade e a condutividade térmicas, o calor específico, o coeficiente de absorção ótica e o gap ótico. Pela quantidade de grandezas físicas obtidas e pela sua confiabilidade, as técnicas fototérmicas, em particular a fotopiroelétrica, demonstram sua grande importância na análise de materiais sólidos.

Este capítulo fornecerá principalmente os resultados espectroscópicos experimentais obtidos com as técnicas PPES e PAS para filmes de polianilinas não-dopadas e dopadas em soluções de ácido clorídrico em diversos pH's. No próximo capítulo, apresentaremos com detalhe o desenvolvimento dos modelos teóricos e as aproximações a casos especiais que serão adaptados aos nossos resultados para o ajuste teórico-experimental.

\section{III.2 - METODOLOGIA EXPERIMENTAL}

\section{III.2.1 - O Espectrômetro Fototérmico}

A figura III.1 mostra um diagrama do espectrômetro fototérmico utilizado. Esse equipamento pertence ao laboratório de Fototérmica do DEE/UNESP/Ilha Solteira-SP. Podese usar a montagem de duplo feixe de luz, utilizando-se duas células porta-amostras e dois amplificadores lock-in, como também a de único feixe, utilizando-se somente uma célula. A figura mostra a montagem de um único feixe, que foi utilizada em nossas medidas. A fonte de luz incandescente (halógena) é da Oriel Corporation, modelo 66181, de $250 \mathrm{~W}$ de potência. Usamos também um laser de He-Ne (marca Oriel, modelo 79290, de $2 \mathrm{~mW}$ de potência), como fonte de luz monocromática, para a obtenção de sinal com a varredura de freqüências. $O$ monocromador é da Oriel, modelo 77200. O chopper para modular a luz é da EGG-PARC, 
modelo 194A, para frequiências de até $500 \mathrm{~Hz}$. Para freqüências superiores a esta, utiliza-se um chopper da Stanford Research System, modelo SR 540. Utilizam-se fibras óticas bifurcadas de quartzo da Oriel, modelo 77565, para duplicação do feixe de luz (na montagem de duplo feixe) e para levar os feixes até as células (na montagem com o laser, como fonte de luz, não se utilizam as fibras óticas, sendo usado um espelho para desviar o feixe até a célula).

O lock-in, que é interfaceado com o microcomputador, é da Stanford Research System, modelo SR 530. A amplificação do sinal vindo da célula, utilizando lock-in, é síncrona com a frequêencia do chopper. Na montagem de duplo feixe, os espectros já são obtidos normalizados, onde o microcomputador realiza esta operação com os sinais vindos de dois lock-in's. A normalização é obtida pela divisão do sinal vindo da amostra pelo da referência, onde se usa um corpo negro. O espectro de corpo negro serve para retirar dos espectros das amostras a curva espectral da fonte de luz associada com a dos componentes óticos do sistema. Na montagem de um único feixe, a normalização dos espectros é realizada posteriormente, depois da obtenção dos espectros das amostras e do corpo negro, utilizando-se sempre a mesma célula. As células fotopiroelétrica e fotoacústica foram fabricadas na oficina mecânica do IFSC/USP/São Carlos-SP. Através de um motor de passo $\left(1,8^{\circ}\right.$ por passo $)$ acoplado ao monocromador e controlado por um driver apropriado (ligado ao microcomputador), faz-se a varredura de comprimentos de onda. O sistema (o lock-in, o chopper e o driver do motor de passo) é controlado pelo microcomputador, um compatível com o IBM-PC 80486/DX de $50 \mathrm{MHz}$. Este é ligado a uma impressora para a reprodução dos espectros em folha de papel. O microcomputador é controlado por um programa de aquisição de dados, elaborado pelo prof. W. L. B. Melo. Este programa pode obter dados através dos quatro canais do lock-in ( $\mathrm{R}, \theta$, $\mathrm{x}$ e y), mostrando toda a aquisição de dados na tela de vídeo do 
microcomputador. Posteriormente, o programa armazena os dados em arquivos, no formato ASCII.

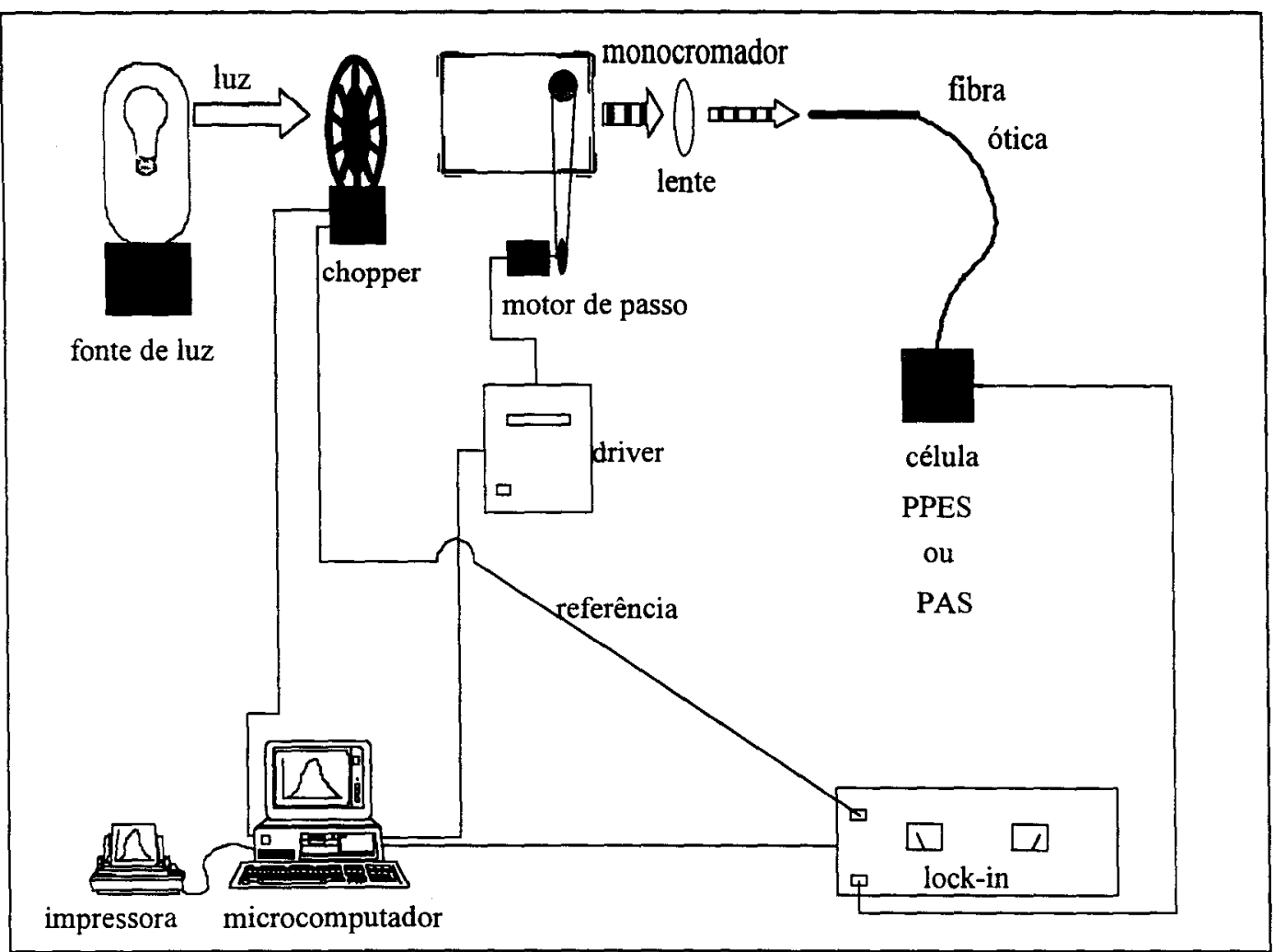

Figura III.1 - Diagrama do Espectrômetro Fototérmico. Na montagem utilizando o laser como fonte de luz (para varredura de freqüências de modulação da luz), não se usa o monocromador e a fibra ótica.

\section{III.2.2 - As Células Fotopiroelétrica e Fotoacústica}

A célula fotopiroelétrica foi projetada pelo prof. W. L. B. Melo e está esquematizada na figura III.2. Ela é composta de [54]:

a. Um filme fino de PVDF, que é usado como sensor piroelétrico. Esse filme possui as dimensões: $15 \mathrm{~mm}$ de comprimento, $4 \mathrm{~mm}$ de largura e $40 \mu \mathrm{m}$ de espessura; 
b. Dois discos de acrílico com diâmetro de $30 \mathrm{~mm}$. Esses discos servem de suporte para o filme de PVDF. O disco superior possui um orifício central cujo diâmetro é de $\cong 8 \mathrm{~mm}$. Quatro orifícios menores posicionados próximos à borda são usados para passar quatro parafusos que servem para manter preso os dois discos;

c. $\mathrm{O}$ disco inferior possui no centro um pino de acrílico de diâmetro $\cong 7,96 \mathrm{~mm}$. Este pino central apresenta aproximadamente a mesma altura do disco superior e se encaixa em seu orifício central. A extremidade superior desse pino central possui superfície plana cuja borda foi cortada fazendo um ângulo de $\cong 60^{\circ}$ com a horizontal. Esse corte altera o formato da borda de circular para quadrado. Próximo ao pino central há um pequeno orifício que serve para a passagem do fio que faz o contato elétrico com o filme de PVDF;

d. Contatos elétricos são obtidos usando um fio fino de cobre esmaltado, um anel de alumínio de $\cong 10 \mu \mathrm{m}$ de espessura e uma fita do mesmo alumínio de dimensões $\cong 50 \times 3 \mathrm{~mm}^{2} . \mathrm{O}$ anel de alumínio se encaixa no pino central, e sua utilidade é aumentar a área de contato sob o filme de PVDF. O fio de cobre esmaltado, após passar pelo orifício no disco inferior, faz contato com o anel. A outra extremidade do fio é soldada ao pino central do conector BNC. A fita de alumínio é introduzida por entre os discos ao longo do diâmetro. Essa fita é conectada com a superfície superior do filme de PVDF. A outra extremidade da fita entra em contato com o corpo metálico da célula;

e. O filme de PVDF é montado entre os discos e passa pela superfície plana superior do pino central. O filme desce pelos lados do pino e suas extremidades ficam presas por entre os discos. Dessa forma, o filme é moldado pelo pino central e a área quadrada na extremidade dele é coberta pelo filme. Portanto, essa é a área útil do sensor piroelétrico sobre a qual é colocada a amostra; 
f. O conjunto montado é introduzido em um corpo de alumínio no qual se encontra o conector BNC. A fita de alumínio é conectada ao corpo, que serve de blindagem eletromagnética. Uma tampa de latão com um orificio para a passagem de luz é usada para fechar a célula. Uma peça na forma de T completa a tampa, servindo de apoio para a fibra ótica.

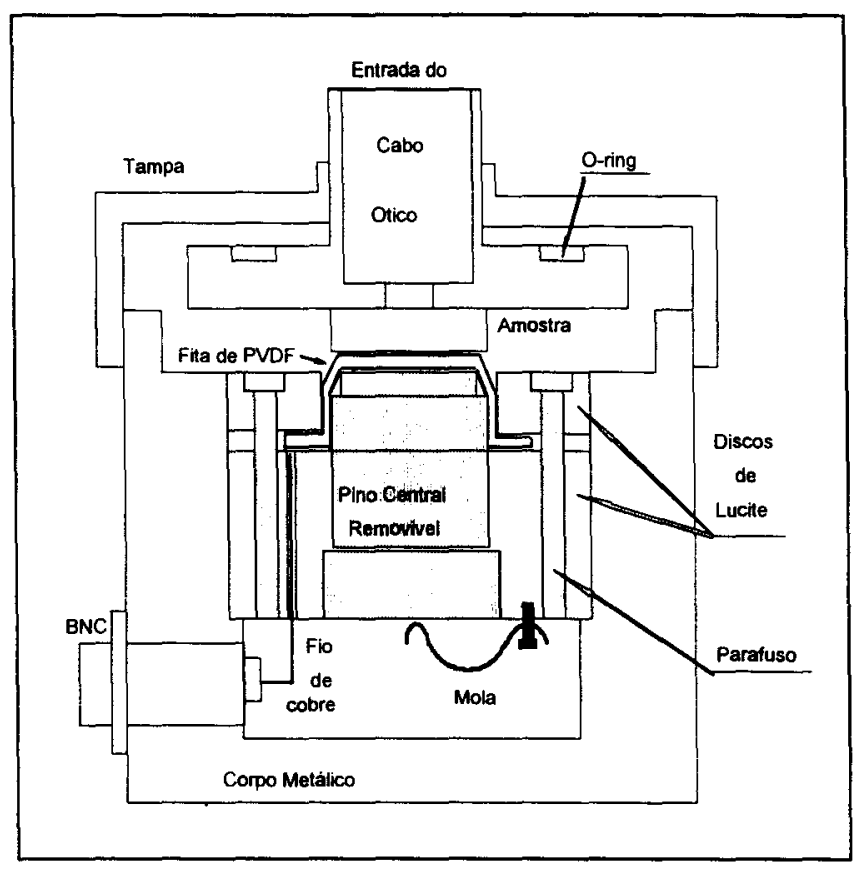

Figura III.2 - Esquema da célula fotopiroelétrica [54].

As diversas partes mostradas na figura III.2 não estão na escala correta para se poderem evidenciar alguns detalhes. $O$ detetor piroelétrico é pintado com tinta preta (de caneta de retroprojetor) para torná-lo oticamente opaco e não refletor de luz [54,55]. Para um perfeito acoplamento térmico entre as amostras e o detetor, usa-se uma finíssima camada de graxa de vácuo (com cobre metálico) entre os dois.

A célula fotoacústica foi projetada também pelo prof. W. L. B. Melo e está esquematizada na figura III.3. O corpo dela é de alumínio e é dividido em duas partes: a maior 
parte é onde fica o microfone, o conector BNC e os fios de alimentação de corrente contínua para o microfone; a parte menor é a célula propriamente dita, onde se coloca a amostra. Esta parte é aberta para os dois lados, podendo fazer incidência de luz pela frente e por trás da amostra. A janela de vidro BK-7 é presa por um anel rosqueado de latão, por onde é feita a incidência de luz. As amostras são colocadas pela parte de baixo por intermédio de um suporte (no nosso caso, placas de quartzo). Esse suporte para a amostra também é preso por um anel rosqueado de latão. Usam-se anéis o-ring de borracha entre o anel prendedor e a janela, e entre o anel prendedor e o suporte da amostra. Utiliza-se graxa de vácuo entre a janela e o corpo da célula (e entre o suporte da amostra e o corpo da célula) para um melhor isolamento acústico do ambiente. Também por este motivo, a parte da célula onde fica o microfone é bem vedada com borracha de silicone. As diversas partes da célula não estão desenhadas na escala correta na figura III.3 para se poderem evidenciar alguns detalhes.

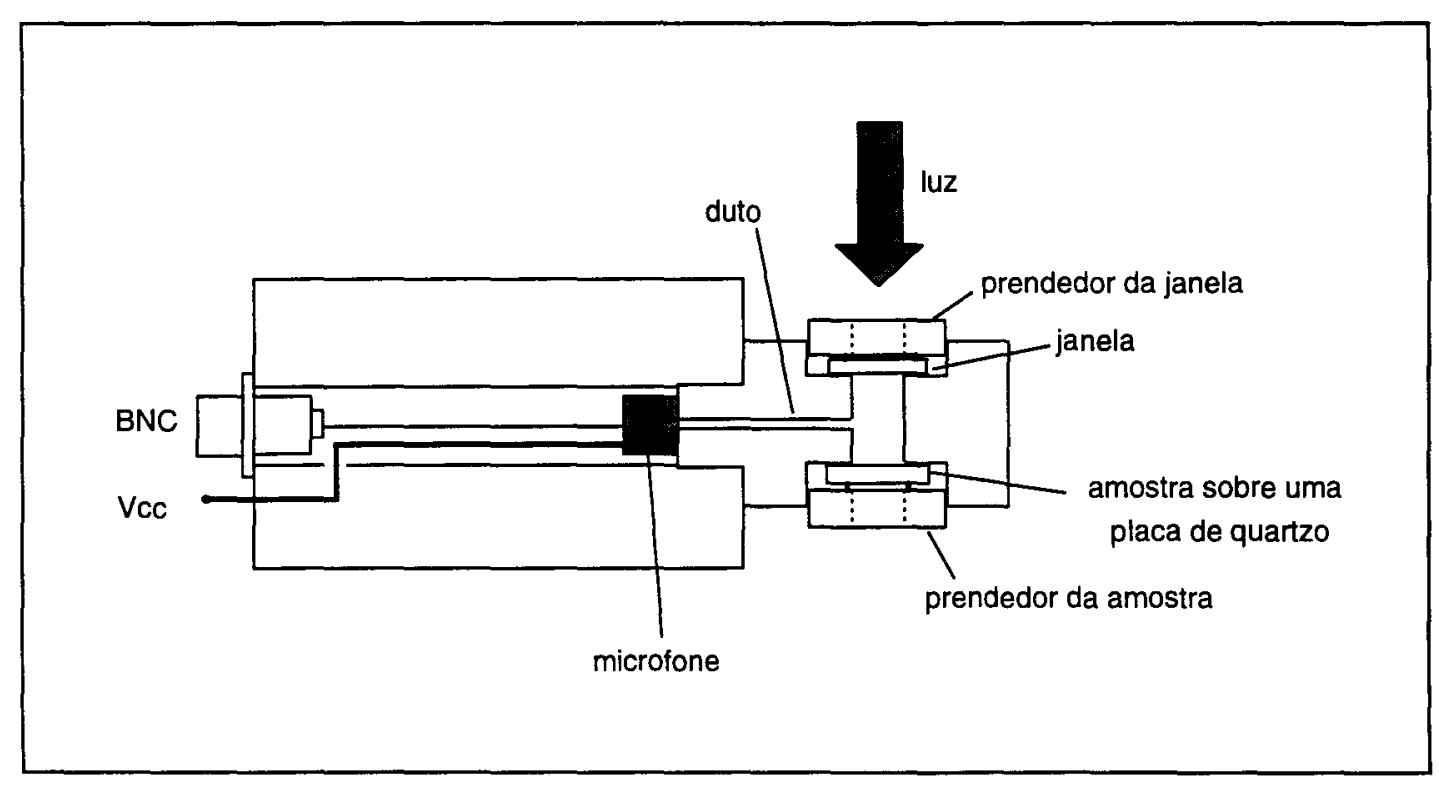

Figura III.3 - Esquema da célula fotoacústica. 


\section{III.2.3 - Preparação das Amostras}

Para as medidas PPES com a varredura de freqüência, utilizamos porções de um mesmo filme de PANI, com áreas em torno de $0,9 \times 1,0 \mathrm{~cm}^{2}$ e com espessuras em torno de 20 $\mu \mathrm{m}$. Esse filme foi preparado por deposição de uma solução de PANI em NMP (concentração $2 \%$ ) sobre uma placa de vidro e aquecido a $40{ }^{\circ} \mathrm{C}$, por um período de $24 \mathrm{~h}$, para que o solvente evaporasse. Os filmes recortados foram dopados em soluções de ácido clorídrico, em diversos pH's, sendo imersos por um período de $24 \mathrm{~h}$. Depois da dopagem, eles eram secados a vácuo, também em torno de 24 h. Para a POMA, usamos um filme que foi depositado em uma placa de quartzo, obtido por evaporação do solvente diclorometano. Como o diclorometano é altamente volátil, o filme ficou com a superfície um pouco irregular, e sua espessura ficou entre 5 e $7 \mu \mathrm{m}$.

As medidas de sinal fotopiroelétrico com a varredura de freqüência foram feitas utilizando-se o laser de He-Ne como fonte de luz. Utilizamos a montagem de único feixe, tendo que fazer a normalização dos espectros posteriormente à sua obtenção. A vantagem deste método é não ter que calibrar todo o sistema para os sinais vindos de duas células, que, mesmo sendo iguais, podem apresentar respostas ligeiramente diferentes. A célula fotopiroelétrica foi usada como um sistema fechado, isto é, colocando-se uma janela de vidro BK-7 sobre as amostras, e exercendo uma pequena pressão sobre elas (para um bom acoplamento térmico). Assim, o meio anterior às amostras é a janela de vidro. Os dados obtidos com a varredura de frequiência serão mostrados no próximo capítulo.

Para a obtenção dos espectros PPES com a varredura de comprimentos de onda, além dos filmes mencionados acima, utilizamos filmes de POMA transparentes (filmes finos), obtidos em placas de quartzo circulares de $2 \mathrm{~mm}$ de espessura, com a técnica de spin coating. O solvente usado para o preparo da solução de POMA foi o diclorometano. Foi usada uma 
frequiência de rotação do spinner, durante a preparação dos filmes, de 1200 rpm. A espessura destes filmes ficou em torno de $0,18 \mu \mathrm{m}$, sendo medida por sulcos feitos nos filmes e usandose o aparelho Talystep da Taylor-Hobson. Alguns dos filmes produzidos foram dopados em soluções de $\mathrm{HCl}$, em diversos $\mathrm{pH}$ 's, com imersões dos filmes nas soluções, por um período de 30 s. Utilizamos também filmes transparentes de PANI, obtidos eletroquimicamente em placas de vidro ITO. Alguns desses filmes foram dopados também nas soluções de $\mathrm{HCl}$ por um período de $5 \mathrm{~s}$. Os espectros foram obtidos com o espectrômetro na montagem de um único feixe de luz. Usamos as frequêencias de 10,50 e $100 \mathrm{~Hz}$ de modulação da luz para a obtenção desses espectros.

Os espectros fotoacústicos foram obtidos com varredura de comprimentos de onda, para os filmes transparentes de POMA nas placas de quartzo. Usamos a frequiência de $10 \mathrm{~Hz}$ para a modulação da luz. Pelo mesmo motivo anterior, usamos a montagem de um único feixe de luz no espectrômetro fototérmico.

\section{III.3 - RESULTADOS E DISCUSSÃo}

\section{III.3.1 - Filmes Espessos de PANI (PPES)}

As figuras III. 4 a III.6 mostram os espectros, com a varredura de comprimentos de onda, obtidos para os pedaços de filme de PANI, respectivamente não-dopado e dopado com $\mathrm{HCl} 10^{-3}$ e $1 \mathrm{M}$ (aproximadamente $\mathrm{pH}=3,0$ e 0,3 ). As espessuras médias desses filmes são respectivamente: 19,22 e $23 \mu \mathrm{m}$. Os espectros foram obtidos entre 400 e $900 \mathrm{~nm}$, onde a intensidade da fonte de luz (lâmpada halógena) provocava um sinal mais forte. Verifica-se que 
o sinal PPES equivale à transmissão ótica, porque ele está invertido em relação à absorção ótica do polímero. Observa-se em todos esses resultados que o sinal apresenta-se saturado entre 400 e aproximadamente $680 \mathrm{~nm}$, onde vê-se claramente que o sinal permanece praticamente constante com o comprimento de onda. A partir daí, o sinal começa a aumentar alcançando um patamar. Acima de $800 \mathrm{~nm}$, um novo aumento no sinal é invariavelmente observado. O aumento do sinal é devido à região mais transparente do filme, assim a luz que chega ao detetor é absorvida por este, produzindo um sinal maior. O sinal cai com o aumento da freqüência de modulação da luz, coerente com o fato de que há um compromisso entre o pulso de luz (efeito da modulação) e a propagação do calor através da amostra. Não há, entretanto, alteração significativa dos espectros com a variação do estado de dopagem dos filmes. Isto parece ser bastante estranho, já que sabemos que os espectros de absorção ótica da polianilina varia com o estado de dopagem do polímero, conforme visto no capítulo I (figura I.3). Parece que o detetor piroelétrico responde pouco à variação do estado de dopagem do polímero (banda larga cima de $800 \mathrm{~nm}$ ), o que é estranho, porque a condutividade elétrica varia mais de dez ordens de grandeza, quando se passa do polímero não-dopado para a dopagem em $\mathrm{HCl} 1 \mathrm{M}$ (dopagem máxima) $[11,12,16]$. Mais importante ainda é o fato de que o espectro de absorção ótica da polianilina não dopada é completamente diferente do da dopada em $\mathrm{HCl} 1 \mathrm{M}$, como pode ser verificado na figura I.3 (cap.I). Mais adiante, voltaremos a discutir esses fenômenos. 


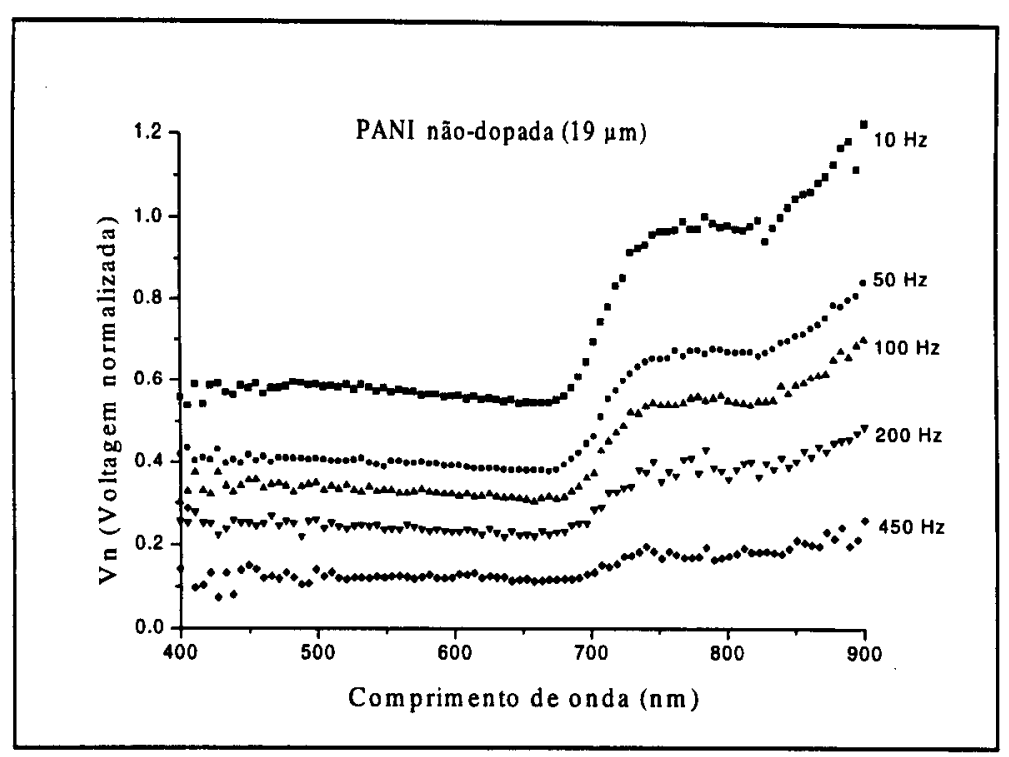

Figura III.4 - Espectros PPES de um filme de PANI não-dopado em diversas freqüências de modulação da luz.

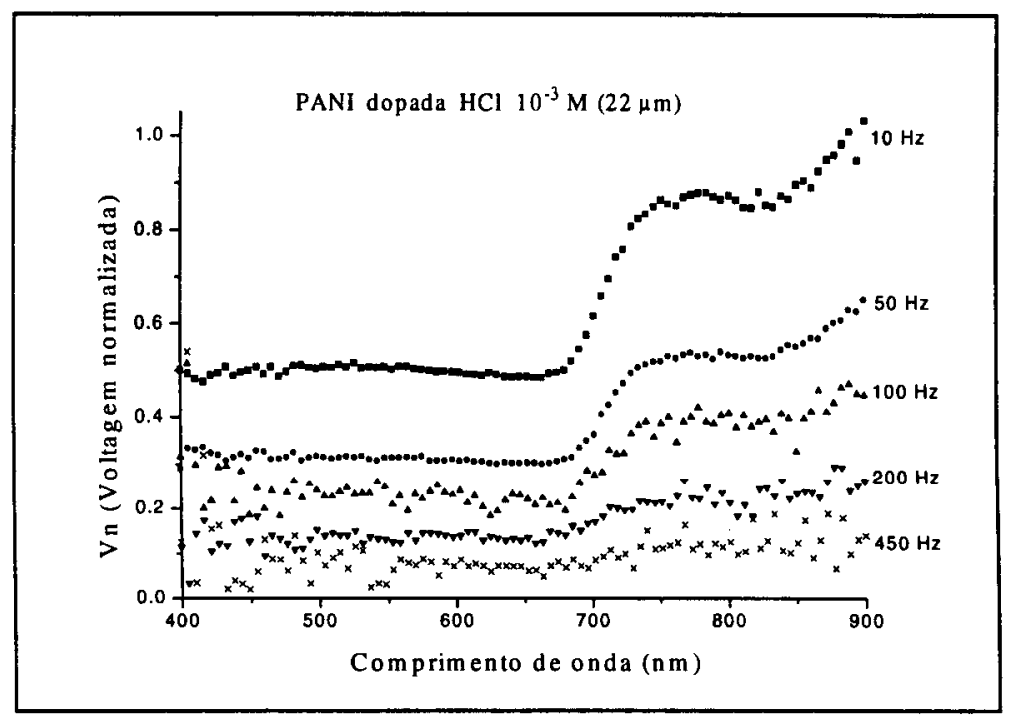

Figura III.5 - Idem para um filme de PANI dopado em $\mathrm{HCl} 10^{-3} \mathrm{M}$.

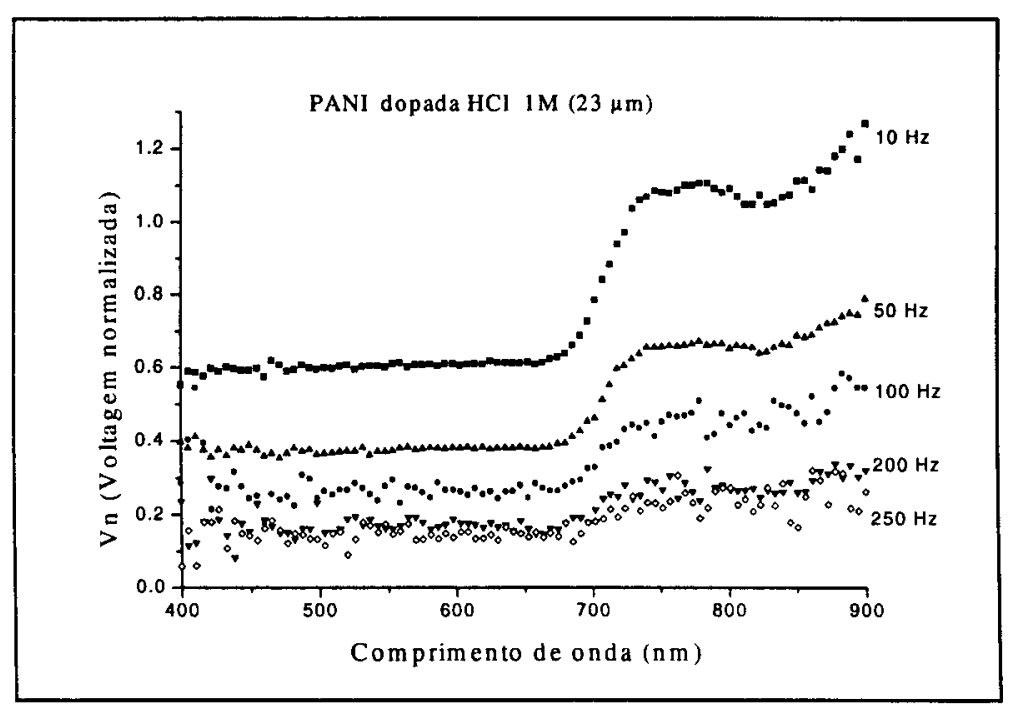

Figura III.6 - Idem para um filme de PANI dopado em $\mathrm{HCl} 1 \mathrm{M}$. 
Para as figuras III.4 e III.6, os espectros obtidos em $10 \mathrm{~Hz}$ apresentam pontos com valores de Vn acima de 1,0 (na região de maiores comprimentos de onda). Esse efeito está relacionado ao sinal da amostra ser maior que o sinal da referência para baixas freqüências de modulação da luz. O detetor piroelétrico, para freqüências abaixo de $10,7 \mathrm{~Hz}$, é termicamente fino (o comprimento de difusão térmica é maior que a espessura do detetor), e assim, em 10 $\mathrm{Hz}$, o sistema praticamente está na transição termicamente espesso para fino. Para a análise teórica a ser desenvolvida no próximo capítulo, não vamos considerar essa menor frequiência devido à transição do detetor. $\mathrm{O}$ intuito de manter esse espectro $(\mathrm{em} 10 \mathrm{~Hz})$ é para evidenciar o aparecimento de uma pequena banda (invertida) em torno de $830 \mathrm{~nm}$ comum a todas as amostras. Esta é a banda polarônica comentada no capítulo I. Assim, verifica-se que a amostra não-dopada apresenta vestígios de dopagem, por causa do surgimento desta banda. Provavelmente, a desdopagem do polímero depois da síntese não foi total. Contudo, a intensidade desta banda deveria ser bem maior para as amostras mais dopadas, o que não é observado.

As figuras III.7 e III.8 mostram os espectros da fase normalizada, isto é, a diferença entre as fases da amostra e do corpo negro, para os filmes não-dopado e dopado em $\mathrm{HCl} 1 \mathrm{M}$. Como pode ser verificado, as fases aumentam de valor (em módulo) com o aumento da frequiência de modulação. Este comportamento é previsto pela teoria da espectroscopia PPES $[53,57]$. Isto é esperado, porque o centróide de calor cada vez mais se afasta do detetor, à medida que a frequiência aumenta. Porém, as fases praticamente permanecem constantes com o comprimento de onda, para cada frequiência. Este desenvolvimento é previsto pela teoria [53] para amostras muito opacas e será mais discutido no próximo capítulo. 


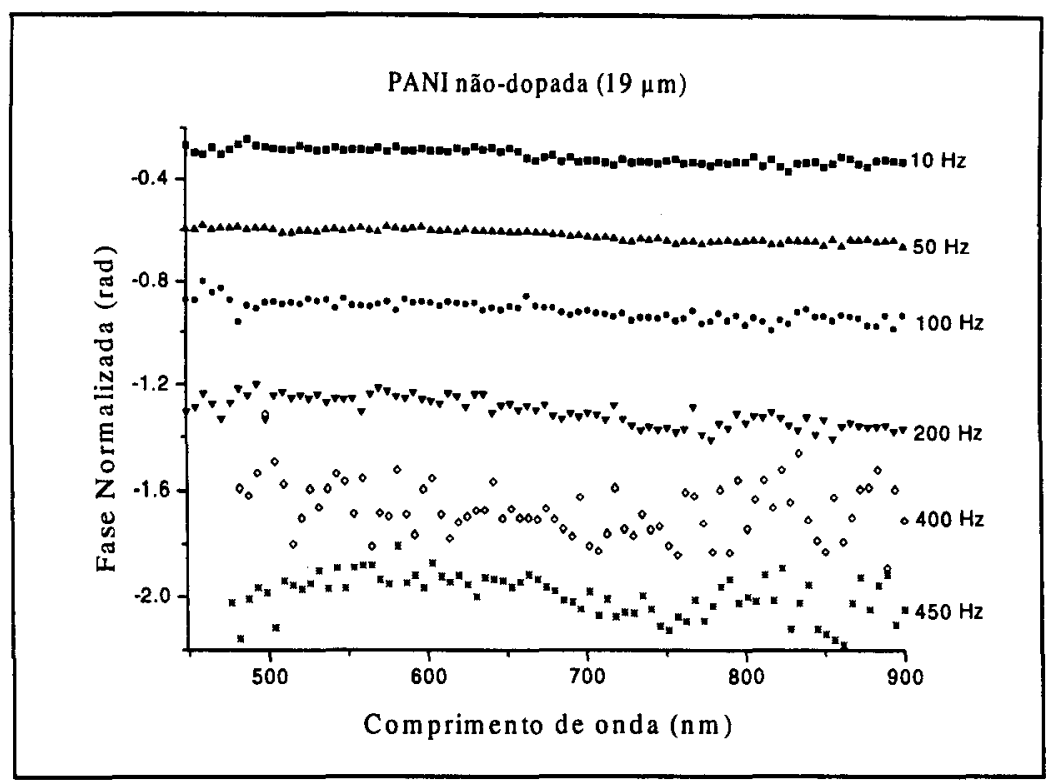

Figura III.7 - Fase normalizada relativa aos espectros PPES da figura III.2.

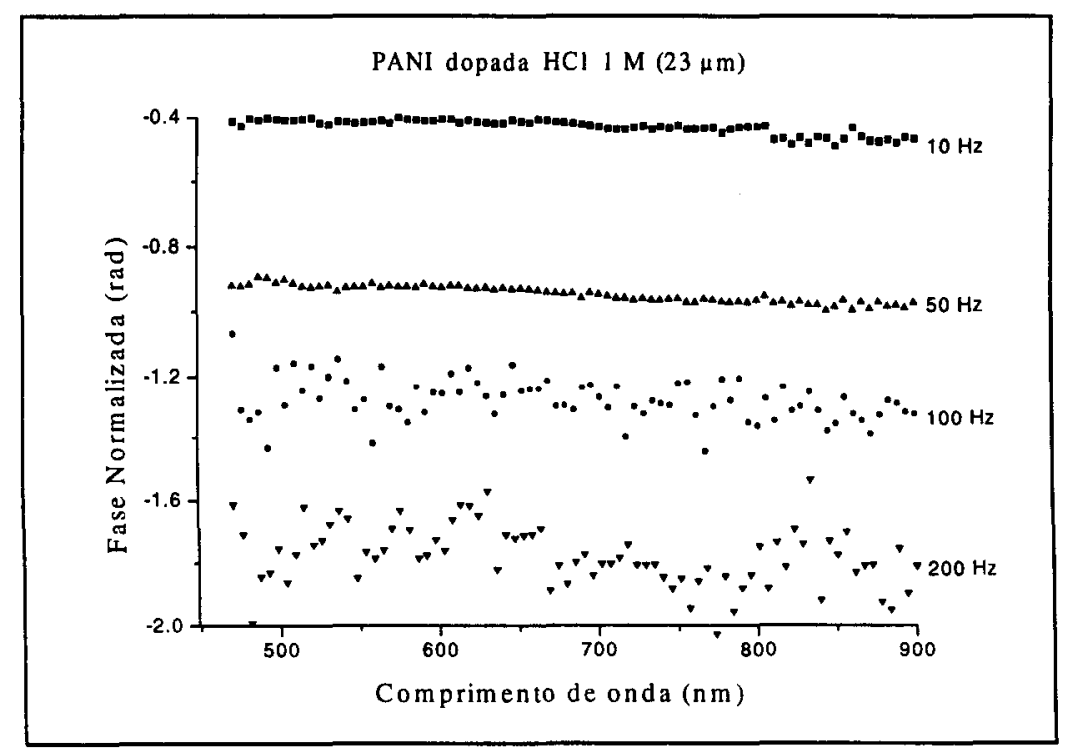

Figura III.8 - Fase normalizada relativa aos espectros PPES da figura III.4.

\section{III.3.2 - Filme de POMA de Espessura entre 5 e $7 \mu \mathrm{m}$ (PPES)}

As figuras III.9 e III.10 mostram os espectros PPES obtidos para o filme de POMA não dopado, feito em uma placa de quartzo por evaporação do solvente (diclorometano). Este filme ficou um pouco irregular, com uma espessura entre 5 e $7 \mu \mathrm{m}$. O comportamento da 
intensidade do sinal fotopiroelétrico Vn é bem semelhante ao caso da PANI (figura III.4). Porém, a fase do sinal apresenta um comportamento diferente, onde vemos que ela acompanha aproximadamente o formato da curva da amplitude do sinal. Este comportamento da fase está relacionado com a espessura menor desse filme em relação aos da PANI. Assim, esse filme é menos opaco que os da PANI.

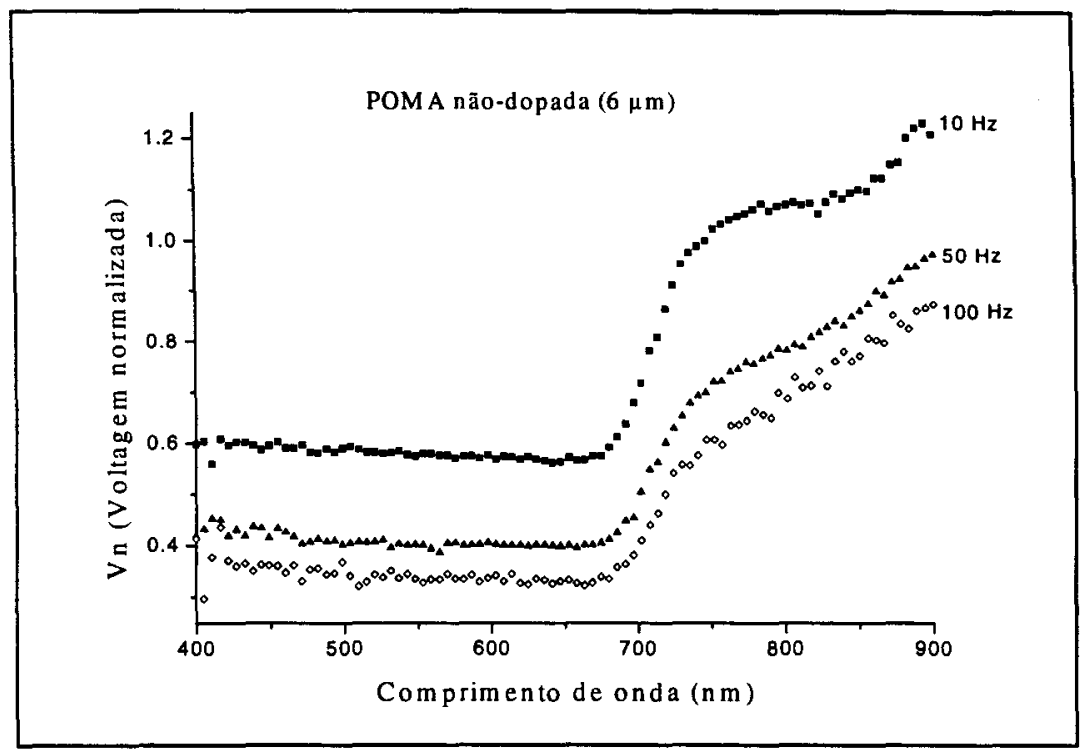

Figura III.9 - Espectros PPES de um filme de POMA não-dopado em três freqüências de modulação da luz.

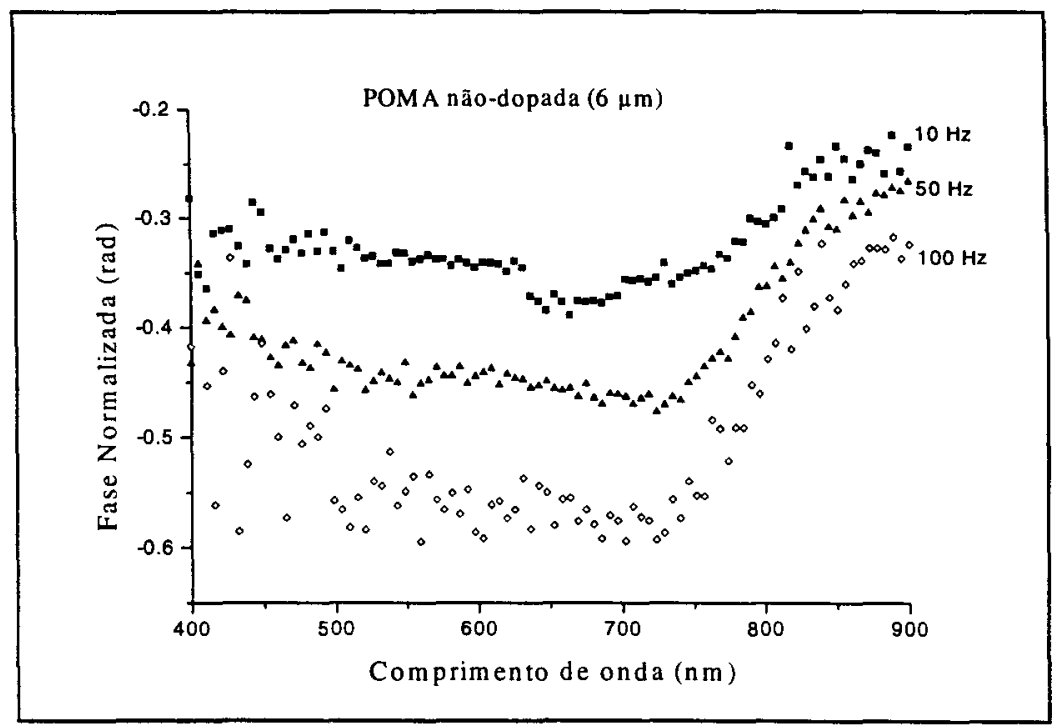

Figura III.10 - Fase normalizada relativa aos espectros PPES da figura anterior. 


\section{III.3.3 - Filmes Finos Transparentes de POMA (PPES)}

As figuras III.11 e III.12 mostram os espectros PPES para um filme de POMA não dopado, feito por spin coating sobre uma placa de quartzo. A espessura deste filme é $0,18 \mu \mathrm{m}$. Vemos que o sinal Vn já não se satura tanto como nos casos anteriores, ocorrendo a saturação entre aproximadamente 520 e $680 \mathrm{~nm}$. $\mathrm{Na}$ freqüência de $10 \mathrm{~Hz}$, o espectro apresenta uma banda para comprimentos de onda superiores a $730 \mathrm{~nm}$, isto ocorrendo com menor intensidade para as outras frequiências. Esta é a banda polarônica, que é característica de vestígios de dopagem do polímero. Verifica-se que a fase acompanha o formato do espectro, sendo que isto é mais pronunciado para as frequiências mais altas. Assim, a fase para amostras mais finas, isto é, mais transparentes, tende a acompanhar o formato da intensidade do sinal $\mathrm{Vn}$.

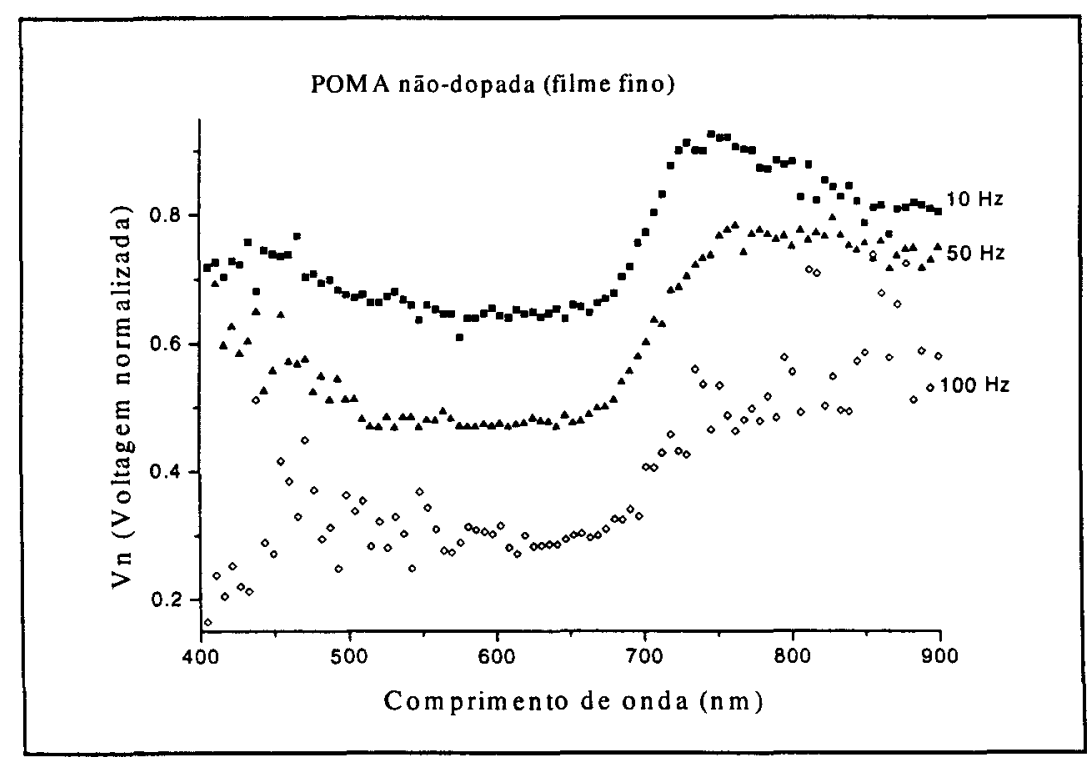

Figura III.11 - Espectros PPES de um filme fino transparente de POMA não dopado, obtido por spin coating, em três frequências de modulação da luz. 


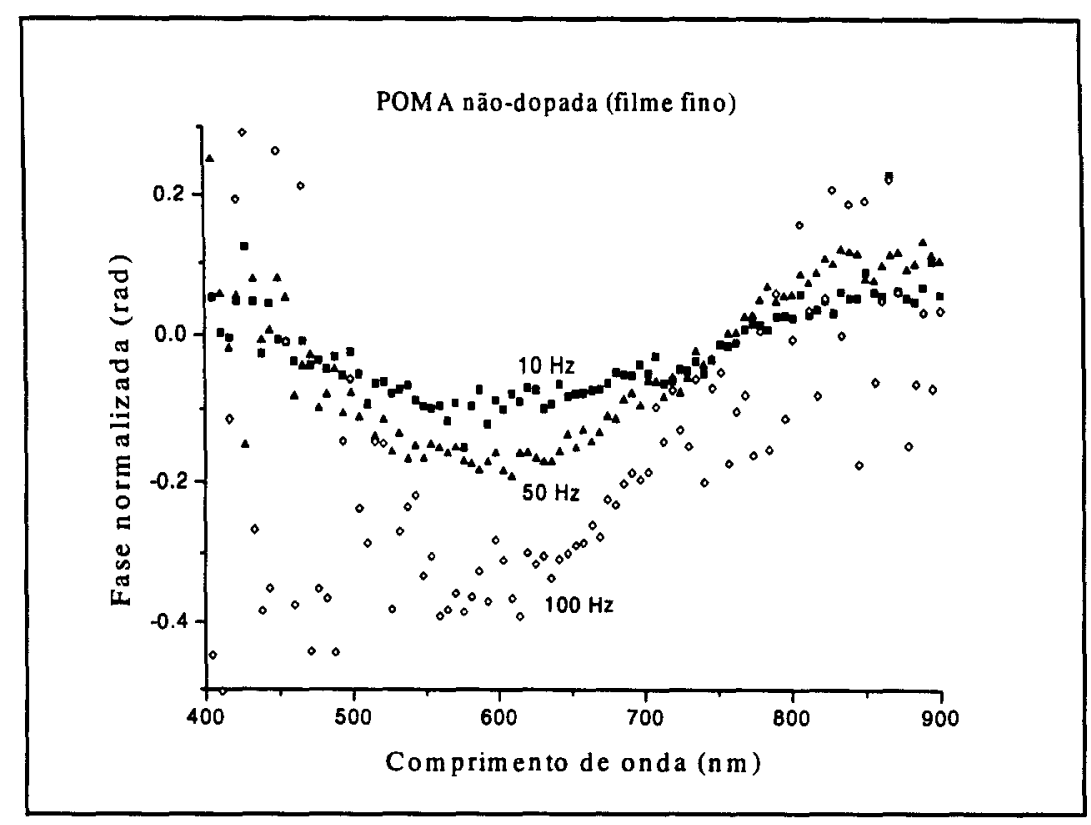

Figura III.12 - Fase normalizada relativa aos espectros PPES da figura anterior.

Se invertermos o filme em relação ao detetor, isto é, colocando-se a placa de quartzo em contato com o detetor (filme para o lado oposto), o sitema fotopiroelétrico se comporta como um espectrômetro de transmitância ótica. As figuras III.13 e III.14 mostram esta situação. Essa é uma prova "experimental" do ótimo funcionamento da técnica, e dá confiabilidade às medidas. É interessante notar que a intensidade do sinal Vn é igual para as duas freqüências de modulação da luz, só aumentando o ruído, porque em freqüências mais altas a intensidade do sinal não normalizado cai. $\mathrm{O}$ mesmo acontece para a fase normalizada. Vemos que a fase não acompanha o formato do sinal Vn, ficando constante ao longo de todo o espectro. Isto se explica devido ao fato de que o sinal gerado pelo detetor neste caso é somente devido à absorção da luz que chega nele. O calor gerado na amostra não chega ao detetor, porque há uma placa de quartzo bastante espessa $(2 \mathrm{~mm})$ entre a amostra e ele. Somente a luz que passa pela amostra e pela placa de quartzo alcança o detetor. 


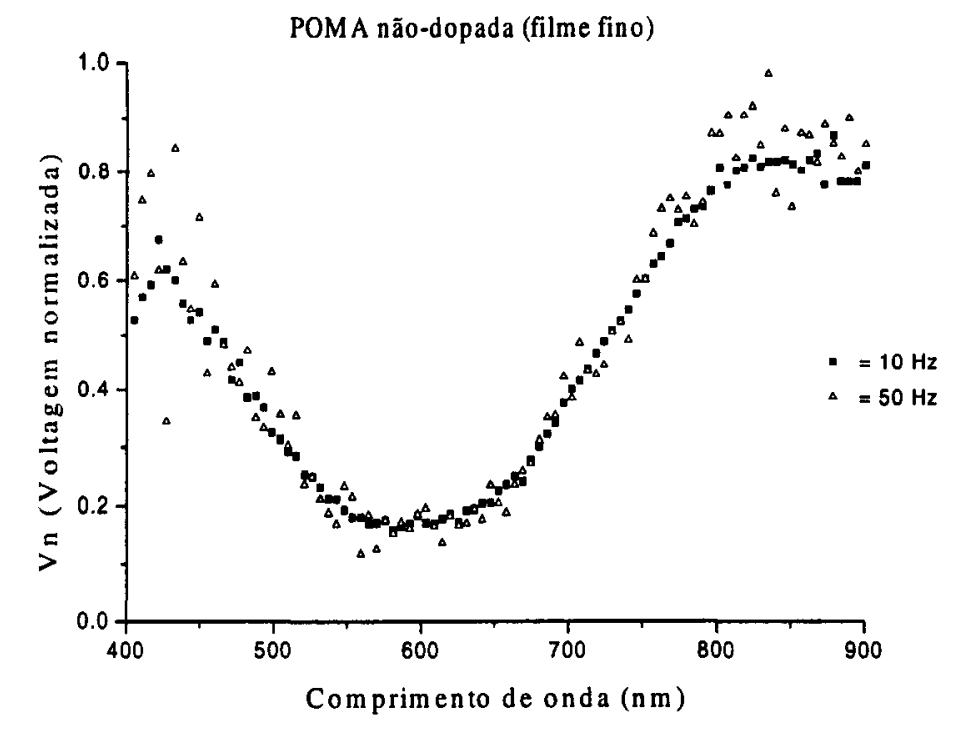

Figura III.13 - Espectros PPES (amostra não estando em contato com o detetor) correspondentes à mesma amostra da figura III.11.

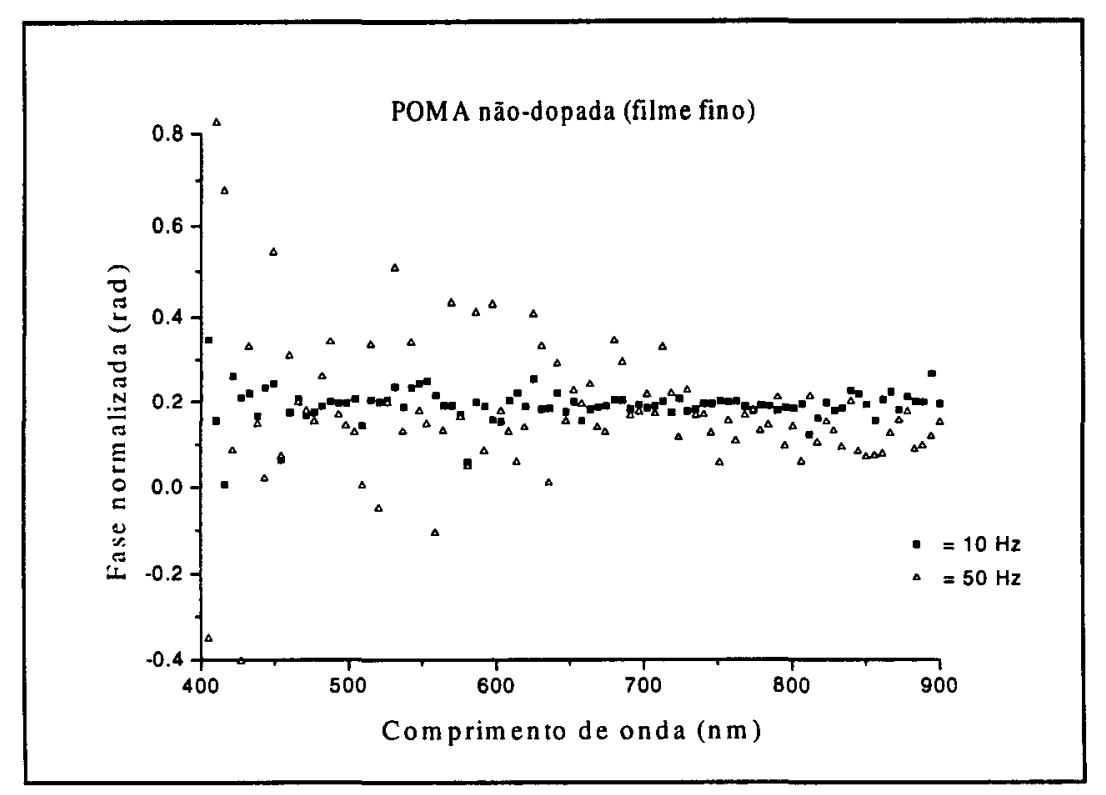

Figura III.14 - Fase normalizada correspondente aos espectros da figura anterior.

As figuras III.15 e III.16 mostram os espectros PPES para um filme fino transparente de POMA, obtido por spin coating e dopado em $\mathrm{HCl} 10^{-2} \mathrm{M}$. A espessura deste filme é 0,19 $\mu \mathrm{m}$. A figura III.17 mostra os espectros quando o mesmo filme é invertido em relação ao 
detetor, ficando a parte de quartzo em contato com ele. Nesta situação, como na figura III.14, a fase permanece constante ao longo de todo o espectro. Comparando a figura III.15 com a III.11, verifica-se que não há mudança significativa dos espectros para o filme não-dopado e o dopado em $\mathrm{HCl} 10^{-2} \mathrm{M}$, a não ser a subida acima de $830 \mathrm{~nm}$. Porém, comparando as figuras III.17 e III.13, nota-se que os espectros de transmitância ótica (obtidos com as amostras invertidas) já são bem diferentes, mostrando a alteração das bandas de absorção com o estado de dopagem. Verifica-se também que a fase (figura III.16) não está acompanhando mais o sinal Vn (figura III.15), como no caso da amostra não-dopada. Ela começa a tomar o formato do sinal Vn, quando a amostra está invertida (comparando as figuras III.16 e III.17).

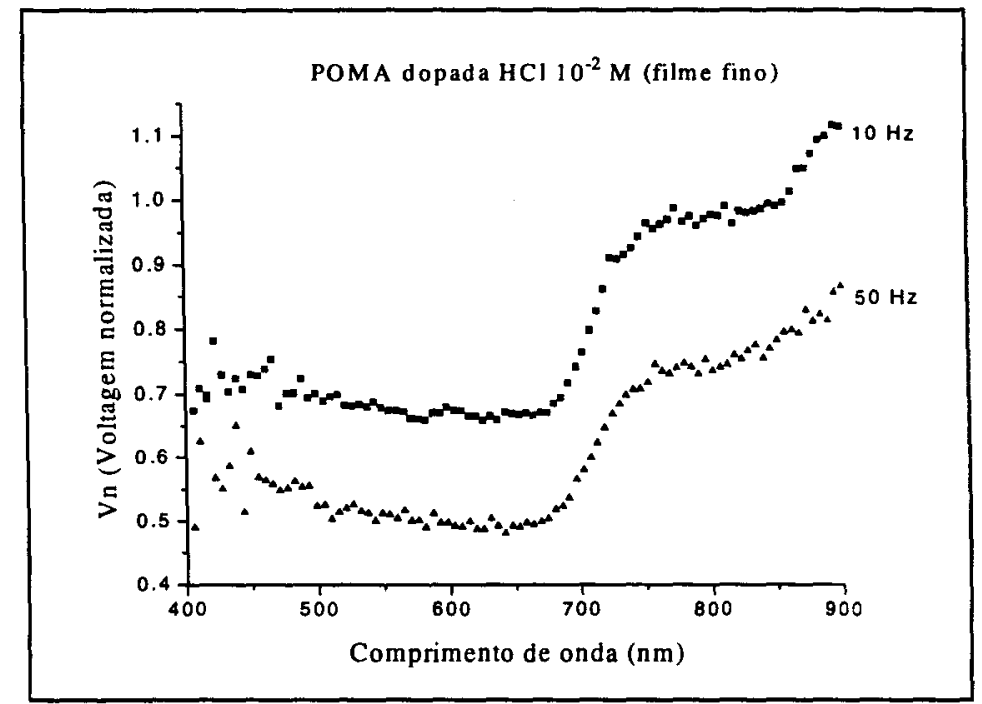

Figura MI.15 - Espectros PPES de um filme fino transparente de POMA, obtido por spin coating, dopado em $\mathrm{HCl} 10^{-2} \mathrm{M}$, em duas freqüências de modulação da luz. 


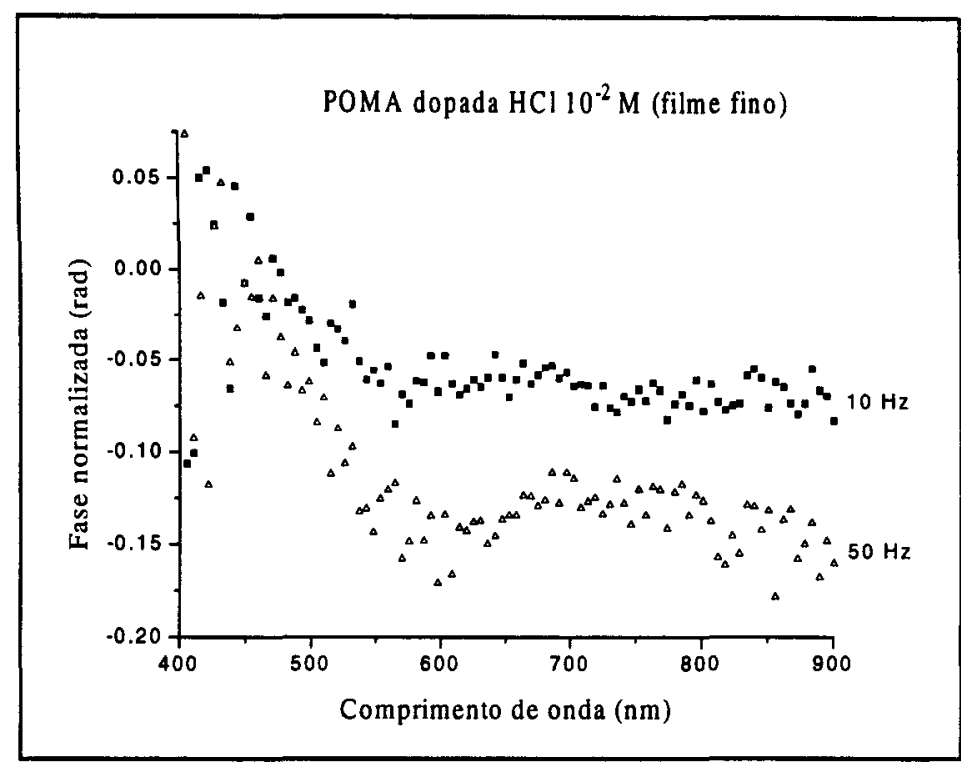

Figura III.16 - Fase normalizada correspondente aos espectros da figura anterior.

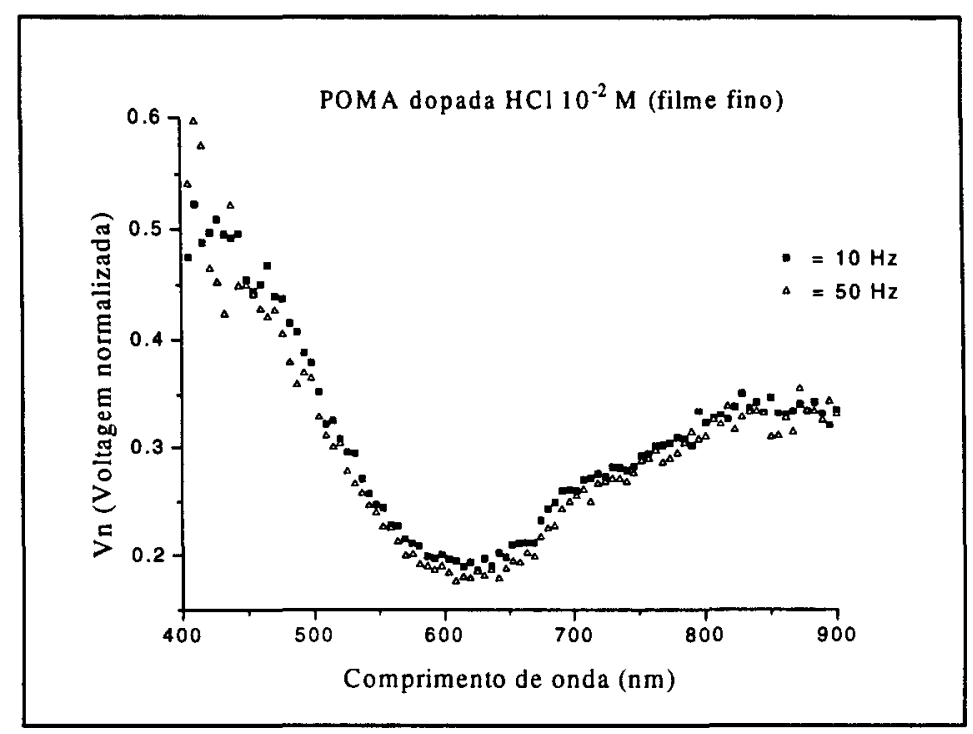

Figura III.17 - Espectros PPES (amostra não estando em contato com o detetor) para a mesma amostra anterior.

As figuras III.18 e III.19 mostram os espectros PPES obtidos para um filme fino transparente de POMA, obtido por spin coating e dopado em $\mathrm{HCl} 1 \mathrm{M}$ (dopagem máxima). A espessura deste filme é $0,18 \mu \mathrm{m}$. A figura III.20 mostra os espectros quando a amostra é invertida, não estando em contato com o detetor. Verifica-se que os espectros da figura III.18 são parecidos com os das figuras III.11 e III.15 (respectivamente, para a amostra não-dopada e 
dopada em $\mathrm{HCl} 10^{-2} \mathrm{M}$ ). Como mencionado anteriormente, este fato é bastante estranho, uma vez que o detetor piroelétrico não fornece resposta diferente para filmes com absorções óticas diferentes. Porém, quando as amostras não estão em contato com o detetor (estando a placa de quartzo entre ele e a amostra), o sinal coincide perfeitamente bem com os espectros de transmissão ótica. Um outro fato interessante é que, de acordo com as figuras III.19 e III.20, a fase do sinal Vn acompanha o formato dos espectros de transmissão, como acontece para as duas amostras anteriores.

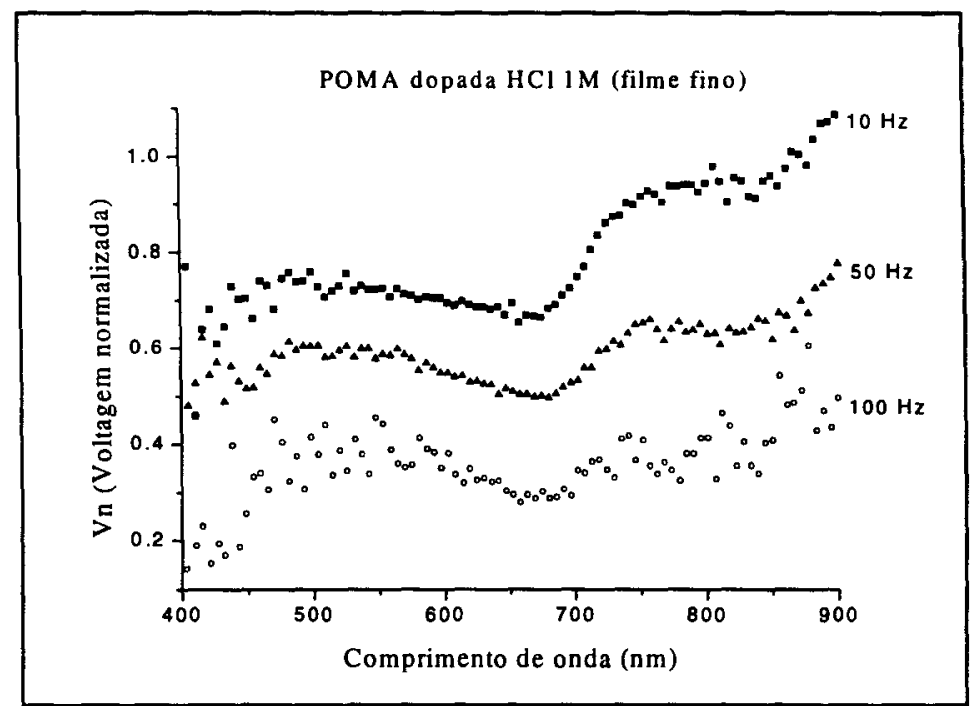

Figura III.18 - Espectros PPES de um filme fino transparente de POMA, obtido por spin coating e dopado em $\mathrm{HCl} 1 \mathrm{M}$, em três freqüências de modulação.

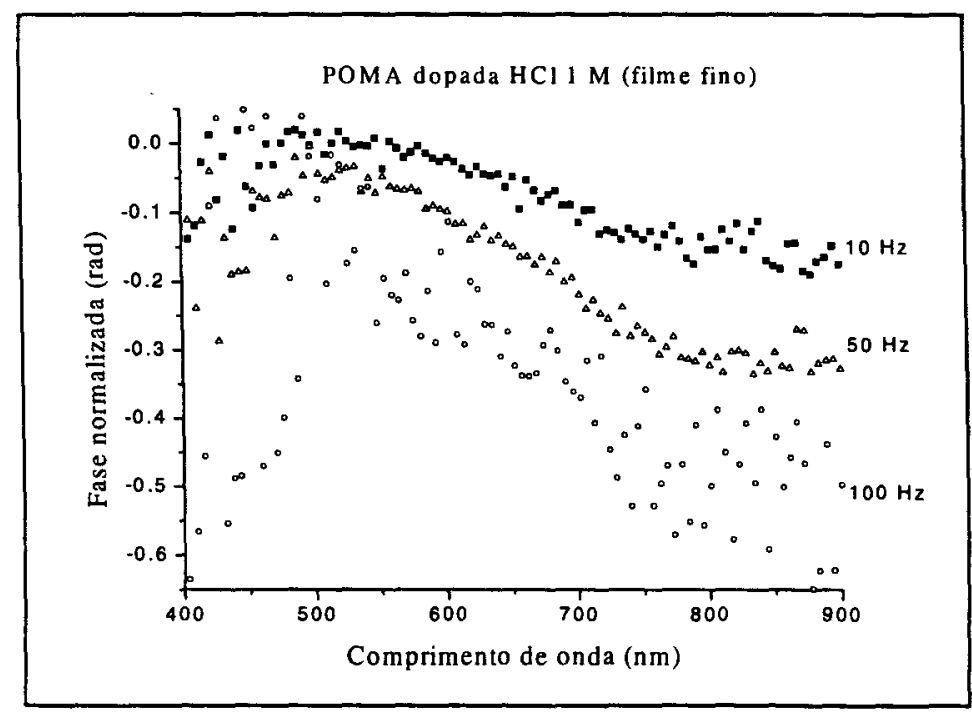

Figura III.19 - Fase normalizada correspondente aos espectros da figura anterior. 


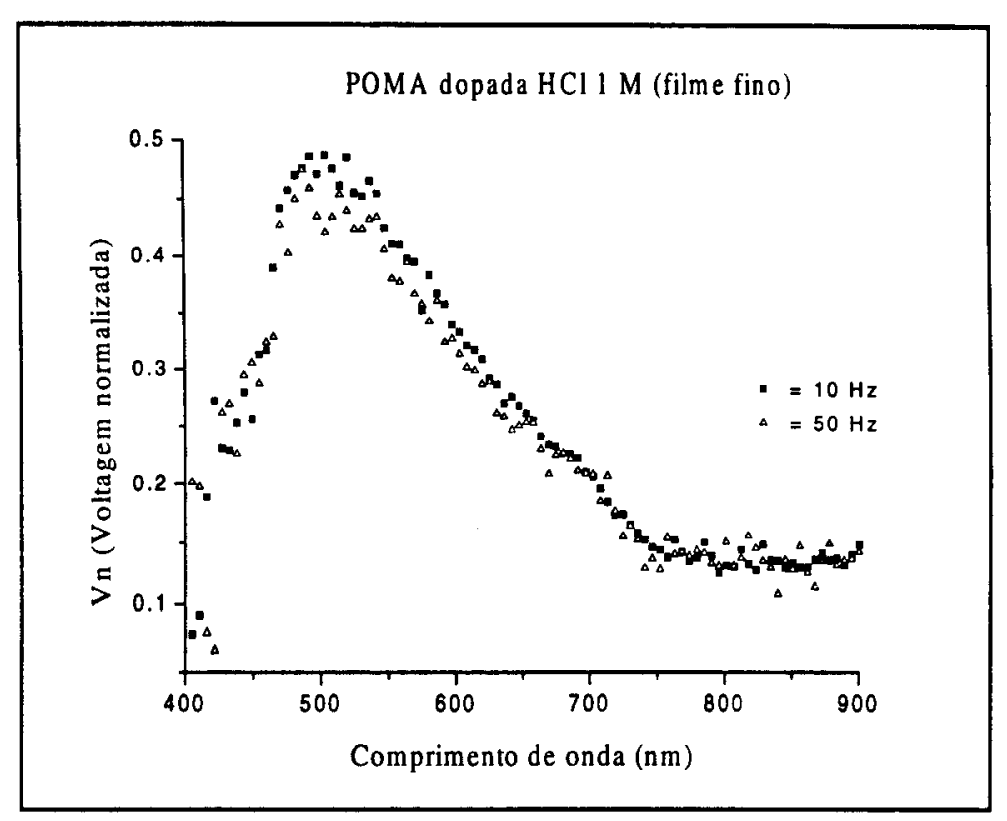

Figura III.20 - Espectros PPES (amostra não estando em contato com o detetor) para a mesma amostra anterior.

Como os espectros PPES, quando as amostras estão em contato com o detetor, não diferem significativamente para as amostras não-dopadas e dopadas, isto nos induz a supor que as amostras dopadas contêm regiões não-dopadas. Podemos verificar isto fazendo uma subtração espectral, de tal forma a tirar do espectro da amostra dopada a parte correspondente à não-dopada. Primeiramente, fizemos uma subtração nos espectros de absorção ótica obtido em um espectrofotômetro convencional. A figura III.21 mostra os espectros de absorção ótica obtidos para um filme fino transparente de POMA, não-dopado e depois dopado em $\mathrm{HCl} 1 \mathrm{M}$ (o mesmo filme). Para fazer a subtração espectral, usamos um peso (concentração de região não-dopada), a fim de que o espectro resultante não apresente parte negativa. Para os dois espectros, o peso foi de $45 \%$ a ser multiplicado pelo espectro da POMA não-dopada. O resultado está mostrado na figura III.22, onde a diferença espectral foi transformada também para espectro de transmitância, para fins de comparação com os espectros PPES. Fizemos também essa diferença espectral para os espectros PPES de transmissão obtidos para as 
amostras não estando em contato com o detetor (espectros da figura III.20 menos os da figura III.13). O resultado foi análogo ao da figura III.22.

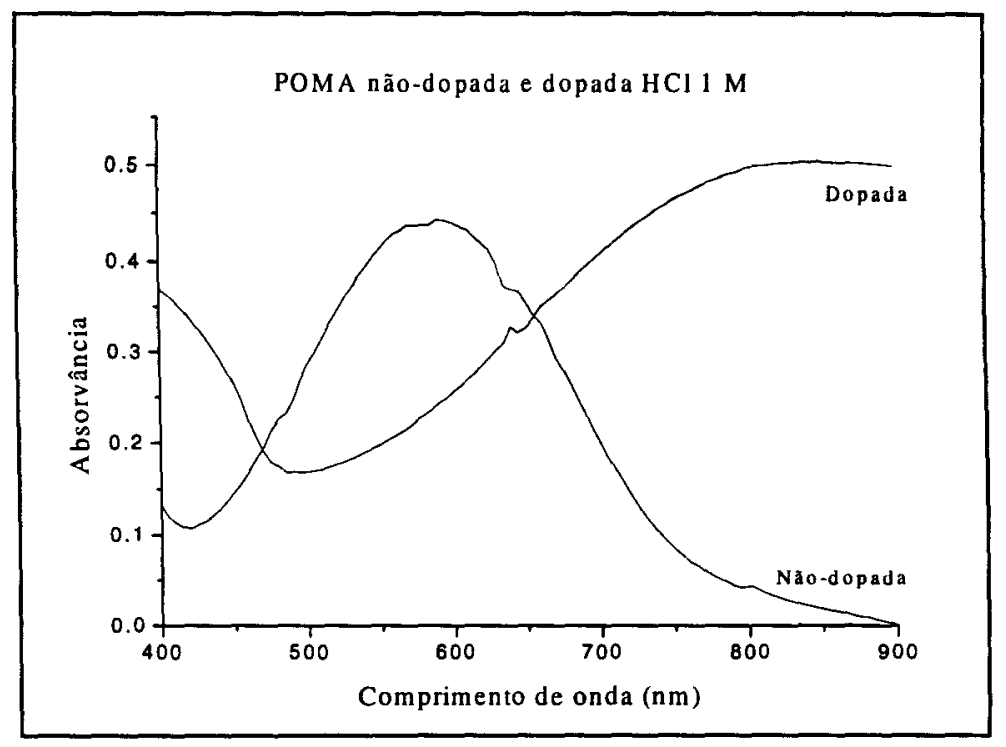

Figura III.21 - Espectros de absorção ótica de um filme fino transparente de POMA em dois estados de dopagem.

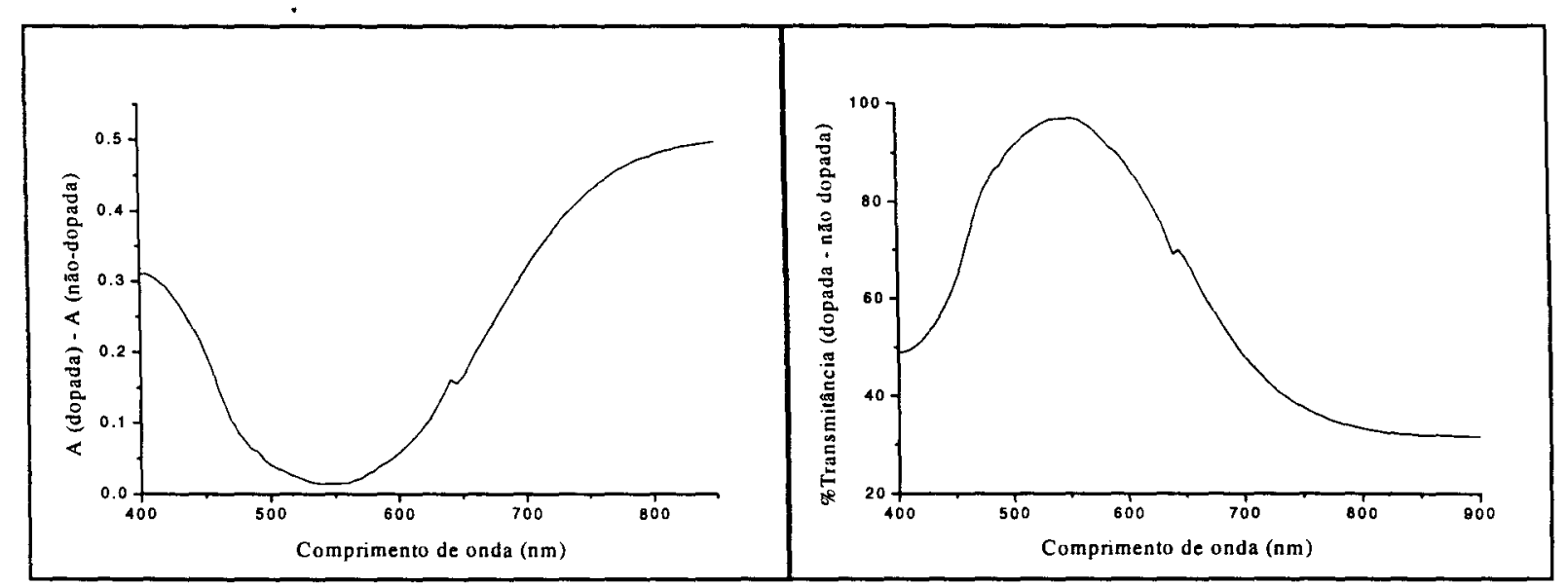

Figura III.22 - Diferença espectral na forma de absorvância e de transmitância (em \%) dos dois espectros da figura anterior. 
As figuras III.23 e III.24 mostram as diferenças feitas para os espectros PPES correspondentes aos filmes de POMA dopado em $\mathrm{HCl} 1 \mathrm{M}$ e não-dopado (espectros da figura III.18 menos os da figura III.11). Foi usado um peso de $65 \%$ na subtração, a fim de não termos sinais negativos para Vn. Surpreendentemente, a diferença do sinal Vn coincide satisfatoriamente com a da figura III.22 para as frequiências mais altas. As diferenças das fases coincidem também com o formato do sinal de transmitância. Em $10 \mathrm{~Hz}$, não se teve a coincidência da diferença dos sinais, provavelmente porque o detetor para esta freqüência está na transição termicamente espesso para fino, e o espectro em $10 \mathrm{~Hz}$ da figura III.11 apresentou um comportamento muito diferente que os outros para a região acima de $730 \mathrm{~nm}$. Assim, na diferença espectral, esse comportamento diferente acima de $730 \mathrm{~nm}$ provocou um aumento do sinal ao invés da diminuição como na diferença espectral para 50 e $100 \mathrm{~Hz}$. Podemos verificar que na diferença espectral da fase normalizada (figura III.24) esse comportamento diferente para $10 \mathrm{~Hz}$ não acontece.

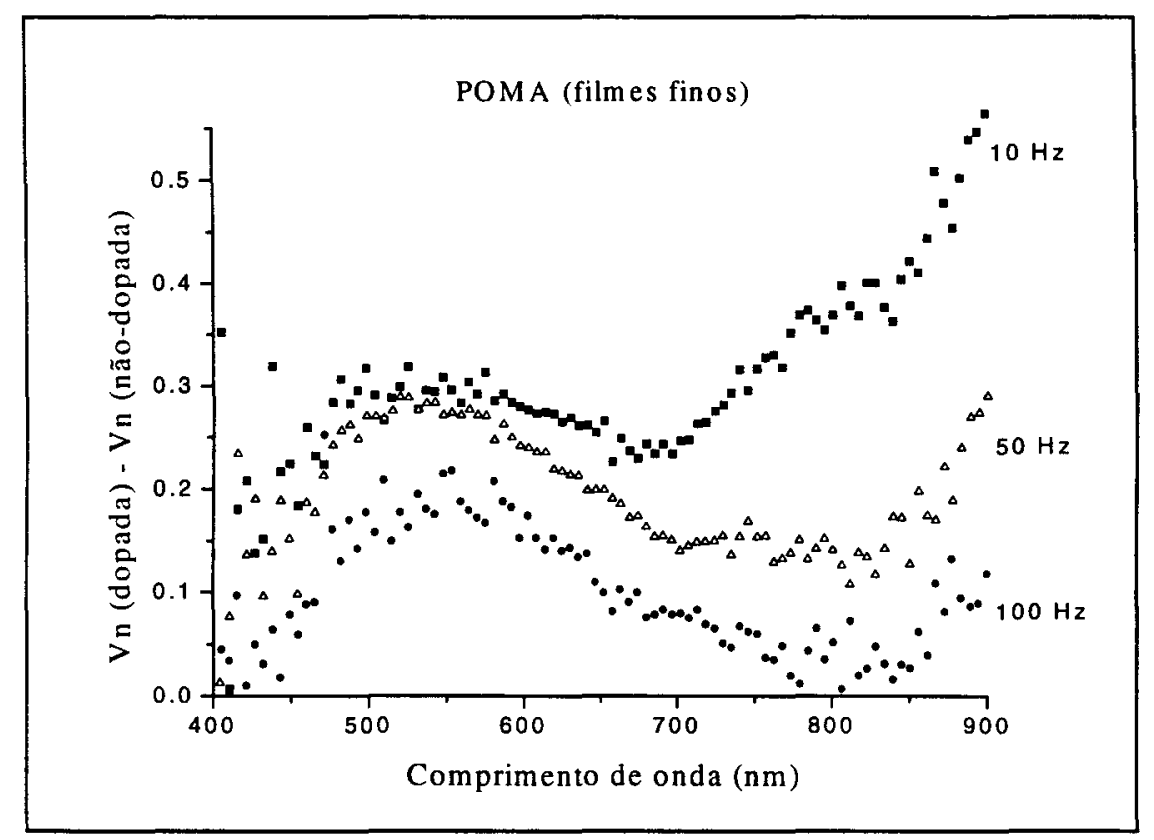

Figura III.23 - Diferença dos espectros PPES do filme de POMA dopado em HCl 1 M para o filme não-dopado. 


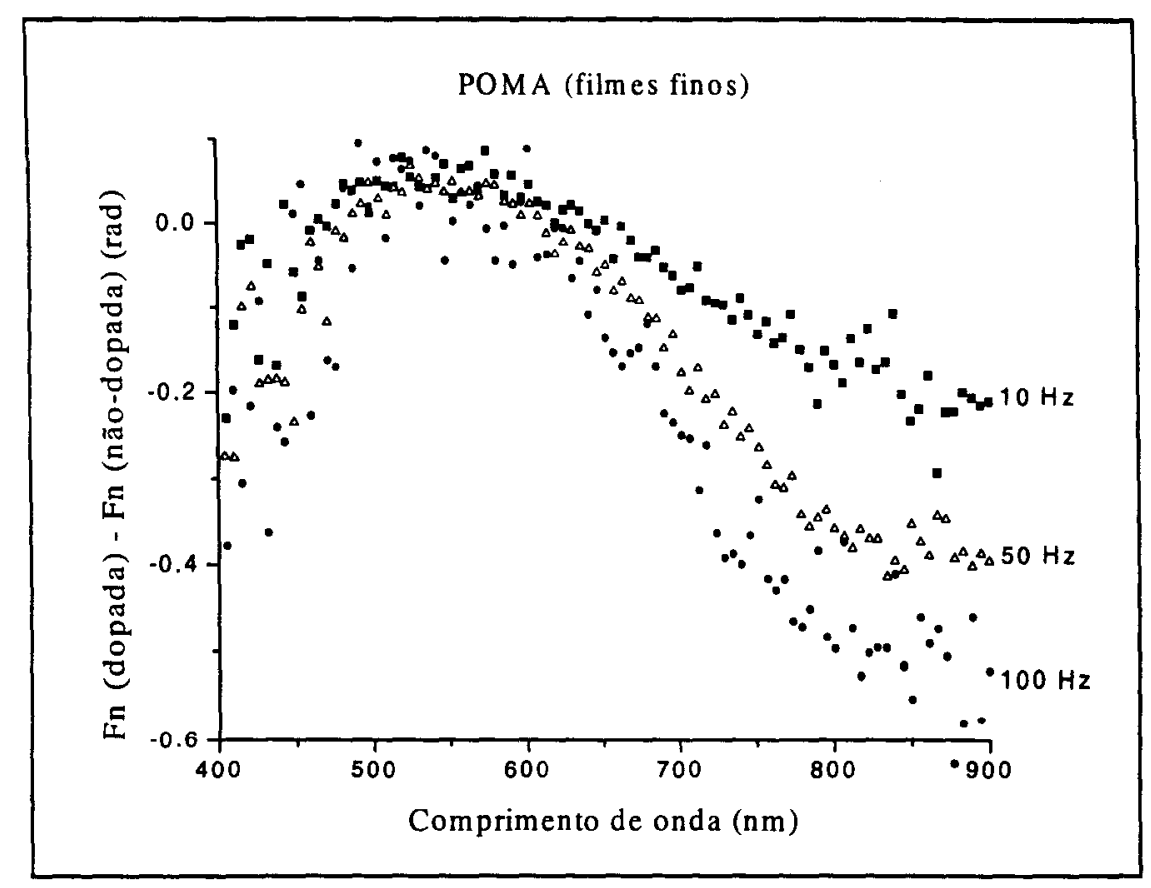

Figura III.24 - Diferença das fases normalizadas correspondentes aos espectros da figura anterior.

Com isto, podemos explicar satisfatoriamente o problema apresentado anteriormente sobre o sinal Vn não ser diferente para os filmes dopados e não-dopados. Os espectros PPES para os filmes dopados não aparecem diferentes dos espectros para os não-dopados, porque aqueles apresentam porções ou regiões não-dopadas. Assim, os espectros dos filmes dopados é uma soma de espectros, contendo os correspondentes às regiões dopadas e não-dopadas. $\mathrm{E}$ tudo isto que foi mostrado para os filmes finos transparentes de POMA, produzidos por spin coating, também se repetiu para filmes finos transparentes de PANI e de POMA produzidos eletroquimicamente. Estes filmes eletroquímicos são ainda mais finos que os produzidos por spin coating. Não fizemos as subtrações espectrais para os filmes espessos de PANI, mostrados nas figuras III.4 e III.6, porque, como o sinal é muito saturado, a diferença não fornece valores reais para os sinais, ocorrendo praticamente a sua anulação. 


\section{III.3.4 - Espectroscopia Fotoacústica (PAS) dos Filmes Finos de POMA}

A figura III. 25 mostra os espectros PAS para os dois filmes finos transparentes de POMA, um não-dopado e o outro dopado em $\mathrm{HCl} 1 \mathrm{M}$, obtidos na frequiência de $10 \mathrm{~Hz}$. Os dois espectros PPES correspondentes a esses filmes estão mostrados nas figuras III.11 e III.18. Para os espectros PAS, o sinal normalizado é sempre análogo ao de absorção ótica (compare as figuras III.25 e III.21). Apesar de a freqüência ser baixa, os sinais PAS estão ruidosos, devido possivelmente a problema de vedação acústica da célula. Enquanto na espectroscopia PPES o maior problema está no contato térmico entre amostra e detetor, na PAS o maior problema é a vedação acústica da célula. A figura III.26 mostra as fases normalizadas para os espectros PAS. Apesar do ruído, pode-se verificar que a fase se mantém constante ao longo de todo o espectro. Para amostras termicamente finas, este comportamento é previsto pela teoria $[44,45,47,48,50]$.

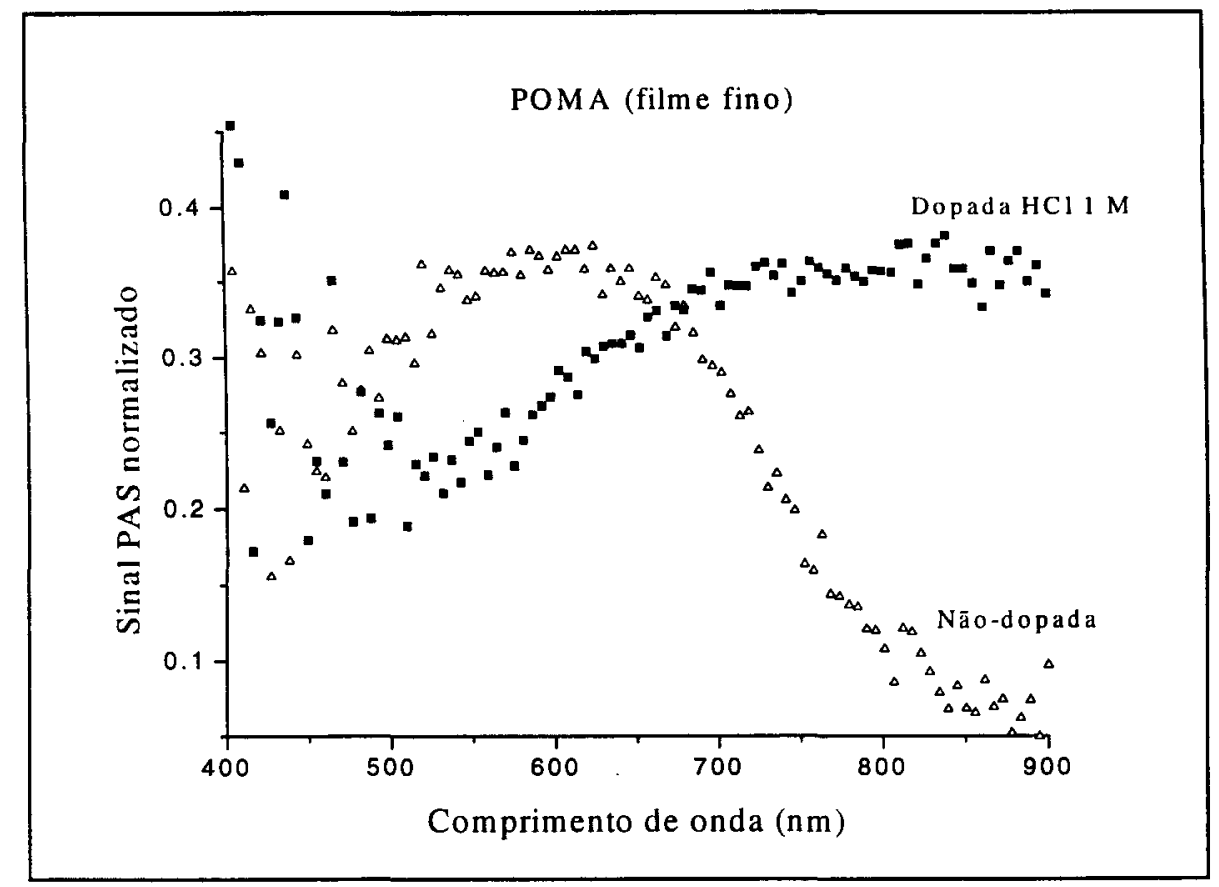

Figura III.25 - Espectros fotoacústicos para dois filmes finos transparentes de POMA, obtidos na frequiência de $10 \mathrm{~Hz}$. 


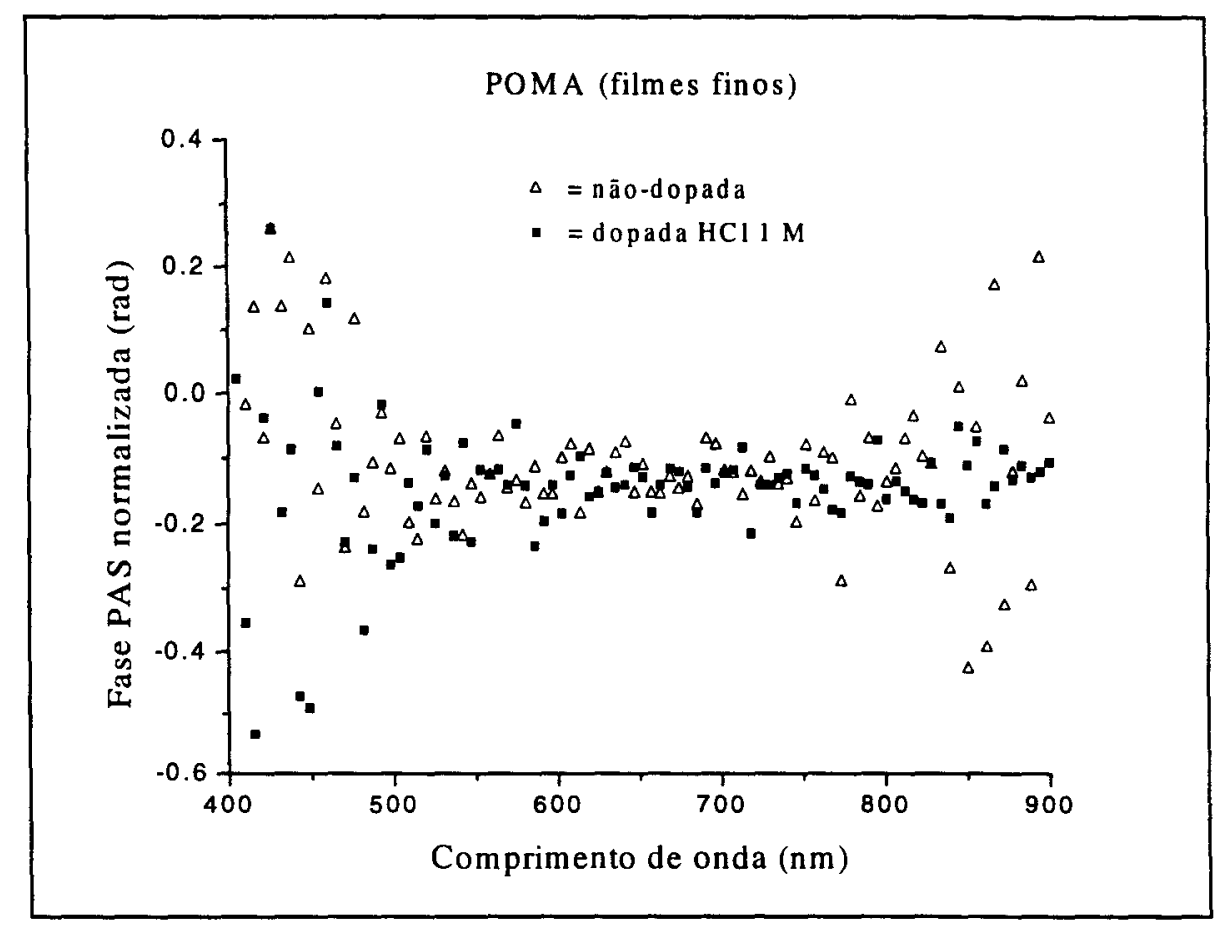

Figura III.26 - Fase normalizada correspondente aos espectros PAS da figura anterior.

A figura III.27 mostra a diferença entre os espectros PAS do filme dopado em $\mathrm{HCl} 1$ M e o não-dopado, para podermos comparar com a diferença para os espectros PPES correspondentes (figura III.23). Para realizarmos essa diferença espectral, usamos um peso de $60 \%$, que foi multiplicado pelo espectro do filme não-dopado, a fim de evitarmos um sinal PAS negativo. Como estamos trabalhando com espectros de absorção, o resultado é também um espectro de absorção. Assim, ao compararmos com os espectros da figura III.23, temos que ter em mente que lá os espectros são de transmissão ótica. Tendo isto em mente, vemos que as diferenças espectrais coincidem muito bem para os dois casos, considerando a frequiência de $100 \mathrm{~Hz}$ para o caso PPES. Comparando com a figura III.22 (diferença dos espectros óticos na forma de absorvância), nota-se também uma grande coincidência entre as diferenças espectrais. 


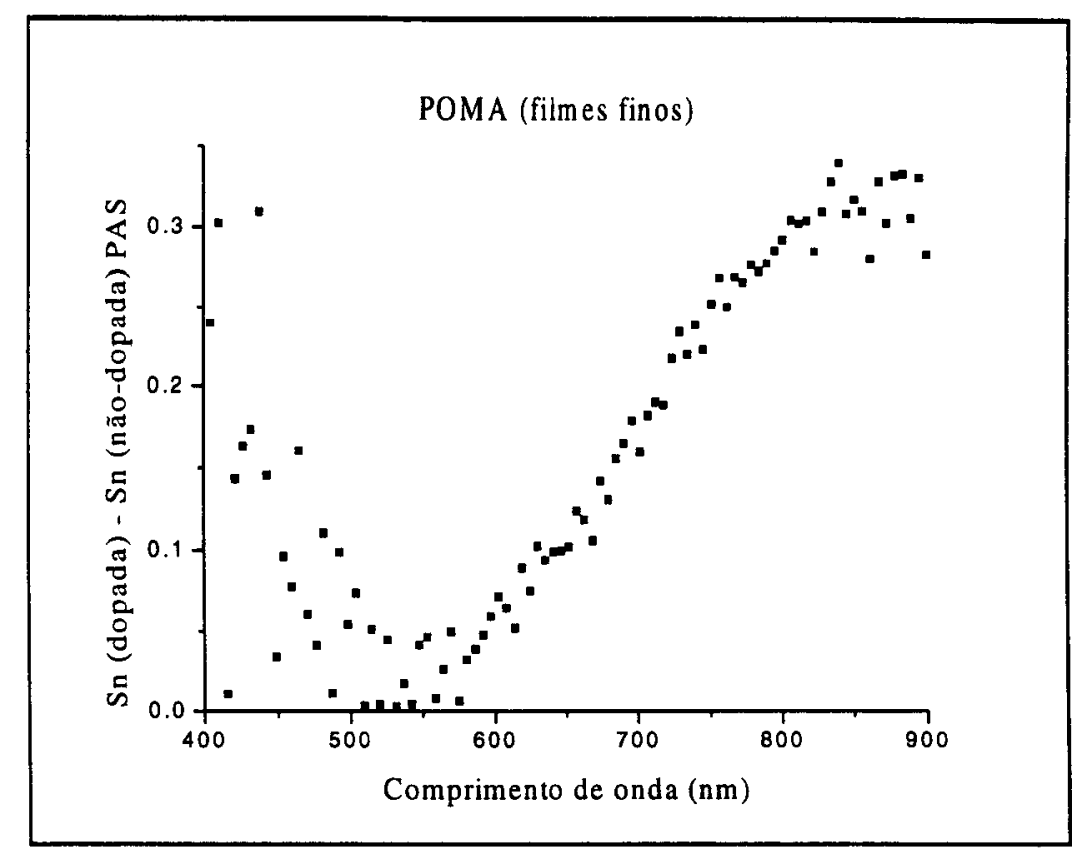

Figura III.27 - Diferença entre os espectros PAS do filme de POMA dopado em HCl $1 \mathrm{M}$ e o filme não-dopado (correspondentes à figura III.25).

\section{III.4 - CONCLUSÕES}

Os espectros PPES para os filmes não-dopados e dopados das polianilinas mostraram que realmente não existem filmes $100 \%$ dopados, e sim uma mistura de regiões dopadas e não-dopadas, provavelmente aleatoriamente distribuídas ao longo do filme. Resultados de EPR e de condutividade [66-70], e de medidas diretas de condutividade com micropontas e de análise STM [71] comprovam a existência de aglomerados de elementos dopantes na matriz isolante do material.

O detetor piroelétrico mostrou uma resposta aproximadamente igual tanto para as amostras dopadas e não-dopadas, apesar de a absorção ótica ser completamente diferente para as espécies diferentes. Isto mostra que as propriedades térmicas não devem variar muito com o estado de dopagem dos filmes. O próximo capítulo mostrará se isto é verdade ou não. 
Pode parecer estranho que uma técnica também fototérmica, a PAS, forneça resultados diferentes que a PPES. Mas há uma justificativa para isto. A técnica PAS é uma técnica de deteção fototérmica indireta, enquanto a PPES é direta. Na PAS, a variação periódica da temperatura na interface amostra-gás, devido à absorção luminosa na amostra, provoca uma onda de pressão acústica que dá origem ao sinal medido pelo microfone. Os efeitos da difusão de calor na amostra são, assim, detetados indiretamente. Já na PPES, os efeitos da difusão de calor na amostra são detetados diretamente pelo detetor, que está em íntimo contato térmico com a amostra. Por outro lado, o detetor piroelétrico pode ser considerado menos sensível às variações óticas das amostras de polianilina, pois ele não diferenciou bem duas amostras diferentes. A PAS mostrou que é bastante sensível a essas diferenças, pois deu resultado análogo à espectroscopia de absorção ótica.

O fato de que a PPES forneceu espectros para as amostras dopadas de polianilinas, que não coincidiram com os de absorção ótica correspondentes, foi verificado também por Toyoda e Nakamura [64,65]. Estes autores mostraram que duas técnicas fototérmicas, a PAS e a fotocalorimétrica, apresentavam desenvolvimento diferente que o de absorção ótica, para a polianilina sintetizada eletroquimicamente em diversos pH's.

No próximo capítulo, aplicaremos as equações teóricas das duas técnicas, a PAS e a PPES, aos dados experimentais, a fim de obtermos diversos parâmetros térmicos e óticos. Os dados obtidos com a varredura de frequiência, que não foram mostrados aqui, serão muito utilizados para a obtenção destes parâmetros. 
CAPÍTULO IV

DETERMINAÇÃo DE PARÂMETROS TÉRMICOS E ÓTICOS DA POLIANILINA POR ESPECTROSCOPIA FOTOTÉRMICA 


\section{CAP. IV - DETERMINAÇÃo DE PARÂMETROS TÉRMICOS E ÓTICOS DA POLIANILINA POR ESPECTROSCOPIA FOTOTÉRMICA}

\section{IV.1 - INTRODUÇÃO}

No capítulo anterior, mostramos os resultados experimentais obtidos pelas espectroscopias PPES e PAS, somente em função do comprimento de onda da luz. Neste capítulo, completaremos os resultados experimentais, mostrando a intensidade do sinal e a fase em função da frequiência de modulação da luz, na região de saturação do espectro. Antes, porém, vamos desenvolver os modelos teóricos e, em seguida, aplicá-los a esses resultados e aos do capítulo anterior. A partir dos ajustes, obteremos parâmetros térmicos e óticos de interesse, como a difusividade e a condutividade térmicas, o calor específico, o coeficiente de absorção ótica e o gap ótico. Os resultados experimentais de varredura de frequiência com incidência de luz monocromática são apresentados no mesmo capítulo do desenvolvimento do modelo teórico do método, porque as figuras das curvas experimentais serão apresentadas juntamente com os ajustes feitos a partir dos modelos.

O modelo teórico que vamos utilizar para a espectroscopia PPES é o de Mandelis e Zver [53] e para a PAS, o de Rosencwaig e Gersho [45]. Ambos tratamentos são baseados em modelo para um sistema unidimensional (a célula). O modelo PPES baseia-se em uma amostra sólida em contato íntimo com um filme fino piroelétrico suportado por um material não-absorvente de luz, em uma célula aberta. O modelo PAS baseia-se em uma amostra sólida suportada por um material não-absorvente de luz, estando em uma câmara fechada, contendo um gás, e isolada acusticamente do ambiente. A deteção é feita por um microfone bem 
sensível, que fornecerá o sinal oriundo da propagação sonora no gás. Os tratamentos de Mandelis-Zver e de Rosencwaig-Gersho serão descritos nos próximos tópicos.

\section{IV.2 - MODELO TEÓRICO DE MANDELIS E ZVER (PPES)}

A célula fotopiroelétrica, que representa o sistema unidimensional mencionado acima, é mostrada na figura IV.1. Nesta figura, a letra g representa o gás (ar), s, a amostra, p, o detetor piroelétrico e $b$, o material de suporte. $L_{s}$ é a espessura da amostra e $L_{p}$, a espessura do detetor piroelétrico.

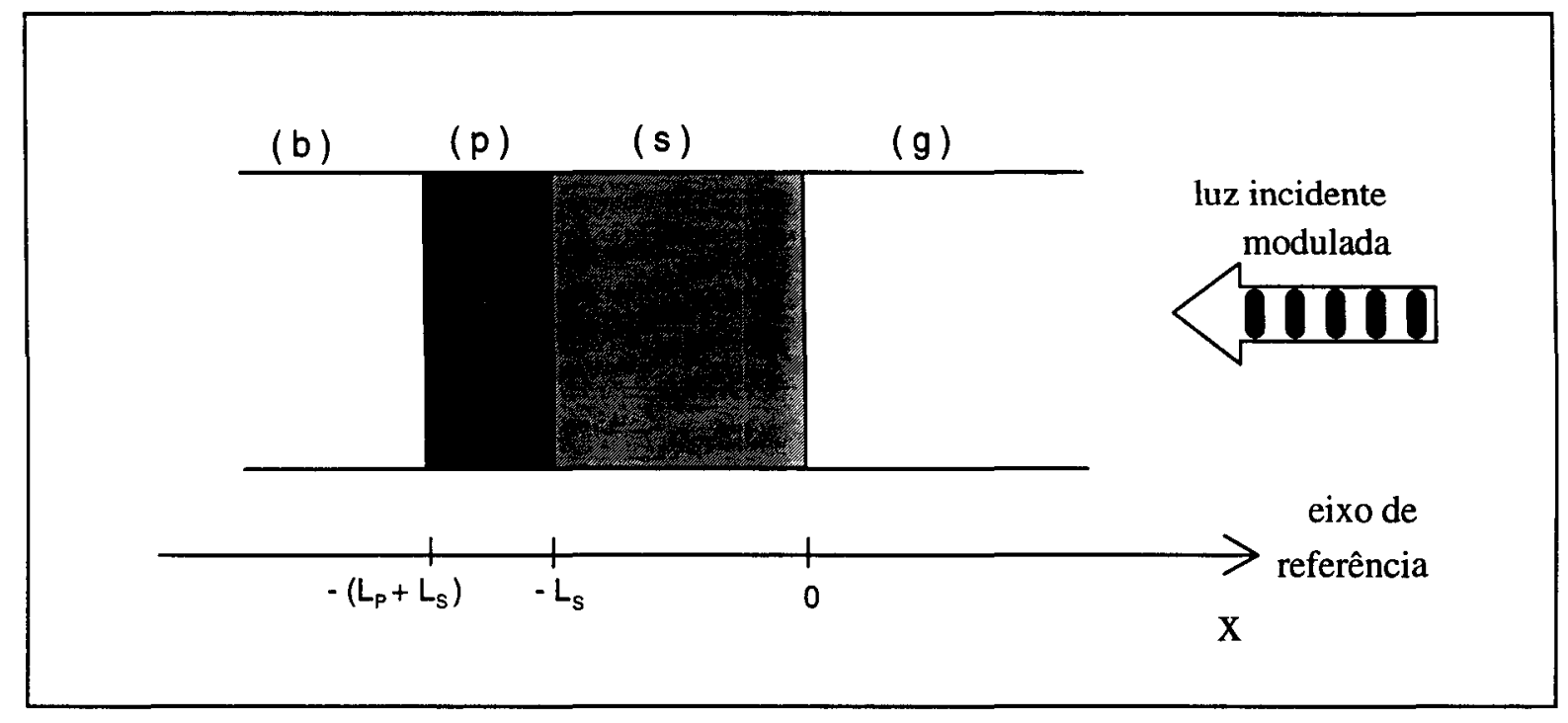

Figura IV.1 - Esquema da célula fotopiroelétrica utilizada para o modelo teórico.

A luz que incide sobre a amostra dentro da célula é monocromática e modulada por um chopper de freqüência angular $\omega$, e sua intensidade é dada por $\mathrm{I}(\omega)=\mathrm{I}_{0}(1+\cos \omega \mathrm{t}) / 2$, onde $\mathrm{I}_{0}$ é a amplitude da luz incidente monocromática. A luz absorvida pela amostra é 
convertida em calor, por processos de transições não-radiativas, que se propaga ao longo da amostra e alcança o detetor. A distribuição de calor em um dado ponto $\mathrm{x}$ da amostra é dado por: $\mathrm{I}(\omega) \beta_{\mathrm{s}} \eta_{\mathrm{s}} \exp \left(\beta_{\mathrm{s}} \mathrm{x}\right)$, onde $\beta_{\mathrm{s}}$ e $\eta_{\mathrm{s}}$ são, respectivamente, o coeficiente de absorção ótica e a eficiência quântica das transições não-radiativas da amostra. A voltagem fotopiroelétrica (ac) gerada pelo detetor, em função do tempo, é dada por [53-56,58,61]:

$$
\mathrm{V}(\omega, t)=\left[\frac{p}{K \varepsilon_{0}} \int_{L_{P}} T_{P}(\omega, x) d x\right] e^{i \omega t}
$$

onde $\mathrm{p}$ é o coeficiente piroelétrico do detetor, $\mathrm{K}$, sua constante dielétrica, $\varepsilon_{0}$, a permissividade elétrica do vácuo e $T_{p}(\omega, x)$, o campo de temperatura dentro do detetor piroelétrico, que resulta do processo de condução de calor.

Sendo a difusão térmica o processo dominante no transporte do calor ao longo da célula fotopiroelétrica, o campo de temperatura $T_{p}(\omega, x)$ pode ser calculada usando equações de difusão térmica unidimensionais para cada componente da célula, isto é, para $x>0$ :

$$
\frac{d^{2} T_{g}}{d x^{2}}-\sigma_{g}^{2} T_{g}=0
$$

para $-\mathrm{L}_{\mathrm{s}} \leq \mathrm{x} \leq 0$ :

$$
\frac{d^{2} T_{S}}{d x^{2}}-\sigma_{S}^{2} T_{S}=-\frac{I_{0} \beta_{S} \eta_{S}}{2 k_{S}} e^{\beta_{S} x}
$$

para $-\left(\mathrm{L}_{\mathrm{p}}+\mathrm{L}_{\mathrm{s}}\right) \leq \mathrm{x} \leq-\mathrm{L}_{\mathrm{s}}$ :

$$
\frac{d^{2} T_{P}}{d x^{2}}-\sigma_{P}^{2} T_{P}=-\left(\frac{I_{0} \beta_{P} \eta_{P}}{2 k_{P}} e^{-\beta_{S} L_{S}}\right) e^{\beta_{P}\left(x+L_{S}\right)}
$$


$\operatorname{para} x \leq-\left(\mathrm{L}_{\mathrm{p}}+\mathrm{L}_{\mathrm{s}}\right):$

$$
\frac{d^{2} T_{b}}{d x^{2}}-\sigma_{b}^{2} T_{b}=0
$$

onde $\sigma_{\mathrm{n}}=(1+\mathrm{i}) \mathrm{a}_{\mathrm{n}},(\mathrm{i}=\sqrt{-1}), \mathrm{a}_{\mathrm{n}}$ é o coeficiente de difusão térmica, $\mathrm{k}_{\mathrm{n}}$, a condutividade térmica do material $(n=g, s, p, b)$, e $\eta_{s}$ e $\eta_{p}$ são as eficiências quânticas das transições nãoradiativas, respectivamente, da amostra e do detetor piroelétrico. $\mathrm{O}$ coeficiente de difusão térmica é dado por:

$$
\mathrm{a}_{\mathrm{n}}=\left(\frac{\pi f}{\alpha_{n}}\right)^{1 / 2}
$$

onde $\alpha_{\mathrm{n}}$ é a difusividade térmica do material $\mathrm{n}$ e $f$, a freqüência de modulação da luz. $\mathrm{O}$ comprimento de difusão térmica, $\mu_{n}$, é o inverso de $a_{n}$, isto é, $\mu_{n}=a_{n}{ }^{-1}$.

As equações (2)-(5) acima são acopladas por condições de contorno de continuidade de temperatura e de fluxo de calor em todas as interfaces, isto é, $T_{n}=T_{m}$ e $\left(k_{n} d T_{n} / d x\right)=$ $\left(\mathrm{k}_{\mathrm{m}} \mathrm{dT}_{\mathrm{m}} / \mathrm{dx}\right)$ nas interfaces $(\mathrm{n} \neq \mathrm{m})$. A quantidade de interesse é a função para o campo de temperatura no detetor piroelétrico $\mathrm{T}_{\mathrm{p}}(\omega, \mathrm{x})$. Depois de intenso trabalho algébrico, chega-se a uma expressão para o campo de temperatura em função dos parâmetros físicos dos meios envolvidos visualizados na figura IV.1. Essa expressão é bastante complicada e não tem tanto interesse prático devido à sua extensão [53]. Porém, para alguns casos especiais de interesse físico, essa expressão é bastante simplificada e útil. Para o caso de interesse em nosso trabalho, onde o detetor é considerado como sendo termicamente espesso $\left(\mu_{\mathrm{p}}<\mathrm{L}_{\mathrm{p}}\right)$ e oticamente opaco $\left(\beta_{\mathrm{p}}^{-1}<<\mathrm{L}_{\mathrm{p}}\right)$ e considerando $\beta_{\mathrm{p}}^{-1}<\mu_{\mathrm{p}}$, a voltagem piroelétrica (independente da parte temporal) é dada por [53-57,59,60]: 


$$
\begin{gathered}
\mathrm{V}=\frac{A b_{p s}}{k_{P} \sigma_{P}^{2}}\left[\left(\frac{\eta_{s} r_{s}}{\left(r_{s}^{2}-1\right)}\right)\left\{2\left(b_{s g} r_{s}+1\right)-\left[\left(r_{s}+1\right)\left(b_{s g}+1\right) e^{\sigma_{s} L_{s}}+\left(r_{s}-1\right)\left(b_{s g}-1\right) e^{-\sigma_{s} L_{s}}\right] e^{-\beta_{s} L_{s}}\right\}\right. \\
\left.+\eta_{P} e^{-\beta_{S} L_{s}}\left[\left(b_{s g}+1\right) e^{\sigma_{s} L_{s}}+\left(b_{s g}-1\right) e^{-\sigma_{s} L_{s}}\right]\right] \\
\div\left[\left(b_{s g}+1\right)\left(b_{p s}+1\right) e^{\sigma_{s} L_{s}}+\left(b_{s g}-1\right)\left(b_{p s}-1\right) e^{-\sigma_{s} L_{s}}\right]
\end{gathered}
$$

onde $A=p I_{0} / 2 K \varepsilon_{0}, r_{n}=\beta_{n} / \sigma_{n}$, e $b_{n m}=k_{n} a_{n} / k_{m} a_{m}$. Essa equação é dada em função dos parâmetros ótico, térmico e geométrico do sistema e ainda é bastante complicada. Ela pode ainda ser simplificada para alguns casos especiais de interesse físico, tornando-se em expressões mais simples [53].

A voltagem de referência, para o detetor sem a amostra e pintado com tinta preta, é dado por [53-57,59,60]:

$$
\mathrm{V}_{\mathrm{R}}=\frac{A}{k_{P} \sigma_{P}^{2}}\left(\frac{1}{b_{g p}+1}\right)
$$

considerando que a camada preta sobre a superfície do detetor seja termicamente fina, isto é, $\exp \left( \pm \sigma_{R} L_{R}\right) \cong 1,\left|r_{R}\right| \gg>1$ e $\eta_{R}=1$. A voltagem normalizada $V n$, que é igual à razão $V / V_{R}$, fornece o sinal gerado pela amostra. Dividindo a equação (7) pela (8), obtemos a seguinte equação para a voltagem normalizada $\operatorname{Vn}[54,55]$ :

$$
\begin{aligned}
& \mathrm{Vn}=\left[\left(\frac{\eta_{s} r_{S}}{r_{S}^{2}-1}\right)\left[2\left(b_{g s}+r_{s}\right)-\left[\left(r_{s}+1\right)\left(b_{g s}+1\right) e^{\sigma_{s} L_{s}}-\left(r_{s}-1\right)\left(b_{g s}-1\right) e^{-\sigma_{s} L_{s}}\right] e^{-\beta_{s} L_{s}}\right]+\right. \\
& \left.\left[\left(b_{g s}+1\right) e^{\sigma_{s} L_{S}}-\left(b_{g s}-1\right) e^{-\sigma_{s} L_{s}}\right] e^{-\beta_{s} L_{s}}\right] \times\left[\frac{b_{g s}+b_{p s}}{\left(b_{g s}+1\right)\left(b_{p s}+1\right) e^{\sigma_{s} L_{s}}-\left(b_{g s}-1\right)\left(b_{p s}-1\right) e^{-\sigma_{s} L_{s}}}\right]
\end{aligned}
$$


Essa equação vai ser a equação básica que utilizaremos para ajustar aos resultados experimentais referentes aos espectros fotopiroelétricos e aos sinais de voltagem e de fase em função da freqüência de modulação da luz.

\section{IV.3 -MODELO TEÓRICO DE ROSENCWAIG E GERSHO (PAS)}

A célula fotoacústica, que representa o modelo unidimensional, está mostrado na figura IV.2. Analogamente ao caso PPES, g representa o gás (ar), s, a amostra e b, o material de suporte. Os símbolos $\mathrm{L}_{\mathrm{g}}, \mathrm{L}_{\mathrm{s}}$ e $\mathrm{L}_{\mathrm{b}}$ representam as espessuras da camada de gás, da amostra e do material de suporte, respectivamente. A fonte primária do sinal acústico resulta do fluxo periódico de calor do sólido para o gás circundante, quando o sólido é periodicamente aquecido pela absorção da luz modulada. Somente uma camada relativamente fina do gás, adjacente à superfície do sólido, responde termicamente ao fluxo periódico de calor dele para o gás circundante. A espessura desta camada é igual a $2 \pi \mu_{\mathrm{g}}$, onde $\mu_{\mathrm{g}}$ é o comprimento de difusão térmica do gás. Assim, esta camada fronteiriça do gás funciona como um pistão oscilante, criando o sinal acústico detetado pelo microfone da célula [44-50].

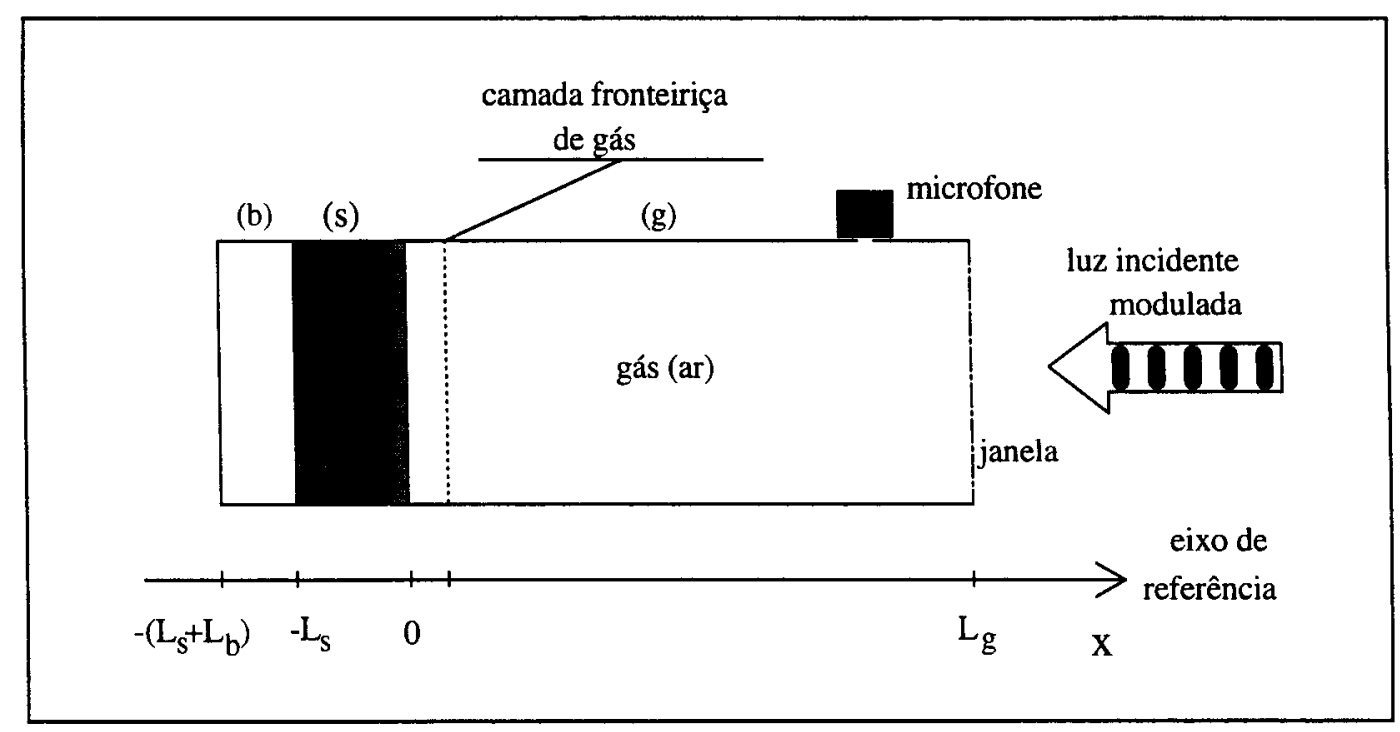

Figura IV.2 - Esquema da célula fotoacústica utilizada para o modelo teórico. 
Analogamente ao caso PPES, o processo dominante no interior da célula PAS é a difusão de calor devido à absorção de luz pelo sólido, considerando que o gás e o material de suporte não sejam absorvedores de luz. Assim, as equações de difusão térmica para as três regiões no interior da célula são $[44,45,47,48,50,54]$ :

para $0 \leq \mathrm{x} \leq \mathrm{L}_{\mathrm{g}}$ :

$$
\frac{d^{2} T_{g}}{d x^{2}}-\sigma_{g}^{2} T_{g}=0
$$

para $-\mathrm{L}_{\mathrm{s}} \leq \mathrm{x} \leq 0$ :

$$
\frac{d^{2} T_{S}}{d x^{2}}-\sigma_{s}^{2} T_{S}=-\left(\frac{\beta_{s} I_{0} \eta_{S}}{2 k_{S}}\right) e^{\beta_{S} x}\left[1+e^{i \omega t}\right]
$$

$\operatorname{para}-\left(\mathrm{L}_{\mathrm{s}}+\mathrm{L}_{\mathrm{b}}\right) \leq \mathrm{x} \leq-\mathrm{L}_{\mathrm{s}}$ :

$$
\frac{d^{2} T_{b}}{d x^{2}}-\sigma_{b}^{2} T_{b}=0
$$

Aplicando-se as condições de contorno de continuidade da temperatura e do fluxo de calor em todas as interfaces entre os meios envolvidos, e supondo que o gás se comporta idealmente na fina camada fronteiriça à superfície da amostra e no restante adiabaticamente, obtém-se que a variação de pressão no gás, que dá origem ao sinal acústico produzido pelo microfone, é dado por $[44,45,47,48,50,54]$ :

$$
\begin{aligned}
\Delta \mathrm{P}= & \frac{\eta_{s} \beta_{s} I_{0} \gamma P_{0}}{2 \sqrt{2} k_{s} L_{g} a_{g} T_{0}\left(\beta_{s}^{2}-\sigma_{s}^{2}\right)}\left[\left(r_{s}-1\right)\left(b_{b s}+1\right) e^{\sigma_{s} L_{s}}-\left(r_{s}+1\right)\left(b_{b s}-1\right) e^{-\sigma_{s} L_{s}}\right. \\
& \left.+2\left(b_{b s}-r_{s}\right) e^{-\beta_{s} L_{s}}\right] \div\left[\left(b_{g s}+1\right)\left(b_{b s}+1\right) e^{\sigma_{s} L_{s}}-\left(b_{g s}-1\right)\left(b_{b s}-1\right) e^{-\sigma_{s} L_{s}}\right]
\end{aligned}
$$


onde $\gamma=c_{\mathrm{p}} / c_{\mathrm{v}}$ é a razão entre os calores específicos do gás, a pressão e a volume constantes, e $\mathrm{P}_{0}$ e $\mathrm{T}_{0}$ são a pressão e a temperatura ambientes, respectivamente. Essa equação, que é dada em função dos parâmetros ótico, térmico e geométrico do sistema, pode também ser simplificada para alguns casos especiais de interesse físico $[44,45,47,48,50]$. Para o caso em que o sólido é oticamente opaco $\left(\beta_{\mathrm{s}}^{-1}<<\mathrm{L}_{\mathrm{s}}\right)$ e termicamente fino $\left(\mu_{\mathrm{s}} \gg \mathrm{L}_{\mathrm{s}}\right.$ e $\left.\mu_{\mathrm{s}} \gg \beta_{\mathrm{s}}^{-1}\right)$, temse a seguinte expressão para o sinal fotoacústico $[45,48,50]$ :

$$
\Delta \mathrm{P}=\frac{(1-i) \gamma P_{0} I_{0}}{4 \sqrt{2} L_{g} T_{0} a_{g}}\left(\frac{\mu_{b}}{k_{b}}\right)
$$

onde foi considerado $\eta_{\mathrm{s}}=1$. Esta expressão é válida para o sinal fotoacústico obtido para um corpo absorvedor negro, que fornece o sinal de referência para a normalização dos espectros. Dividindo a equação (13) pela (14), obtém-se que o sinal fotoacústico normalizado é:

$$
\begin{gathered}
\Delta \mathrm{Pn}=\frac{\eta_{s} r_{s} b_{b s}}{r_{s}^{2}-1}\left[\left(r_{s}-1\right)\left(b_{b s}+1\right) e^{\sigma_{s} L_{s}}-\left(r_{s}+1\right)\left(b_{b s}-1\right) e^{-\sigma_{s} L_{s}}+2\left(b_{b s}-r_{s}\right) e^{-\beta_{s} L_{s}}\right] \\
\div\left[\left(b_{g s}+1\right)\left(b_{b s}+1\right) e^{\sigma_{s} L_{s}}-\left(b_{g s}-1\right)\left(b_{b s}-1\right) e^{-\sigma_{s} L_{s}}\right]
\end{gathered}
$$

\section{IV.4 - RESULTADOS E DISCUSSÃO}

\section{IV.4.1 - VARREDURA DE FREQÜÊNCIAS NA ESPECTROSCOPIA PPES}

A equação de Mandelis, dada pela expressão (9), é bastante complicada, devido à sua extensão e aos diversos parâmetros térmicos e óticos que nela aparecem. Porém, se trabalharmos na região de saturação da absorção ótica da amostra, podemos simplificar a 
expressão Vn. Na região saturada, a amostra é altamente absorvedora, então $\exp \left(-\beta_{s} L_{s}\right) \cong 0,0$ que implica $\left|r_{s}\right| \gg>1$, e bgs, no caso da câmara fechada, é o parâmetro de acoplamento entre a janela e a amostra. Assim, de acordo com a equação (9), obtém-se para Vn, na região de saturação, a seguinte expressão [54]:

$$
\operatorname{Vn}=2 \eta_{s}\left[\frac{\left(b_{g s}+b_{p s}\right)}{\left(b_{g s}+1\right)\left(b_{p s}+1\right) e^{\sigma_{s} L_{s}}-\left(b_{g s}-1\right)\left(b_{p s}-1\right) e^{-\sigma_{s} L_{s}}}\right]
$$

onde foi considerado que $\left|r_{s}\right| \gg b_{g s}$. Usando uma janela de vidro BK-7 na célula fotopiroelétrica, a razão $b_{g s} / b_{p s}$ é igual a 2,77 , para os valores $k_{p}=0,13 \mathrm{~W} / \mathrm{mK}, \mathrm{k}_{\mathrm{g}}=1,114$ $\mathrm{W} / \mathrm{mK}, \alpha_{\mathrm{p}}=5,4 \times 10^{-8} \mathrm{~m}^{2} / \mathrm{s}$ e $\alpha_{\mathrm{g}}=51,7 \times 10^{-8} \mathrm{~m}^{2} / \mathrm{s}[54]$. Como $\sigma_{\mathrm{s}}=(1+\mathrm{i}) \mathrm{a}_{\mathrm{s}}$ e $\mathrm{a}_{\mathrm{s}}=\left(\pi f / \alpha_{\mathrm{s}}\right)^{1 / 2}$, onde $\alpha_{s}$ é a difusividade térmica da amostra e $f$, a freqüência de modulação da luz, e conhecendo a espessura $L_{s}$ da amostra, o ajuste da equação (16), em módulo, aos pontos experimentais dados pelo gráfico $|\mathrm{Vn}| \times f$, fornece $\alpha_{\mathrm{s}}$ e $b_{\mathrm{ps}}$, considerando $\eta_{\mathrm{s}} \approx 1$. Este é um valor razoável para polímeros condutores [54,55], principalmente para a PANI, que não fluoresce para estados de oxidação maiores que 0,5 (base esmeraldina) $[62,63]$. Com as expressões para $b_{p s}, a_{p}$ e $a_{s}$, chega-se à seguinte equação $k_{s}=\left(k_{p} / b_{p s}\right)\left(\alpha_{s} / \alpha_{p}\right)^{1 / 2}$. Assim, obtémse também a condutividade térmica da amostra. Sabendo que $k=c \rho \alpha$, onde c é o calor específico e $\rho$, a massa específica, pode-se obter ainda o calor específico da amostra. $O$ módulo da expressão (16) é fornecido no apêndice A.

A equação para a fase normalizada (Fn) na região de saturação, obtida a partir da equação (16), é dada por [54,55]:

$$
\mathrm{Fn}=-\arctan \left[\frac{\left(b_{g s} b_{p s}+1\right) \cosh \left(a_{s} L_{s}\right)+\left(b_{g s}+b_{p s}\right) \operatorname{senh}\left(a_{s} L_{s}\right)}{\left(b_{g s}+b_{p s}\right) \cosh \left(a_{s} L_{s}\right)+\left(b_{g s} b_{p s}+1\right) \operatorname{senh}\left(a_{s} L_{s}\right)} \cdot \tan \left(a_{s} L_{s}\right)\right]
$$


As equações (16) e (17) só são válidas se o detetor piroelétrico for termicamente espesso e oticamente opaco, e se estivermos na região de saturação para as absorções óticas da amostra. Para o detetor ser termicamente espesso, $\mu_{p}$ tem que ser menor que $L_{p}(=40 \mu \mathrm{m}), o$ que implica que a freqüência de modulação da luz tem que ser maior que 10,7 Hz. Para ele ser

oticamente opaco $\left(\beta_{\mathrm{p}}^{-1} \ll<\mathrm{L}_{\mathrm{p}}\right)$ e não refletor, a aplicação de uma camada fina de tinta preta na sua superfície é suficiente para atingir essa condição [54,55]. Obtivemos espectros com a varredura de freqüência entre 12 e $600 \mathrm{~Hz}$, utilizando uma fonte de laser He-Ne, que emite em 632,8 nm. Neste comprimento de onda, as amostras são altamente absorvedoras, como pode ser verificado nos espectros mostrados no capítulo anterior.

\section{IV.4.1.1 - Resultados para a PANI}

As figuras IV.3 a IV.5 mostram os pontos experimentais obtidos para a fase normalizada Fn e para o módulo de Vn, para os filmes de PANI, respectivamente não-dopado e dopados com $\mathrm{HCl} 10^{-3}$ e $1 \mathrm{M}$. Somente estão mostrados os pontos obtidos para frequiências acima de aproximadamente $100 \mathrm{~Hz}$, onde o detetor está bem longe da região de transição termicamente espesso para fino. A linha cheia representa a melhor curva ajustada aos pontos experimentais. Estes ajustes foram feitos utilizando-se o programa matemático "Microcal Origin 3.5 para Windows", aplicado às equações (16) (em módulo) e (17). Nas figuras, estão mostrados os resultados para o ajuste fornecidos pelo programa. Na frente de cada parâmetro, estão indicados os erros obtidos com o ajuste. O programa fornece também o $\chi^{2}$ (chi-square) para o ajuste para $\mathrm{Vn}$. Todos os resultados do ajuste para os parâmetros físicos de interesse estão mostrados na tabela IV.1. A fim de obtermos o calor específico, determinamos a massa 
específica das amostras utilizadas pela razão massa/volume. Estes valores também estão mostrados na tabela IV.1.

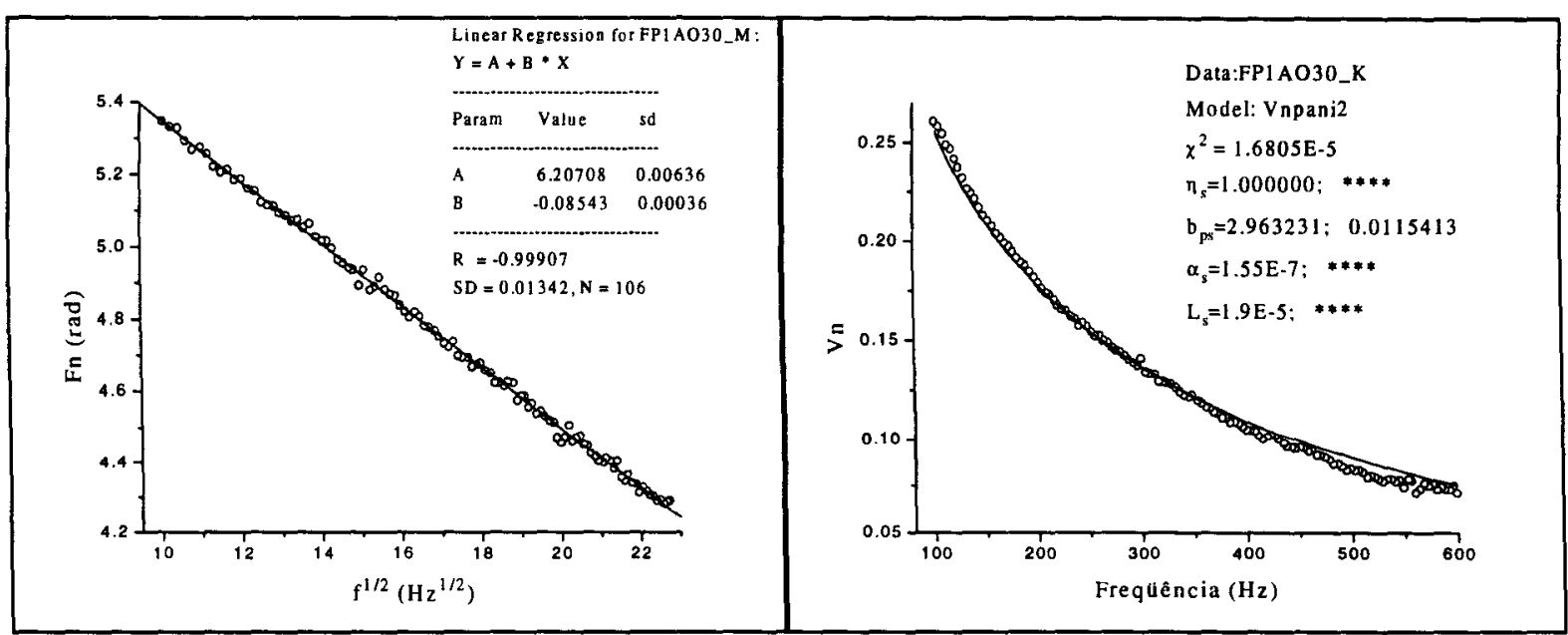

Figura IV.3 - Pontos experimentais obtidos e melhores curvas ajustadas para a fase e a voltagem normalizadas (Filme de PANI não-dopado). As unidades para os parâmetros estão no SI.

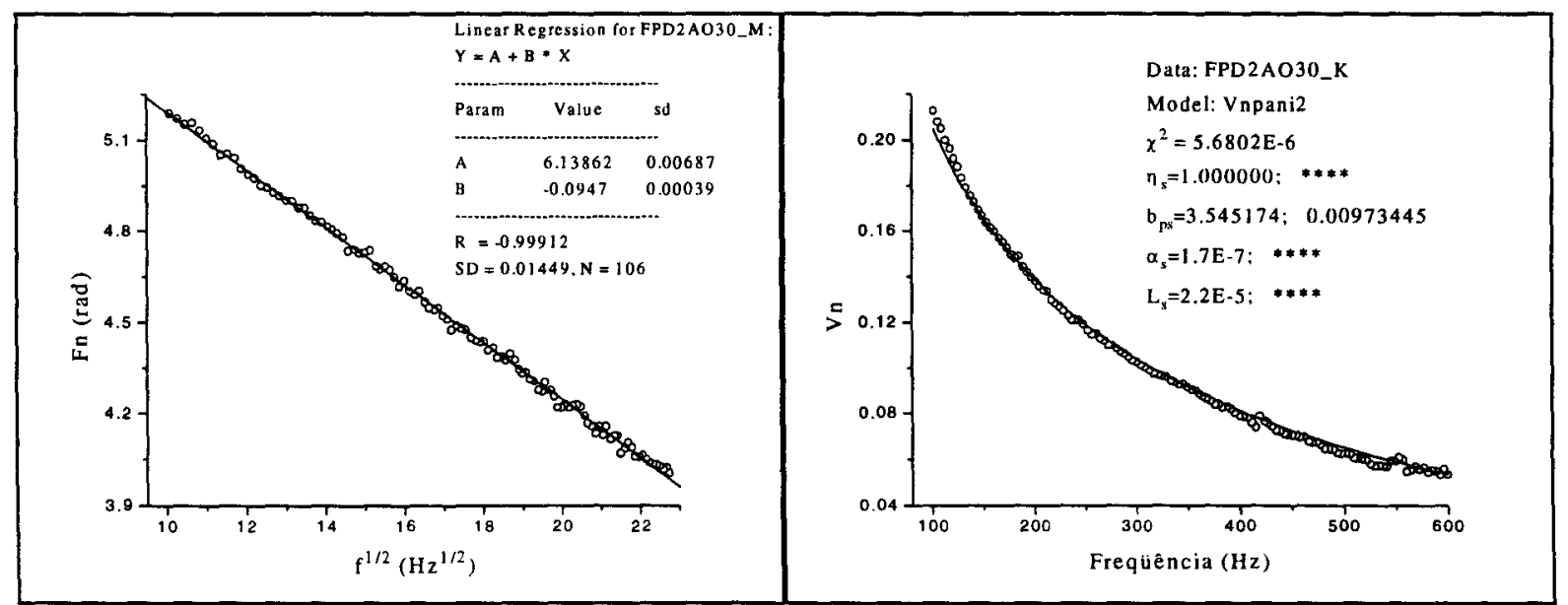

Figura IV.4 - Idem para o filme de PANI dopado com $\mathrm{HCl} 10^{-3} \mathrm{M}$.

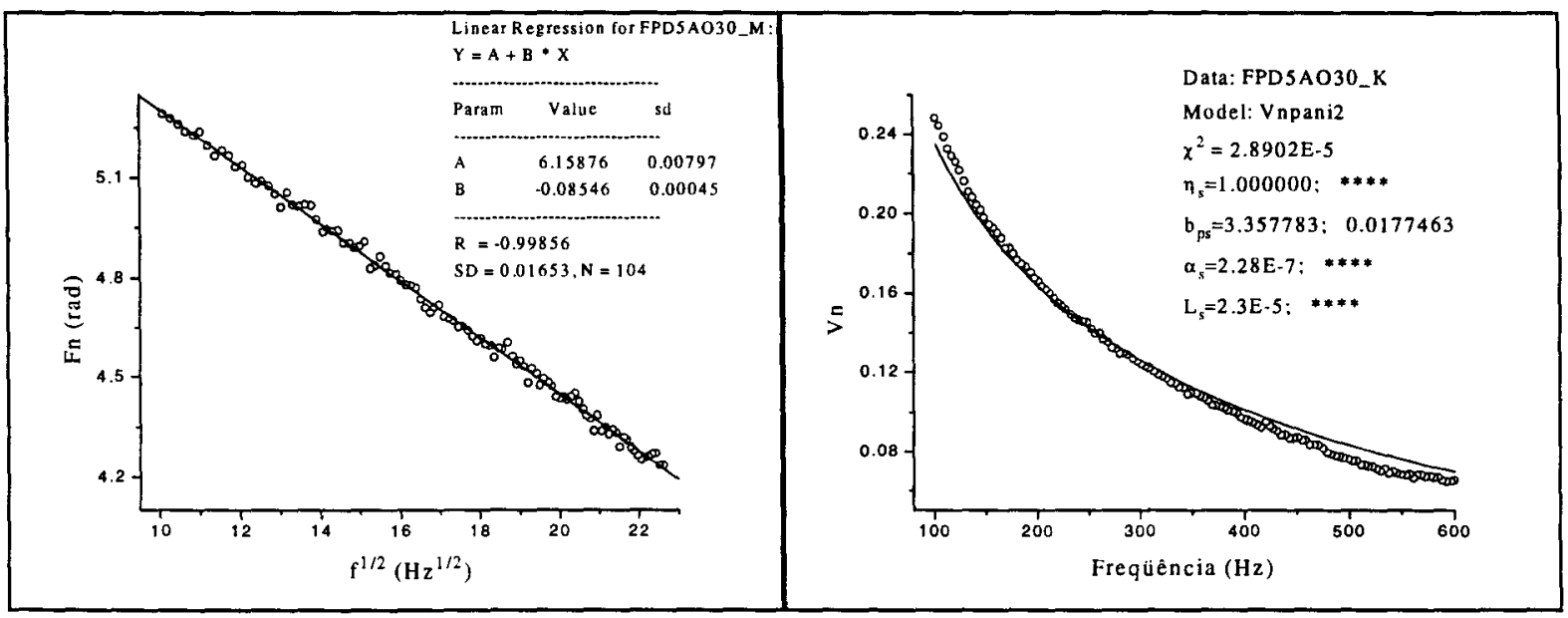

Figura IV.5 - Idem para o filme de PANI dopado com $\mathrm{HCl} 1 \mathrm{M}$. 
Nota-se que os pontos obedecem a uma reta para a fase normalizada em função da raiz quadrada da frequiência. Para todas as amostras, utilizando os resultados dos ajustes para $V n$, verifica-se que o termo que antecede a $\tan \left(a_{s} L_{s}\right)$ na equação (17) varia entre 1,01 e 1,15 aproximadamente, para frequiências entre 600 e $100 \mathrm{~Hz}$, respectivamente. Pode-se verificar esta afirmação, observando a figura IV.6, que mostra o termo que antecede a $\tan \left(a_{s} L_{s}\right)$ em função da frequiência de modulação. Esse termo fica bem próximo de 1 para freqüências mais altas. Assim, podemos considerar, com boa precisão, este termo como sendo igual a 1, o que implica que a equação (17) se reduz a uma equação simples do tipo: $F n=-a_{s} L_{s}$. Esta equação é linear se Fn for dado em função da raiz quadrada da frequiência, porque $a_{s}=\left(\pi f / \alpha_{s}\right)^{1 / 2}$. Com a declividade desta reta, pode-se obter diretamente a difusividade térmica.

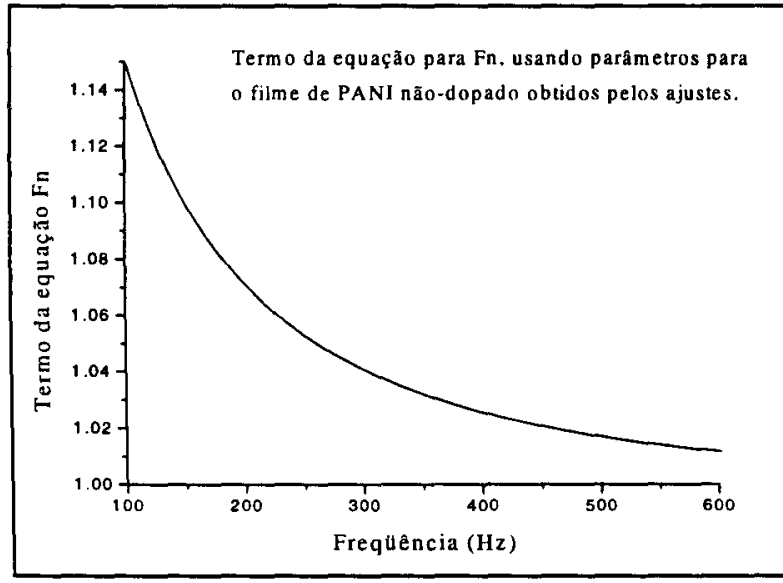

(a)

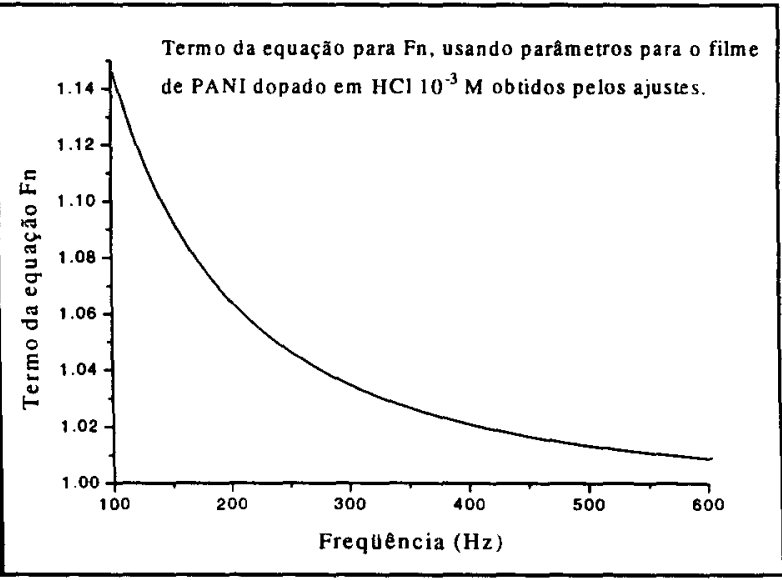

(b)

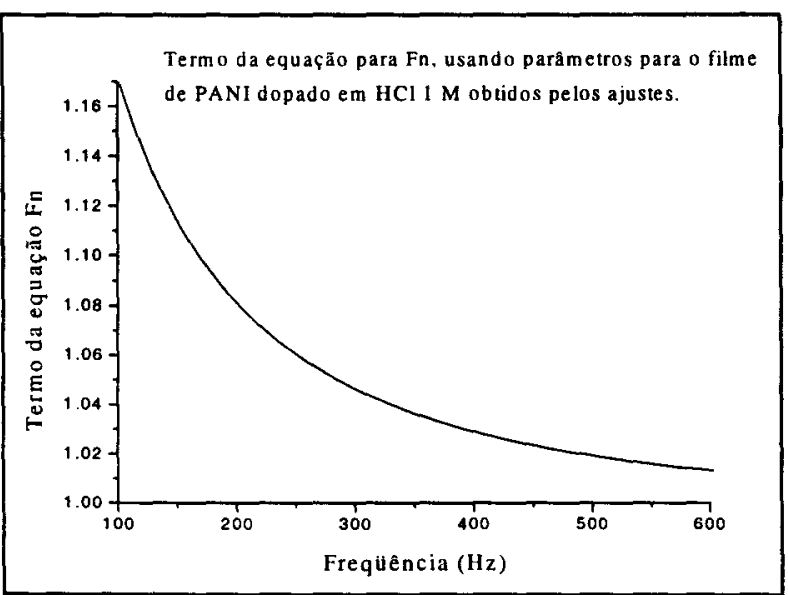

(c)

Figura IV.6 - Gráficos do termo que antecede a $\tan \left(\mathrm{a}_{\mathrm{s}} \mathrm{L}_{\mathrm{s}}\right)$ na expressão (17) em função da freqüência de modulação, usando os parâmetros de ajuste para os filmes de PANI: (a) não-dopado; (b) dopado em $\mathrm{HCl} 10^{-3} \mathrm{M}$; e (c) dopado em $\mathrm{HCl} 1 \mathrm{M}$. 
A tabela IV.1 mostra os resultados obtidos para os parâmetros de ajuste fixando as difusividades obtidas pelo ajuste da fase normalizada. As figuras IV.3 a IV.5 mostram, portanto, resultados em que o único parâmetro de ajuste para o sinal Vn é o b $b_{p s}$.

Tabela IV.1 - Resultados para os parâmetros $\left(\alpha_{s}\right.$ e $\left.b_{p s}\right)$ de ajuste matemático aos pontos experimentais para Fn e Vn mostrados nas figuras IV.3 a IV.5, juntamente com os parâmetros calculados a partir deles $\left(k_{s}\right.$ e $\left.c_{s}\right)$ mais os dois medidos $\left(L_{s}\right.$ e $\left.\rho_{s}\right)$.

\begin{tabular}{|c|c|c|c|}
\hline $\begin{array}{c}\text { Filmes } \rightarrow \\
\downarrow \text { Parâmetros }\end{array}$ & não-dopado & $\begin{array}{c}\text { dopado em } \mathrm{HCl} 10^{-3} \mathrm{M} \\
(\mathrm{pH} \sim 3)\end{array}$ & $\begin{array}{c}\text { dopado em HCl 1 M } \\
(\mathrm{pH} \sim 0)\end{array}$ \\
\hline $\mathrm{L}_{\mathrm{s}}(\mu \mathrm{m})$ & 19 & 22 & 23 \\
\hline$\rho_{\mathrm{s}}\left(\mathrm{g} / \mathrm{cm}^{3}\right)$ & 1,2 & 1,2 & $2,28 \times 10^{-7}$ \\
\hline$\alpha_{\mathrm{s}}\left(\mathrm{m}^{2} / \mathrm{s}\right)$ & $1,55 \times 10^{-7}$ & $1,70 \times 10^{-7}$ & 3,36 \\
\hline $\mathrm{b}_{\mathrm{ps}}$ & 2,96 & 3,54 & $7,95 \times 10^{-2}$ \\
\hline $\mathrm{k}_{\mathrm{s}}(\mathrm{W} / \mathrm{m} \mathrm{K})$ & $7,44 \times 10^{-2}$ & $6,52 \times 10^{-2}$ & 0,27 \\
\hline $\mathrm{c}_{\mathrm{s}}(\mathrm{J} / \mathrm{g} \mathrm{K})$ & 0,40 & 0,32 & \\
\hline
\end{tabular}

Podemos notar que os parâmetros térmicos não apresentam grandes variações com a taxa de dopagem do polímero (ficam limitados a variações inferiores a uma ordem de grandeza). A difusividade térmica apresenta um aumento com a taxa de dopagem (em torno de $47 \%$ para o extremos), enquanto o calor específico, uma diminuição (em torno de $48 \%$ para os extremos). A condutividade térmica é o parâmetro que menos varia (em torno de $7 \%$ para os extremos de dopagem). A aparente discrepância observada na diminuição da 
condutividade térmica para a amostra dopada em $10^{-3} \mathrm{M}$ de $\mathrm{HCl}$ reflete o pouco domínio que temos sobre o processo de dopagem. No caso de uma grandeza que varia muito pouco como a condutividade térmica, um resultado mais confiável deve ser obtido depois de um número muito grande de medidas em diferentes amostras submetidas às mesmas condições de dopagem. Nota-se que a PANI (dopada e não-dopada) apresenta difusividade e condutividade térmicas típicas de materiais isolantes (como o polietileno, a borracha e a água) e calor específico de metais (como cobre, zinco e prata). Assim, a PANI apresenta um comportamento dual, isto é, o polímero possui duas propriedades físicas com características de isolante e uma com característica de metal. Esse comportamento dessas propriedades físicas pode estar relacionado com o fato de que o polímero quando dopado apresenta também regiões não-dopadas, conforme mencionado no capítulo anterior. Como o calor específico é obtido a partir do processo transiente da condução de calor, é difícil de se saber como esse calor é conduzido por entre as regiões dopadas e não-dopadas do polímero. Portanto, esses fatos podem estar relacionados com essa aparente discrepância desse parâmetro físico (o calor específico).

\section{IV.4.1.2 - Resultados para a POMA}

Obtivemos também dados para o filme de POMA não-dopado feito na placa de quartzo de $2 \mathrm{~mm}$ de espessura, por secagem do solvente diclorometano. Conforme mencionado anteriormente, este filme ficou um pouco irregular com uma espessura entre 5 e 7 $\mu \mathrm{m}$. As medidas foram feitas com a fonte de luz halógena de $250 \mathrm{~W}$ e com o monocromador fixo em $638 \mathrm{~nm}$. A janela para a célula fotopiroelétrica foi a própria placa de suporte do filme. 
A figura IV.7 mostra o sinal Vn e a fase Fn normalizados, somente entre 100 e $490 \mathrm{~Hz}$, onde o detetor piroelétrico está longe da transição termicamente espesso para fino. Pode-se notar que os dados são bem mais ruidosos que os da PANI mostrados nas figuras IV.3 a IV.5, obtidos com a fonte de laser.

Para essa amostra, verifica-se que o termo que antecede a $\tan \left(a_{s} L_{s}\right)$ na equação (17) não está próximo de 1 (um) como no caso da PANI. Os seus valores variam entre 1,5 e 2,4 aproximadamente (para frequiências entre 500 e $100 \mathrm{~Hz}$, respectivamente), usando os valores do ajuste para o sinal Vn. Assim, não se pode aproximar a equação (17) por uma função linear, e tem-se que usar a equação (17) inteira para o ajuste. Os ajustes para a voltagem Vn e para a fase Fn foram feitos considerando-se que a razão $b_{g s} / b_{p s}$ é igual a 2,48, pois $k_{g}=0,92$ $\mathrm{W} / \mathrm{m} \mathrm{K}$ e $\alpha_{\mathrm{g}}=44 \times 10^{-8} \mathrm{~m}^{2} / \mathrm{s}$ [54] (g é a placa de quartzo). Para esses ajustes, fixamos a difusividade térmica em $1,55 \times 10^{-7} \mathrm{~m}^{2} / \mathrm{s}$, considerando igual ao da PANI, e a espessura do filme foi considerada igual ao valor médio $6 \mu \mathrm{m}$. Pode-se notar que o ajuste para o sinal $\mathrm{Vn}$ saiu melhor que para a fase. Os valores obtidos para o parâmetro $b_{p s}$ ficaram ligeiramente diferentes para os dois ajustes (em torno de $24 \%$ menor para o ajuste da fase). Como é difícil o controle da espessura em filmes mais finos feitos por deposição e evaporação do solvente, usando solventes muito voláteis como o diclorometano, essa diferença se justifica devido à incerteza oriunda da variação da espessura observada. A irregularidade desse filme de POMA pode provocar um mau acoplamento térmico entre ele e o detetor (isto pode provocar mais ruído nos sinais). Como o ajuste para o sinal Vn ficou melhor, vamos usar os resultados desse ajuste para o cálculo da condutividade térmica e do calor específico. Obtivemos que a condutividade térmica é igual a $2,81 \times 10^{-2} \mathrm{~W} / \mathrm{m} \mathrm{K}$ e o calor específico, $0,15 \mathrm{~J} / \mathrm{g} \mathrm{K}$ (considerando também que a densidade da POMA é igual ao da PANI). Estes valores são menores que os da PANI, como pode ser verificado na tabela IV.1. 


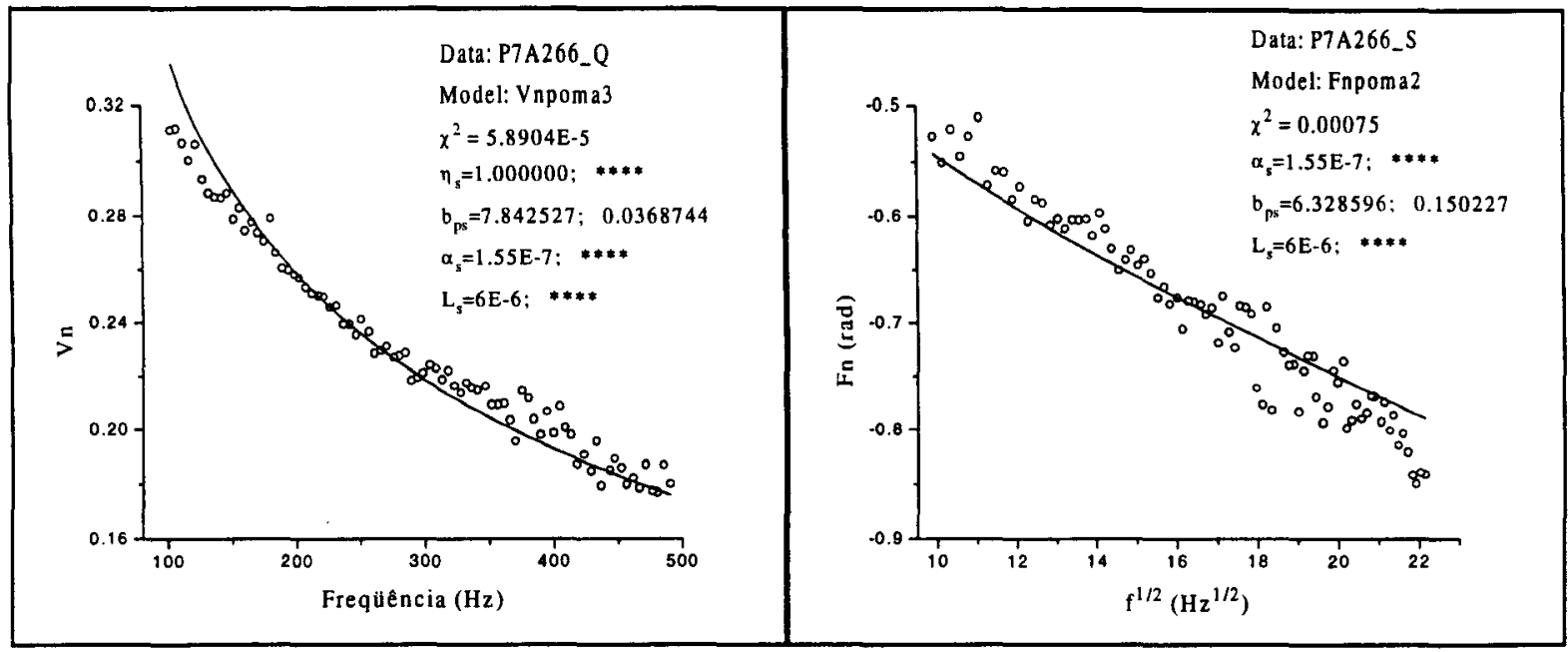

Figura IV.7 - Pontos experimentais obtidos e melhores curvas ajustadas para a voltagem e a fase normalizadas (Filme de POMA não-dopado). As unidades para os parâmetros estão no SI.

\section{IV.4.2 - VARREDURA DE COMPRIMENTOS DE ONDA NA ESPECTROSCOPIA PPES}

Conforme mencionado anteriormente, a equação de Mandelis, dada pela expressão (9), é bastante complicada devido à sua extensão e aos diversos parâmetros térmicos e óticos nela contidos. Trabalha-se, então, na região de saturação da absorção ótica da amostra, o que torna a expressão independente de $\beta$, e assim fica mais fácil obter os parâmetros térmicos desejados. A equação (9) pode, entretanto, ser usada para o ajuste aos pontos experimentais dados por $|\mathrm{Vn}|$ versus comprimento de onda, uma vez que se tenha alguns parâmetros já conhecidos. Esses parâmetros são obtidos pelo ajuste de $|\mathrm{Vn}|$ na região saturada, que é uma simplificação da equação (9). Com esse processo iterativo, podem-se obter ajustes e derivar os parâmetros desejados do material, como veremos a seguir. Aplicamos essa metodologia aos espectros fornecidos no capítulo anterior para os filmes espessos de PANI, dopados e nãodopado, e para o filme de POMA não-dopado de espessura entre 5 e $7 \mu \mathrm{m}$ feito na placa de quartzo. 
Para se obter o módulo da equação de Mandelis em função do comprimento de onda, é preciso, em primeiro lugar, inserir na equação as bandas de absorção ótica dos filmes estudados. Para tanto, vamos supor que as bandas de absorção ótica da polianilina são funções gaussianas, que é uma boa aproximação. Como a polianilina dopada apresenta também as bandas características da não-dopada, conforme vimos no capítulo anterior, vamos usar uma soma de três funções gaussianas para o coeficiente de absorção ótica. Uma gaussiana é para a banda característica da polianilina dopada, a banda polarônica, em torno de $830 \mathrm{~nm}$. A segunda é para a banda característica da não-dopada, a banda de éxciton molecular, em torno de $640 \mathrm{~nm}$. E a terceira é para a banda característica da transição $\pi-\pi^{*}$, em torno de $330 \mathrm{~nm}$. A polianilina dopada apresenta mais uma banda em torno de $430 \mathrm{~nm}$, que é característica também da transição polarônica. Porém, esta banda é bastante fraca como pode ser visto no capítulo I, aparecendo geralmente como um "ombro" ao lado da banda $\pi-\pi^{*}$. Assim, não vamos considerar esta banda no nosso modelo, porque, além de complicar ainda mais a obtenção do módulo da equação de Mandelis, sua influência sobre o ajuste teóricoexperimental é muito pequena. O módulo da equação de Mandelis, dada pela expressão (9), levando-se em conta as três gaussianas, é fornecido no apêndice B. Para a obtenção deste módulo, recorremos ao programa matemático "Maple V para Windows". O ajuste do módulo da equação de Mandelis aos pontos experimentais foi realizado com o programa "Origin" utilizado anteriormente.

A figura IV.8 mostra, a título de exemplo comparativo, o espectro de absorção ótica de uma solução de PANI em NMP, e sua representação pela superposição de duas gaussianas. Pode-se observar que ocorre um deslocamento da posição do centro das gaussianas com o ajuste pelas gaussianas. 


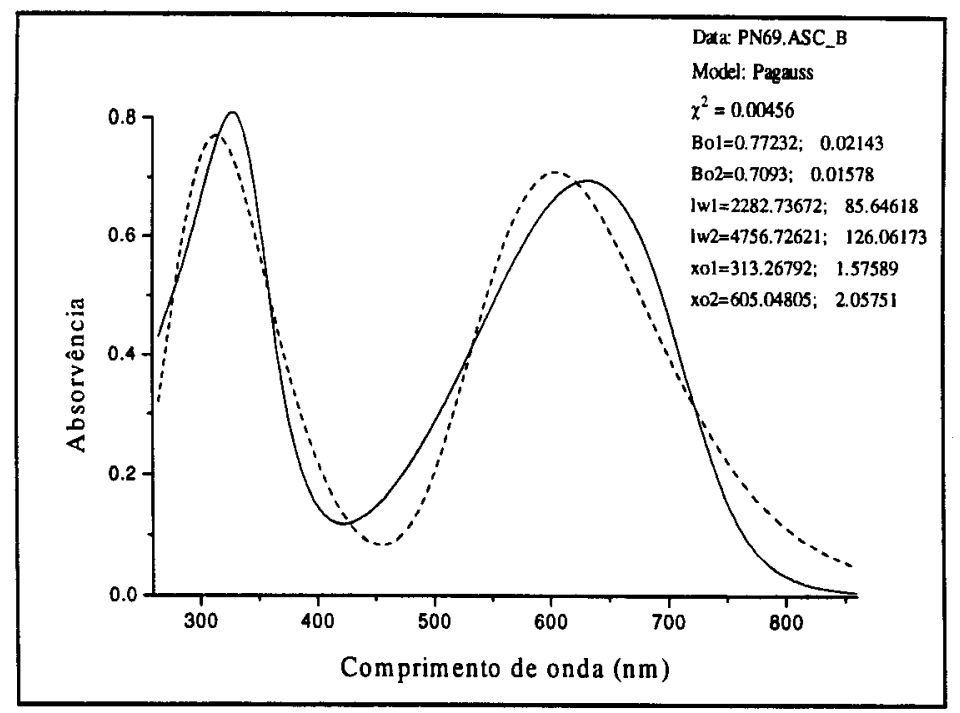

Figura IV.8 - Ajuste (linha tracejada) por duas gaussianas ao espectro de absorção ótica (linha cheia) de uma

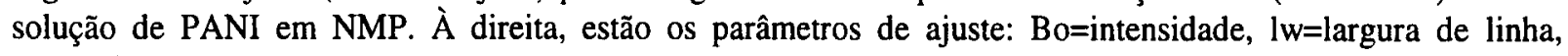
$\mathrm{xo}=$ posição do centro da gaussiana, com os respectivos erros.

\section{IV.4.2.1 - Resultados para a PANI}

A figura IV.9 mostra os espectros obtidos para os filmes espessos de PANI, já mostrados no capítulo anterior, agora contendo a curva de ajuste da equação de Mandelis aos pontos experimentais. Para a obtenção desta curva, usamos os parâmetros $b_{p s}$ e $\alpha_{s}$ obtidos no ajuste anterior da equação na região saturada. Deixamos livre para o programa ajustar a intensidade, a largura de linha e a posição do centro das gaussianas. Uma vez ajustados os centros das gaussianas para a amostra não-dopada, fixamos essas posiç̃̃es para os ajustes para as outras amostras. Para todos os espectros, verifica-se que a curva ajustada está em muito boa concordância com os pontos experimentais. Esses resultados reforçam os obtidos nos ajustes anteriores com a equação de Mandelis simplificada para a região saturada. 


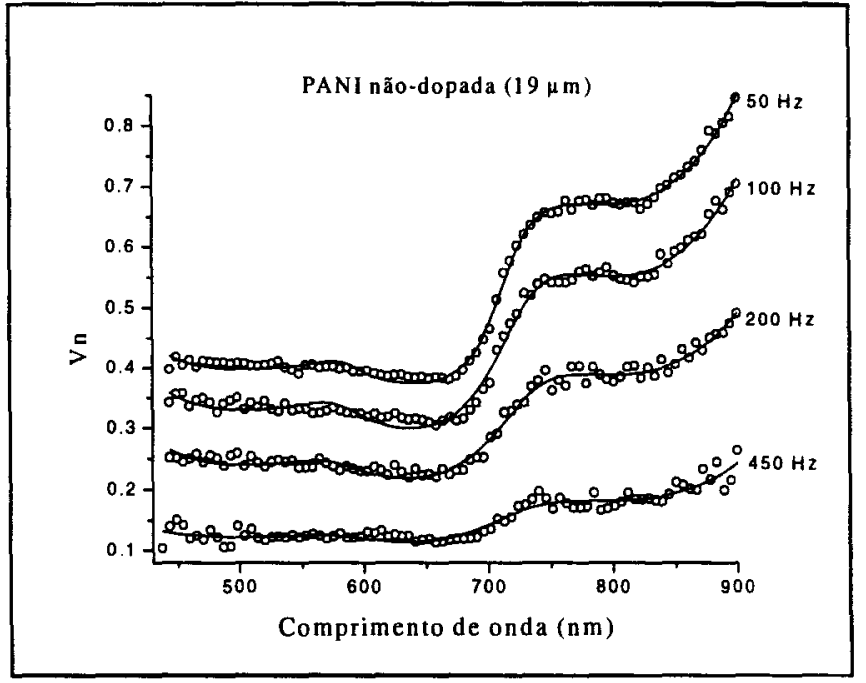

(a)

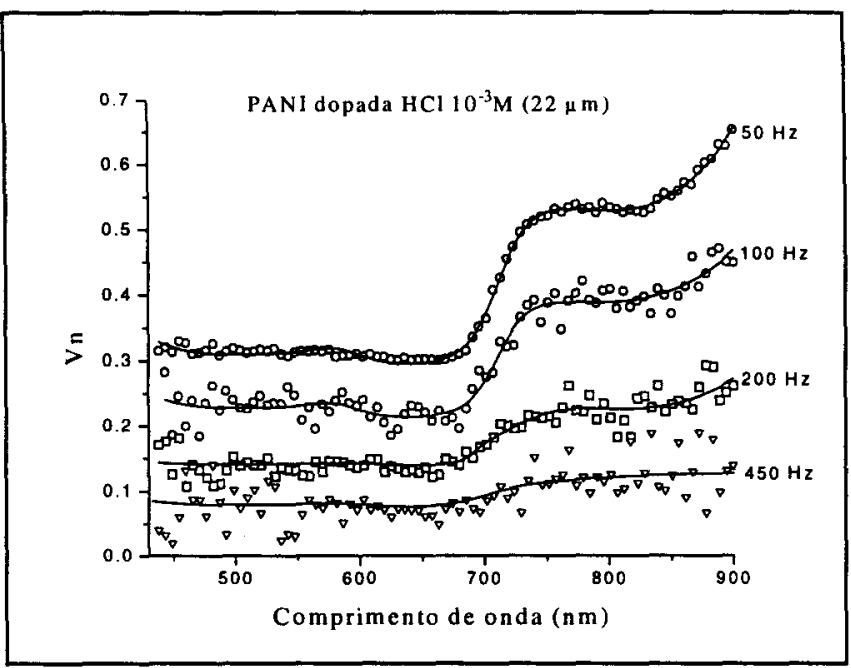

(b)

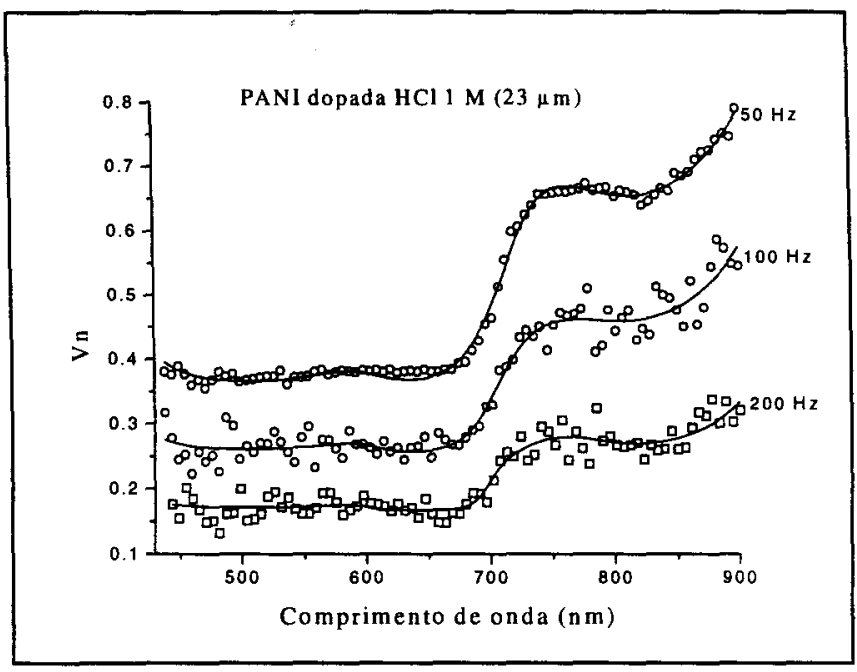

(c)

Figura IV.9 - Melhores curvas ajustadas pela equação de Mandelis aos espectros para o filme de PANI: (a) nãodopado; (b) dopado em $\mathrm{HCl} 10^{-3} \mathrm{M}$; e (c) dopado em $\mathrm{HCl} 1 \mathrm{M}$. 
Se fixarmos as posições dos centros das gaussianas nas posições reais das bandas da polianilina, o programa consegue ainda fazer os ajustes, com um pequeno aumento no fator de erro (o $\chi^{2}$, chi-square, fica um pouco maior). É importante observar que, como mostra a figura IV.8, o ajuste do espectro de absorção ótica da polianilina não-dopada, por duas gaussianas, não fica perfeito, ocorrendo um deslocamento das posições dos centros das gaussianas. Por esse motivo, deixamos livre para o ajuste a posição dos centros das gaussianas. Para todos os ajustes, a intensidade das gaussianas ficou entre $10^{6}$ e $10^{7} \mathrm{~m}^{-1}$ para as duas primeiras bandas, $\mathrm{e}$ em torno de $10^{5} \mathrm{~m}^{-1}$ para a banda em $830 \mathrm{~nm}$. Ocorre um pequeno alargamento desta banda, à medida que se aumenta a taxa de dopagem do polímero. A intensidade das duas primeiras gaussianas implica que o comprimento de absorção ótica $\left(\beta_{\mathrm{s}}{ }^{-1}\right)$ nessa região (entre 400 e 680 nm) está entre 0,1 e $1 \mu \mathrm{m}$, ou seja, as amostras são altamente opacas $\left(\beta_{\mathrm{s}}^{-1} \ll \mathrm{L}_{\mathrm{s}}\right)$. Já na região da banda polarônica, em torno de $830 \mathrm{~nm}$, o comprimento de absorção ótica está em torno de $10 \mu \mathrm{m}$, isto é, as amostras são menos opacas nessa região. Acima de $830 \mathrm{~nm}$, as amostras ficam mais transparentes à passagem de luz.

Verificamos que não há muita diferença entre a amostra não-dopada e as dopadas em $\mathrm{HCl}$, como mostra a figura IV.9. No capítulo anterior, já observamos a semelhança entre os resultados para as amostras dopadas e não-dopadas. Conforme mencionado anteriormente, uma das possíveis explicações leva em conta que mesmo para as amostras dopadas deve haver regiões não-dopadas. Inúmeros estudos sobre mecanismos de dopagem e de condução elétrica em polianilinas [66-70] têm mostrado que a distribuição de contra-íons no volume do material não é uniforme, mas preferencialmente ocorrem segregações, formando "ilhas dopadas" na matriz isolante. Outro efeito que pode ocorrer é que a dopagem seja mais efetiva na superfície da amostra, sendo fraca em seu interior. 


\section{IV.4.2.2 - Resultados para a POMA}

A figura IV.10 mostra os espectros PPES obtidos para o filme de POMA não-dopado de espessura entre 5 e $7 \mu \mathrm{m}$, com as curvas de ajuste da equação de Mandelis. Para este ajuste, usamos os resultados do ajuste para a equação na região saturada, mostrados na figura IV.7. Observa-se que, a $100 \mathrm{~Hz}$, o ajuste foi melhor. Em $50 \mathrm{~Hz}$, não se está muito longe da transição termicamente espesso para fino do detetor. As intensidades ajustadas das duas primeiras gaussianas (na região de saturação) ficaram entre $10^{7}$ e $10^{10} \mathrm{~m}^{-1}$ e da terceira (banda polarônica), da ordem de $10^{6} \mathrm{~m}^{-1}$, sendo assim valores bem mais altos que o caso da PANI. Esses valores altos podem estar relacionados com a irregularidade da espessura desse filme.

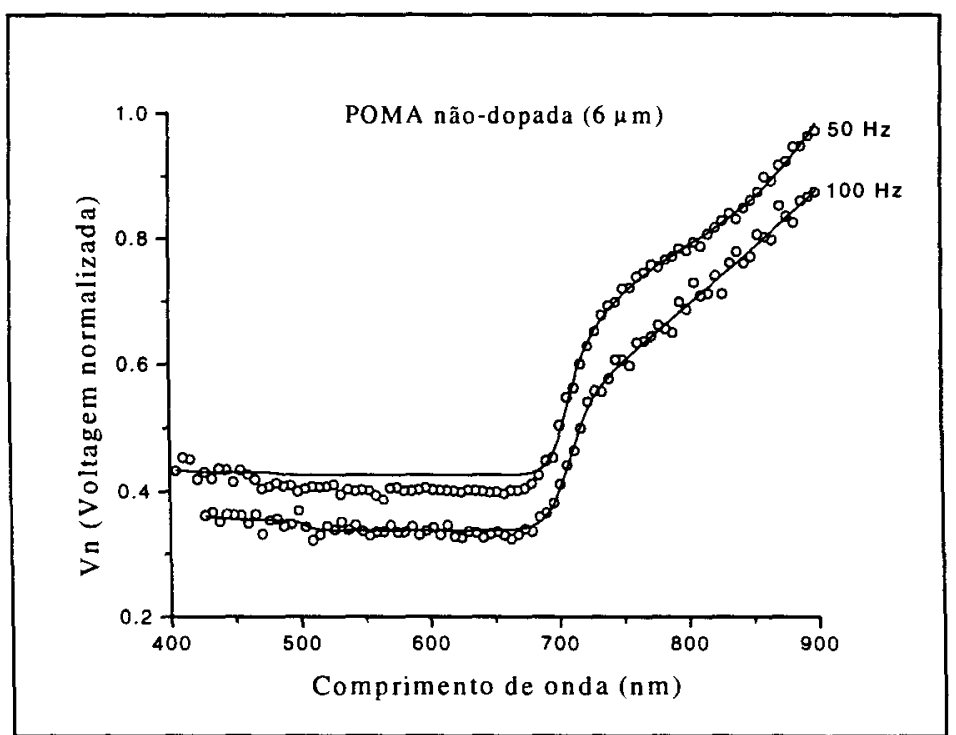

Figura IV.10 - Melhores curvas ajustadas pela equação de Mandelis aos espectros do filme de POMA (5-7 $\mu \mathrm{m})$.

\section{IV.4.2.3 - Efeitos na Fase do Sinal PPES para os Filmes Espessos de PANI}

As figuras III.5 e III.6 do capítulo anterior mostram a fase normalizada relativa aos espectros da figura IV.9 (a) e (c), respectivamente. O comportamento praticamente independente em relação ao comprimento de onda segue as equações de Mandelis para 
amostras oticamente opacas $\left(\beta_{s}^{-1}<<L_{s}\right)$ e termicamente finas $\left(\mu_{s} \gg L_{s}, \mu_{s} \gg \beta_{s}^{-1}\right)$ ou termicamente espessas $\left(\mu_{s}<L_{s}, \mu_{s}>\beta_{s}^{-1}\right)$. Essas equações são dadas por [53]:

$$
V\left(\omega_{0}\right)=A\left(\frac{\eta_{s} \alpha_{p}}{k_{p}\left(1+b_{g p}\right) \omega_{0}}\right) \exp (-i \pi / 2)
$$

para amostras oticamente opacas e termicamente finas; e

$$
V\left(\omega_{0}\right)=A\left(\frac{\eta_{s} \alpha_{p}}{k_{p}\left(1+b_{s p}\right) \omega_{0}}\right) \exp \left[-\left(\frac{\omega_{0}}{2 \alpha_{s}}\right)^{1 / 2} L_{s}\right] \exp \left\{-i\left[\frac{\pi}{2}+\left(\frac{\omega_{0}}{2 \alpha_{s}}\right)^{1 / 2} L_{s}\right]\right\}
$$

para amostras oticamente opacas e termicamente espessas. Nessas equações, $\omega_{0}=2 \pi f$. Essas equações são válidas para o sinal não normalizado. A equação (18) aplicada ao caso de um corpo negro corresponde à equação (8), que é utilizada para a normalização dos espectros. Verifica-se que as fases nessas equações são independentes de $\beta_{\mathrm{s}}$ (ou seja, do comprimento de onda). De acordo com os dados obtidos pelos ajustes anteriores para os filmes de PANI, mostrados na tabela IV.1, podemos obter o comprimento de difusão térmica para as amostras nas diversas frequiências de modulação da luz. A tabela IV.2 mostra os resultados obtidos. Para $10 \mathrm{~Hz}$, não vale a condição de detetor termicamente espesso, conforme mencionado anteriormente. Verifica-se que ocorre uma transição de amostra termicamente fina para espessa em torno de $137 \mathrm{~Hz}$ para as amostras não-dopada e dopada em $\mathrm{HCl} 1 \mathrm{M}$, e em $112 \mathrm{~Hz}$ para a dopada em $\mathrm{HCl} 10^{-3} \mathrm{M}$. Assim, para 50 e $100 \mathrm{~Hz}$, poderíamos utilizar a equação (18) acima para as nossas amostras, tendo em mente que a condição $\mu_{\mathrm{s}} \gg \mathrm{L}_{\mathrm{s}}$ é uma aproximação, porque não é inteiramente satisfeita para as nossas amostras (para estas, a condição seria melhor definida como $\mu_{s}>L_{s}$ ). Também, as condições $\beta_{s}^{-1} \ll L_{s}$ e $\mu_{s} \gg \beta_{s}^{-1}$ não são 
inteiramente satisfeitas ao longo de toda a região entre 400 e $900 \mathrm{~nm}$. Para a região entre 400 e $680 \mathrm{~nm}\left(\beta_{\mathrm{s}}^{-1}\right.$ entre 0,1 e $\left.1 \mu \mathrm{m}\right)$, essas condições são inteiramente satisfeitas, mas para a região acima de $730 \mathrm{~nm}\left(\beta_{\mathrm{s}}^{-1} \sim 10 \mu \mathrm{m}\right), \beta_{\mathrm{s}}^{-1}<\mathrm{L}_{\mathrm{s}}$ e $\mu_{\mathrm{s}}>\beta_{\mathrm{s}}^{-1}$.

Tabela IV.2 - Resultados para o comprimento de difusão térmica para os três filmes de PANI evidenciados na tabela IV.1.

\begin{tabular}{|c|c|c|c|}
\hline $\begin{array}{c}\text { Filmes } \rightarrow \\
\downarrow \text { Parâmetros }\end{array}$ & não-dopado & dopado em $\mathrm{HCl} 10^{-3} \mathrm{M}$ & dopado em $\mathrm{HCl} 1 \mathrm{M}$ \\
\hline $\mathrm{L}_{\mathrm{s}}(\mu \mathrm{m})$ & 19 & 22 & 23 \\
\hline$\alpha_{\mathrm{s}}\left(\mathrm{m}^{2} / \mathrm{s}\right)$ & $1,55 \times 10^{-7}$ & $1,70 \times 10^{-7}$ & $2,28 \times 10^{-7}$ \\
\hline$\mu_{\mathrm{s}}(\mu \mathrm{m})$ & & & \\
\hline$\rightarrow 10 \mathrm{~Hz}$ & 70,2 & 73,6 & 85,2 \\
\hline$\rightarrow 50 \mathrm{~Hz}$ & 31,4 & 32,9 & 38,1 \\
\hline$\rightarrow 100 \mathrm{~Hz}$ & 22,2 & 23,3 & 26,9 \\
\hline & $19(136,7 \mathrm{~Hz})$ & $22(112 \mathrm{~Hz})$ & $23(137 \mathrm{~Hz})$ \\
\hline$\rightarrow 200 \mathrm{~Hz}$ & 15,7 & 16,4 & 19,0 \\
\hline$\rightarrow 250 \mathrm{~Hz}$ & 14,0 & 14,7 & 17,0 \\
\hline$\rightarrow 400 \mathrm{~Hz}$ & 11,1 & 11,6 & 13,5 \\
\hline$\rightarrow 450 \mathrm{~Hz}$ & 10,5 & 11,0 & 12,7 \\
\hline
\end{tabular}

Normalizando a equação (18), a fase seria zero, mas devido aos deslocamentos de fase instrumentais este resultado pode não se verificar [57,59]. Esses fatos e mais as aproximações 
mencionadas acima explicam as fases normalizadas não nulas para 50 e $100 \mathrm{~Hz}$. Acima de $200 \mathrm{~Hz}$, podemos utilizar a equação (19) para as nossas amostras. Normalizando esta equação, obtemos que a fase é constante em função do comprimento de onda e é dada por: $F n=-a_{s} L_{s}$, ou seja, varia com a raiz quadrada da frequiência de modulação da luz. Quantitativamente, a amostra não-dopada segue bem essa equação, porém, para a dopada em $\mathrm{HCl} 1 \mathrm{M}$, onde o acoplamento térmico entre a amostra e o detetor não foi muito bom, não se verifica essa concordância. Um mau acoplamento térmico produz deslocamentos consideráveis na fase. Este comportamento se verifica para a amostra dopada.

\section{IV.4.3 - RESULTADOS PARA A ESPECTROSCOPIA PAS}

Passamos agora a apresentar os ajustes feitos para os resultados da Espectroscopia Fotoacústica (PAS). Para isso, usa-se a equação de Rosencwaig (15), em módulo. Os espectros fotoacústicos dos filmes finos de POMA, feitos por spin coating em placas de quartzo, são os já apresentados no capítulo anterior. Fizemos o ajuste seguindo a mesma metodologia anterior usada para a PANI. A razão $\mathrm{b}_{\mathrm{gg}} / \mathrm{b}_{\mathrm{bs}}$, onde $\mathrm{g}$ é o ar e b, a placa de quartzo, é igual a $3,94 \times 10^{-3}$, sabendo-se que $\mathrm{k}_{\mathrm{g}}=2,4 \times 10^{-2} \mathrm{~W} / \mathrm{m} \mathrm{K}, \alpha_{\mathrm{g}}=1,9 \times 10^{-5} \mathrm{~m}^{2} / \mathrm{s}, \mathrm{k}_{\mathrm{b}}=0,92 \mathrm{~W} / \mathrm{m}$ $\mathrm{Ke} \alpha_{b}=44 \times 10^{-8} \mathrm{~m}^{2} / \mathrm{s}[50,54]$.

Para os ajustes, usamos também três gaussianas representando o espectro de absorção ótica. Uma é para a banda situada em torno de $320 \mathrm{~nm}$; a outra, para a banda de éxciton molecular situada em torno de $600 \mathrm{~nm}$; e a terceira, para a banda polarônica situada em torno de 820 nm. Para o filme de POMA não-dopado, usamos os resultados do ajuste da equação de Mandelis na região saturada, dados na seção IV.4.1.2. Para o filme dopado em $\mathrm{HCl} 1 \mathrm{M}$, 
usamos os resultados para os parâmetros obtidos para o filme de PANI dopado em $\mathrm{HCl} 1 \mathrm{M}$ (tabela IV.1), considerando que são iguais aos da POMA. Assim, obtivemos $b_{b s}=19,4$ para o filme não-dopado e $b_{b s}=8,3$ para o filme dopado em $\mathrm{HCl} 1 \mathrm{M}$. Os resultados para os ajustes estão mostrados nas figuras IV.11 e IV.12.

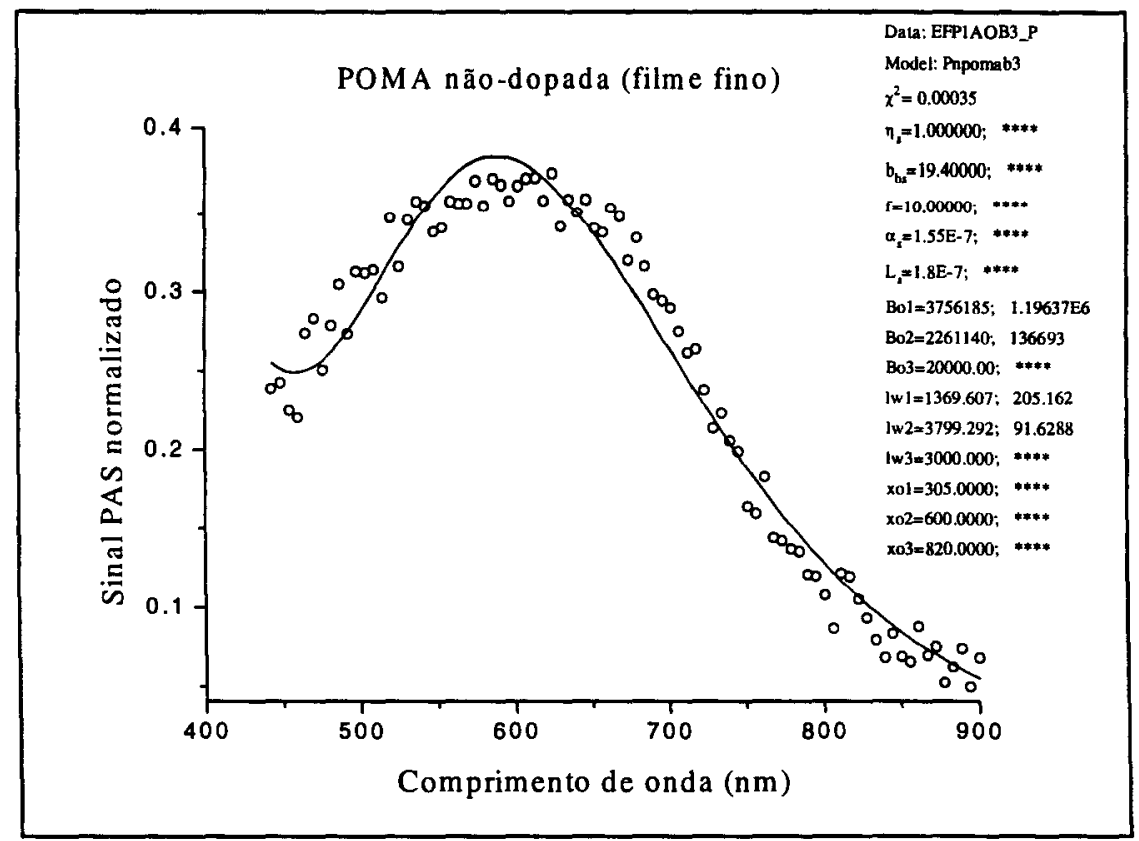

Figura IV.11 - Espectro PAS do filme fino de POMA não-dopado, mostrando a melhor curva ajustada pela equação de Rosencwaig.

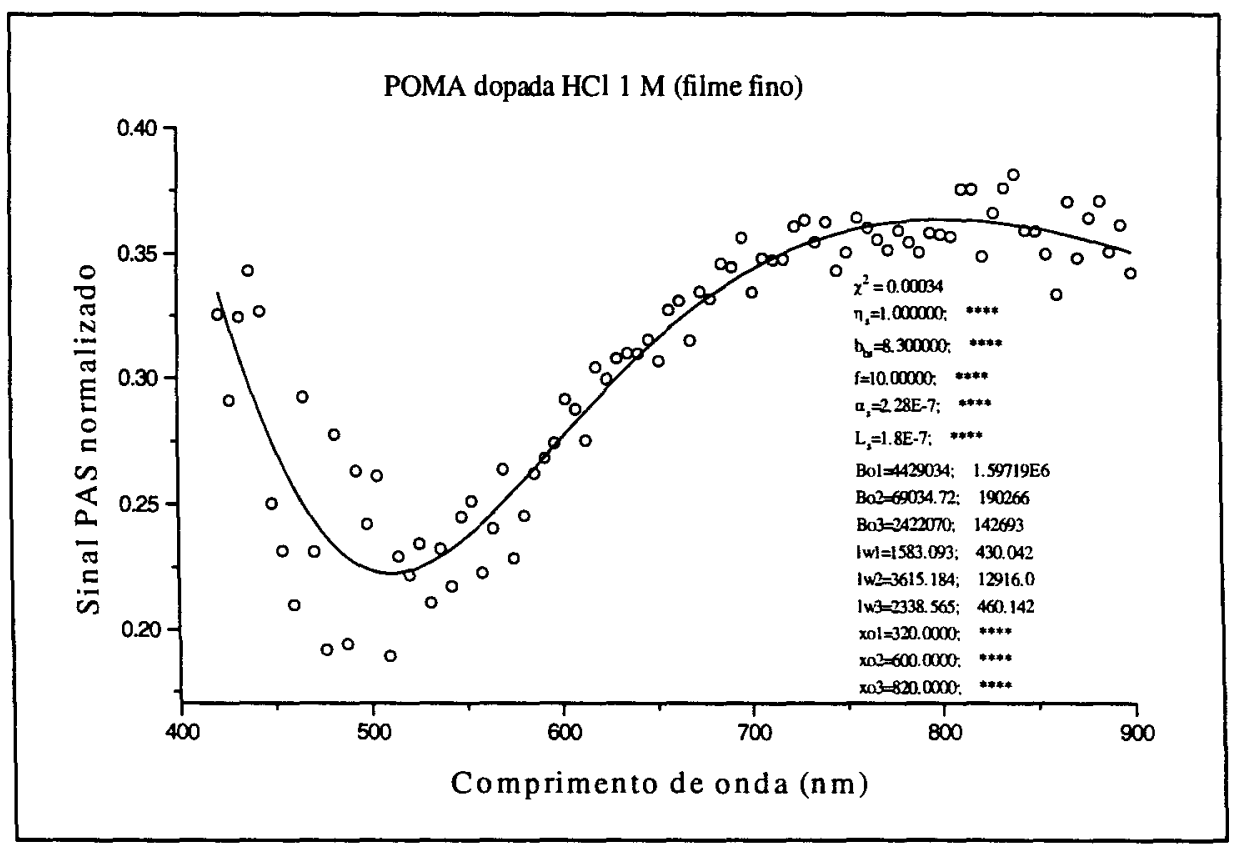

Figura IV.12 - Idem para o filme fino de POMA dopado em $\mathrm{HCl} 1 \mathrm{M}$. 
Como podemos verificar, os ajustes apresentam-se muito bons. Isto vem reforçar os valores dos parâmetros térmicos obtidos na seção IV.4.1.2 para a POMA não-dopada. Comprova também que os parâmetros térmicos para o filme de POMA dopado em $\mathrm{HCl} 1 \mathrm{M}$ são próximos dos valores para a PANI. A PAS, diferentemente da PPES, é similar à espectroscopia de absorção ótica para os filmes da polianilina. A intensidade das duas gaussianas mais intensas nos dois espectros é da ordem de $10^{6}$. A banda polarônica em torno de $820 \mathrm{~nm}$ no espectro do filme não-dopado apresenta uma intensidade duas ordens de grandeza mais baixa que as outras duas bandas. Analogamente, a banda de éxciton molecular em torno de $600 \mathrm{~nm}$ no espectro do filme dopado apresenta uma intensidade uma ordem de grandeza menor que as outras duas. Isto significa que, para a amostra não-dopada, há vestígios de dopagem e, para a dopada, existem regiões não-dopadas, provocando as pequenas absorções características. Este fato, já comentado no capítulo anterior e nas seções anteriores, também se verifica na espectroscopia fotoacústica, só que em menor grau, como podemos verificar nos espectros. A espectroscopia fotoacústica acompanha bem os espectros de absorção ótica correspondentes.

\section{IV.4.4 - DETERMINAÇÃO DO COEFICIENTE DE ABSORÇÃO ÓTICA POR ESPECTROSCOPIA PAS}

A equação de Rosencwaig, dada pela expressão (15), é bastante complicada e pouco eficiente para a obtenção do coeficiente de absorção ótica $\beta$. Para alguns casos especiais, podemos simplificar a equação, tornando-a bem mais simples. Para o caso em que a amostra é oticamente transparente $\left(\beta_{s}{ }^{-1}>L_{s}\right)$ e termicamente fina $\left(\mu_{s}>>L_{s}\right.$ e $\left.\mu_{s}>\beta_{s}{ }^{-1}\right)$, podemos fazer 
as seguintes aproximações para poder simplificar a equação (15): $\exp \left(-\beta_{s} L_{s}\right) \cong 1-\beta_{s} L_{s}$, $\exp \left( \pm \sigma_{\mathrm{s}} \mathrm{L}_{\mathrm{s}}\right) \cong 1[45,48,50]$. Com essas aproximações, a equação (15) se reduz a:

$$
\Delta \mathrm{Pn}=\frac{\eta_{s} \beta_{s} L_{s} b_{b s}\left(r_{s}-b_{b s}\right)}{r_{s}\left(b_{g s}+b_{b s}\right)}
$$

Essa equação é uma função complexa, porque apresenta o termo $\mathrm{r}_{\mathrm{s}}$. Determinando $o$ seu módulo, obtemos:

$$
|\Delta \mathrm{Pn}|=\frac{\sqrt{2} b_{b s} L_{s}}{2\left(b_{g s}+b_{b s}\right)} \sqrt{4\left(\frac{\beta}{2 a}-b_{b s}\right)^{2} a^{2}+\beta^{2}}
$$

Nas referências $[45,48,50]$, Rosencwaig utiliza a aproximação $b_{b s} \sim 1$, a fim de simplificar a equação (15) para alguns casos especiais, incluindo aquele em que a amostra é termicamente fina e oticamente transparente. Porém, esta aproximação não se aplica para os nossos filmes de POMA, porque $b_{b s}=19,4$ para a amostra não-dopada e $b_{b s}=8,3$ para a dopada em $\mathrm{HCl} 1$ M. Os parâmetros térmicos para a POMA não-dopada e dopada em $\mathrm{HCl} 1 \mathrm{M}$ foram obtidos nas seções anteriores. Substituindo os valores para os parâmetros e resolvendo a equação (21) para $\beta$, obtém-se duas raízes, onde só uma apresenta valor positivo, sendo, assim, a solução de interesse. As figuras IV.13 e IV.14 fornecem o coeficiente de absorção ótica em função do comprimento de onda para os filmes finos de POMA não-dopado e dopado em $\mathrm{HCl} 1 \mathrm{M}$. 


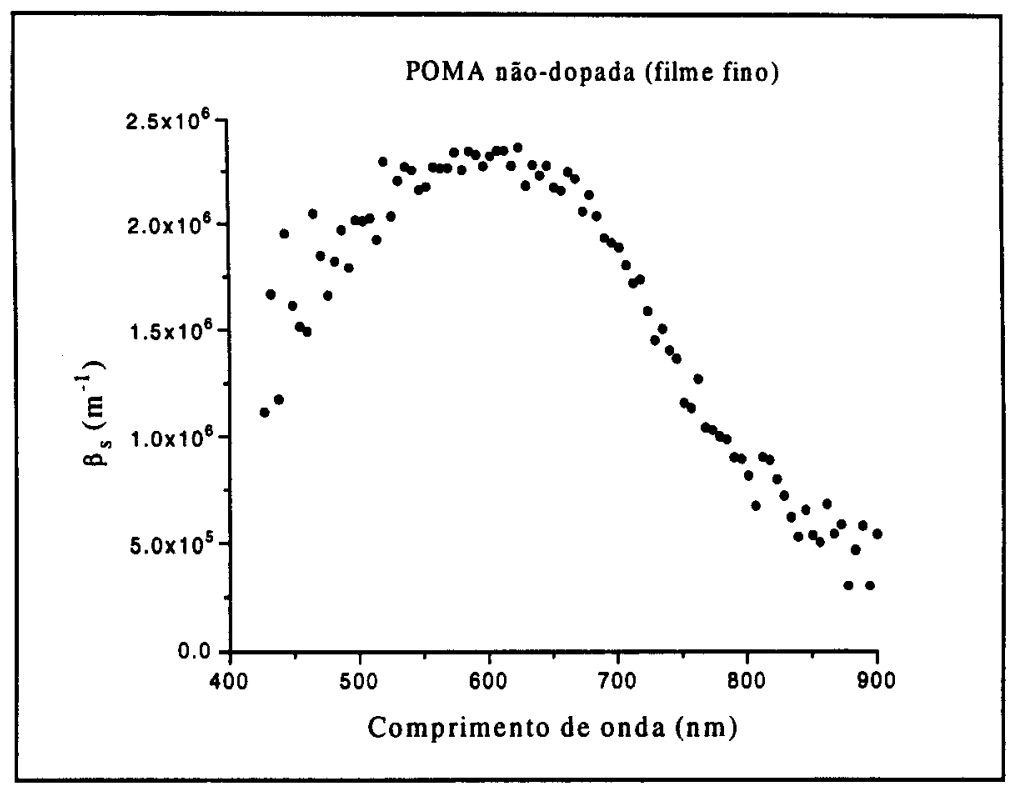

Figura IV.13 - Coeficiente de absorção ótica para o filme fino de POMA não-dopado.

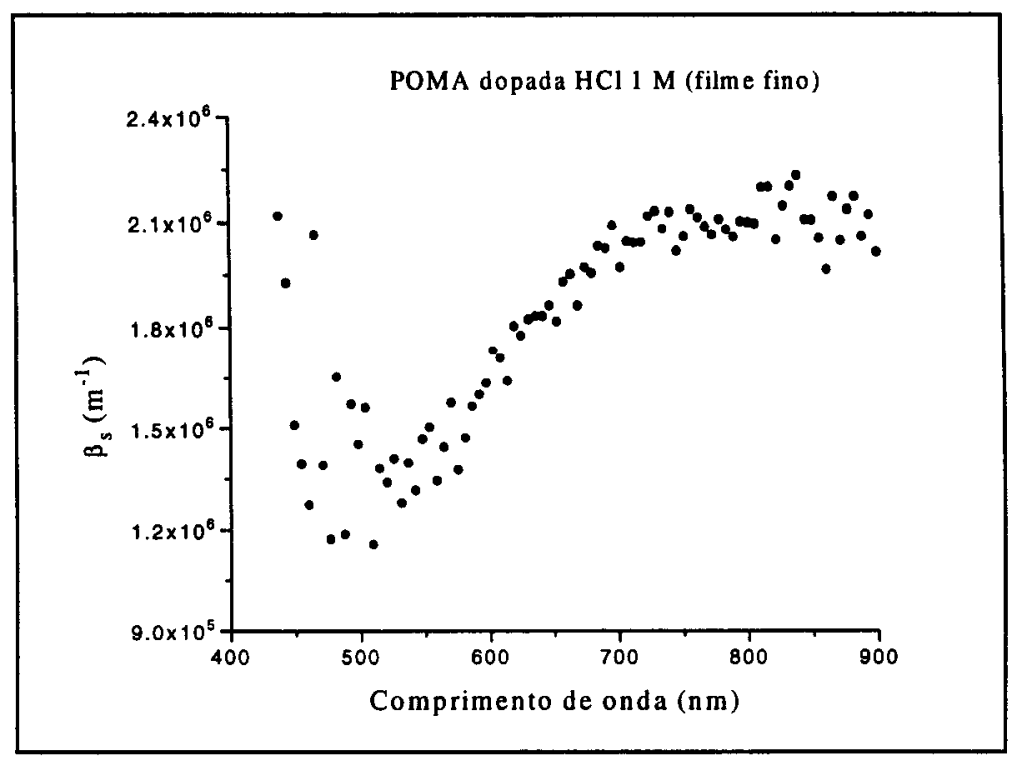

Figura IV.14 - Coeficiente de absorção ótica para o filme fino de POMA dopado em $\mathrm{HCl} 1 \mathrm{M}$.

Os valores de $\beta$ nos máximos das bandas de absorção coincidem muito bem com as intensidades das gaussianas usadas para os ajustes mostrados nas figuras IV.11 e IV.12. Isto comprova que os modelos são coerentes entre si, demonstrando o poder das técnicas fototérmicas para a obtenção dos parâmetros térmicos e óticos de interesse. 
Podemos determinar o gap ótico entre a banda de valência e a banda de éxciton molecular para a POMA não-dopada através do coeficiente de absorção ótica mostrado na figura IV.13. O gap é determinado pelas transições eletrônicas do topo da banda de valência para a banda superior de condução. Assim, transformando o eixo das abscissas do espectro da figura IV.13 para a energia correspondente à transição eletrônica, obtém-se a figura IV.15. O gap ótico é determinado pelo "cotovelo" da curva, isto é, pela interseção das duas retas ajustadas nas duas regiões lineares [54]. O valor para o gap ótico foi de 1,87 eV (que corresponde a $664 \mathrm{~nm}$ ) para o filme de POMA. Este valor pode ser obtido também através do sinal PAS normalizado da figura IV.11. Através dos espectros PPES da figura IV.10, obtivemos o valor 1,81 eV para o gap ótico do filme de POMA de espessura entre 5 e $7 \mu \mathrm{m}$. Essa diferença é devido à obtenção do gap por técnicas fototérmicas com sistemas de deteção de sinal diferentes. Podemos obter o gap ótico para o filme de PANI não-dopado através dos espectros PPES da figura IV.9(a), pelo mesmo processo. O valor do gap obtido para a PANI foi aproximadamente $1,81 \mathrm{eV}$ (que corresponde a $686 \mathrm{~nm}$ ), sendo igual ao da POMA (filme de espessura entre 5 e $7 \mu \mathrm{m}$ ), obtido pela técnica PPES.

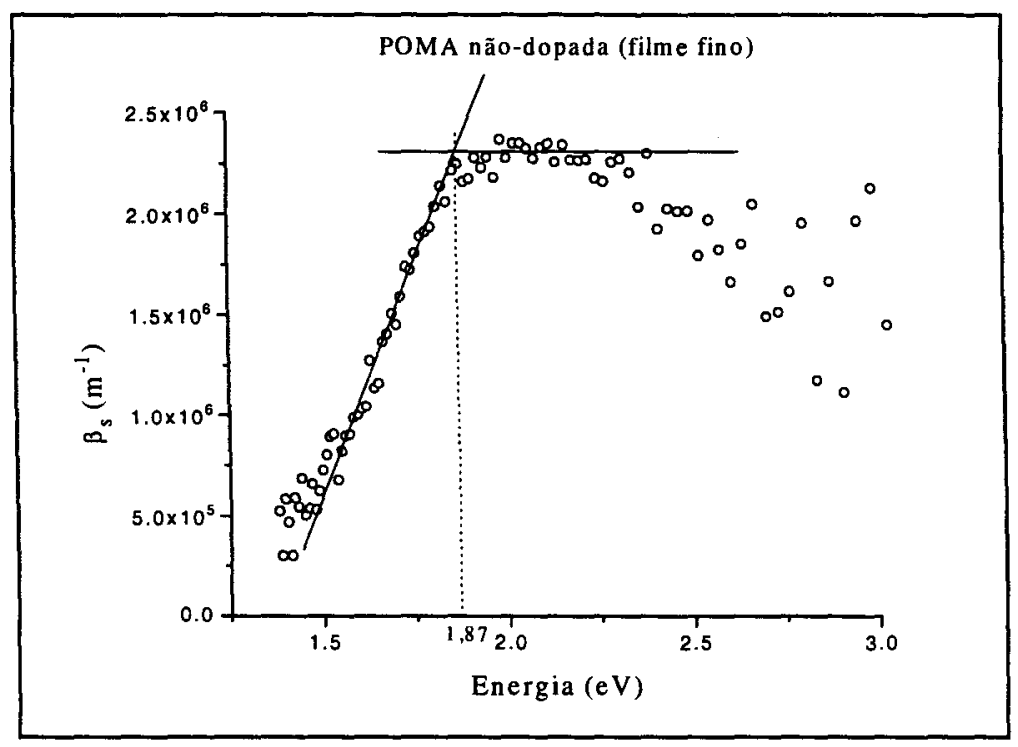

Figura IV.15 - Determinação do gap ótico através do coeficiente de absorção ótica em função da energia da transição eletrônica. 


\section{IV.5 - CONCLUSÕES}

Este capítulo mostrou que as técnicas fototérmicas, fotopiroelétrica e fotoacústica, são de grande utilidade na obtenção de parâmetros térmicos e óticos das polianilinas. Vimos que, apesar de serem técnicas similares, as duas apresentam características próprias, por possuírem sistema de deteção de sinal diferentes. A técnica PPES, em particular, apresenta maior utilidade para a obtenção dos parâmetros térmicos. A PAS veio a comprovar esses dados térmicos e, a partir deles, foi de grande utilidade para a obtenção do coeficiente de absorção ótica, por meio de um processo relativamente simples.

Conforme mencionado no capítulo anterior, foi a técnica PPES que conseguiu revelar o caráter ambíguo dos filmes dopados e não-dopados das polianilinas, isto é, filmes dopados apresentam características dos não-dopados e vice-versa. Sem o auxílio desta técnica, dificilmente chegaríamos a esta conclusão. Esse caráter dual mostrou também que as propriedades térmicas não variam muito para os filmes dopados e não-dopados. Porém, as propriedades óticas variam bastante com o processo de dopagem das polianilinas, como mostram as espectroscopias de absorção ótica e a fotoacústica. Concluímos que as duas técnicas, a PPES e a PAS, se complementam para a determinação dos parâmetros térmicos e óticos.

Vimos que a espessura das amostras é um fator determinante para a precisão dos dados obtidos com os ajustes. Assim, os dados obtidos para o filme de POMA que apresenta a espessura entre 5 e $7 \mu \mathrm{m}$ são pouco precisos, não devido à técnica em si, mas à dificuldade em se obter filmes mais finos de espessura constante pela técnica de casting, usando solventes muito voláteis. A seguir, no próximo capítulo, daremos sugestões para trabalhos futuros nessa área. 
CAPítulo V

\section{CONCLUSÕES FINAIS}




\section{CAP. V - CONCLUSÕES FINAIS}

\section{V.1 - ESTUDO DA INTERCONVERSÃO DOS ESTADOS DE OXIDAÇÃO DAS POLIANILINAS}

Os métodos para a avaliação dos estados de oxidação das polianilinas descritos no capítulo II mostraram que, de uma maneira simples, pode-se obter aproximadamente o estado de oxidação em que o polímero se encontra. A determinação precisa dos estados de oxidação exige métodos de análise mais complexos, como a titulação volumétrica com cloreto de titânio. A análise elementar pode também ser usada para esta determinação, mas este processo exige a síntese do polímero em uma forma completamente pura, sem a presença de subprodutos de reação ou mesmo da água, o que é difícil de se obter. Assim, na prática, ela não tem precisão para determinar corretamente os estados de oxidação do polímero [34].

Mostramos que a precisão das curvas obtidas pela razão das absorções versus estados de oxidação fica limitada pelos erros experimentais. O principal fator de erro foi a formação de precipitado nas soluções. Esse fato pode ter determinado a não-obtenção de pontos isobésticos nas posições características, principalmente no caso da PANI.

O método da deconvolução de bandas enriqueceu o método aqui desenvolvido para a avaliação dos estados de oxidação. A deconvolução das bandas se torna relativamente simples com a utilização de programas matemáticos em microcomputadores. A importância desse trabalho está no fato de não haver ainda uma maneira relativamente simples de avaliar, com certa precisão, os estados de oxidação da polianilina e de seus derivados. $\mathrm{O}$ índice de oxidação (ou de redução) dado por y, é fundamental para estudos posteriores com esses materiais, não só na área de cinética de oxi-redução da cadeia, mas também na cinética de protonação. 
Análise de resultados de condutividade, eletroluminescência, etc., muitas vezes dependem de um conhecimento mais preciso do valor de $\mathrm{y}$.

\section{V.2 - TÉCNICAS FOTOTÉRMICAS APLICADAS ÀS POLIANILINAS NÃO- DOPADAS E DOPADAS}

Os capítulos III e IV, por outro lado, mostraram a utilidade das técnicas fototérmicas na determinação dos parâmetros térmicos e óticos das polianilinas. Das muitas variações das técnicas de espectroscopia fototérmica, aplicamos a mais tradicional, a fotoacústica (PAS), e uma das mais recentes, a fotopiroelétrica (PPES). A espectroscopia fotopiroelétrica, por ser uma técnica de deteção fototérmica direta, apresenta maior utilidade que a fotoacústica na determinação dos parâmetros térmicos. Por outro lado, no caso das polianilinas, a fotoacústica mostrou grande utilidade para a determinação dos parâmetros óticos. Isto porque, a PPES não diferenciou com precisão as amostras dopadas das não-dopadas, principalmente no caso das amostras mais espessas. Porém, se não usássemos a técnica PPES, não chegaríamos à conclusão de que as amostras dopadas apresentam características das não-dopadas e viceversa. Este último resultado permitiu explicar o porquê de as propriedades térmicas das amostras dopadas serem praticamente as mesmas das não-dopadas. Este fato é surpreendente, quando comparamos com as propriedades elétricas, que apresentam variações extremamente grandes para as amostras dopadas em relação às não-dopadas.

A espectroscopia fotoacústica, por ser uma técnica de deteção fototérmica indireta, apresentou um desenvolvimento análogo ao da espectroscopia de absorção ótica convencional para os filmes não-dopado e dopado da polianilina (POMA). A espectroscopia PPES também 
mostrou que, quando o detetor não está em contato com os filmes, apresenta desenvolvimento análogo ao de um espectrômetro de transmitância ótica. Neste caso, o sistema de deteção fototérmica também é indireto. Esses resultados mostraram que as duas técnicas são confiáveis e deram, portanto, suporte à sua utilização como ferramentas úteis para estudos concomitantes de propriedades térmicas e óticas dos polímeros condutores.

\section{V.3 - TRABALHOS FUTUROS}

Como a técnica fotopiroelétrica mostrou uma grande capacidade na determinação de parâmetros térmicos e óticos de filmes de polianilinas dopadas e não-dopadas, o nosso interesse é continuar aplicando esta técnica para o estudo desses polímeros em diversos graus de dopagem. Vimos que, para os filmes espessos, as diferenças espectrais (PPES) foram menores que para os filmes finos. Isto nos induziu a supor que o processo de dopagem pode ser mais eficaz próximo à superfície dos filmes e menos efetivo em seu centro. Este fato precisa ser melhor explorado para outros filmes com diferentes espessuras e usando outros tipos de dopantes, como os ácidos funcionalizados de cadeias longas, a fim de sabermos como o dopante penetra na cadeia polimérica. Com as espectroscopias fototérmicas, podemos realizar um estudo de "perfil de profundidade", variando-se a freqüência de modulação da luz, podendo obter, assim, informações a respeito das camadas mais profundas das amostras. Em baixas frequiências, obtemos informação de suas camadas mais internas, enquanto que em altas frequiências, das camadas mais superficiais. Com isto, podemos monitorar as regiões mais e menos dopadas dos filmes. Este trabalho não foi feito ainda devido às limitações da fonte de luz do equipamento utilizado, que apresentava baixa potência do feixe incidente de 
luz. Para altas frequiências, necessita-se de alta potência da fonte de luz, porque o sinal fica cada vez mais fraco. A fonte de luz halógena utilizada apresentava baixa potência. Esta fonte ainda possui o inconveniente de apresentar muito pouca emissão de luz no ultravioleta (abaixo de $400 \mathrm{~nm}$ ). A fonte de luz de xenônio é mais conveniente para os nossos propósitos.

Os filmes dopados das polianilinas apresentam condutividades elétricas mais de dez ordens de grandeza maiores que os não-dopados. Se for correta a suposição de que o processo de dopagem é mais efetivo nas regiões mais externas da amostra, então a condutividade no interior dos filmes deve ser inferior à da superfície. Nosso intuito é, portanto, fazer essas medidas de condutividade nas partes mais internas dos filmes. Um processo seria preparar filmes espessos e tentar cortá-los obliquamente, a fim de podermos medir a condutividade nos pontos mais internos dos filmes. Se conseguíssemos esse intento, poderíamos comprovar a suposição de que o processo de dopagem é mais efetivo na superfície externa dos filmes.

Temos o propósito de comprovar ainda se o que foi obtido, com a técnica fotopiroelétrica, para os filmes das polianilinas, acontece também para outros tipos de polímeros condutores, como o poliacetileno, o poli(3-butiltiofeno), etc. Isto é interessante para podermos verificar como se processam os diversos tipos de dopagens dos polímeros condutores, em comparação com os dados que obtivemos para as polianilinas. 


\section{REFERÊNCIAS BIBLIOGRÁFICAS}

1. MACDIARMID, A. G.; EPSTEIN, A. J. Makromol. Chem.-Macromol. Symp. 51, 11-28 (1991).

2. MACDIARMID, A. G. Conducting Polymers: Science and Technology, não publicado.

3. HEEGER, A. J.; KIVELSON, S.; SCHRIEFFER, J. R.; SU, W.-P. Rev. Mod. Phys. 60(3), $781-850$ (1988).

4. SALANECK, W. R.; BRÉDAS, J. L. Sol. State Commun. 92(1-2), 31-36 (1994).

5. SALANECK, W. R.; BRÉDAS, J. L. Synth. Met. 67, 15-22 (1994).

6. CAO, Y.; SMITH, P.; HEEGER, A. J. Synth. Met. 48, 91-97 (1992).

7. MASTERS, J. G.; GINDER, J. M.; MACDIARMID, A. G.; EPSTEIN, A. J. J. Chem. Phys. 96(6), 4768-78 (1992).

8. MASTERS, J. G.; SUN, Y.; MACDIARMID, A. G.; EPSTEIN, A. J. Synth. Met. 41-43, 715-718 (1991).

9. MACDIARMID, A. G.; EPSTEIN, A. J. in: Conjugated Polymeric Materials: Opportunities in Electronics, Optoelectronics and Molecular Electronics, ed. by BRÉDAS, J. L.; CHANCE, R. R.; Kluwer Academic Publishers, Netherlands, 1990.

10. CHIANG, J.-C.; MACDIARMID, A. G. Synth. Met. 13, 193-205 (1986).

11. MACDIARMID, A. G.; CHIANG, J.-C.; RICHTER, A. F.; EPSTEIN, A. J. Synth. Met. 18, 285-290 (1987). 
12. RAY, A.; ASTURIAS, G. E.; KERSHNER, D. L.; RICHTER, A. F.; MACDIARMID, A. G. Synth. Met. 29, E141-E150 (1989).

13. ADAMS, P. N.; LAUGHLIN, P. J.; MONKMAN, A. P.; BERNHOEFT, N. Sol. State Commun. 91(11), 875-78 (1994).

14. HUANG, W. S.; HUMPHREY, B. D.; MACDIARMID, A. G. J. Chem. Soc., Faraday Trans. 1 82(8), 2385-2400 (1986).

15. EPSTEIN, A. J.; GINDER, J. M.; ZUO, F.; WOO, H. S.; TANNER, D. B.; RICHTER, A. F.; HUANG, W. S.; MACDIARMID, A. G. Synth. Met. 18, 303-309 (1987).

16. STAFSTRÖM, S.; BRÉDAS, J. L.; EPSTEIN, A. J.; WOO, H. S.; TANNER, D. B.; HUANG, W. S.; MACDIARMID, A. G. Phys. Rev. Lett. 59(13), 1464-67 (1987).

17. GALVÃO, D. S.; SANTOS, D. A.; LAKS, B.; MELO, C. P.; CALDAS, M. J. Phys. Rev. Lett. 63(7), 786-89 (1989).

18. SCHULZ, P. A.; GALVÃO, D. S.; CALDAS, M. J. Phys. Rev. B 44(12), 6073-77 (1991).

19. MASTERS, J. G. PhD. Thesis, University of Pennsylvania, 1992.

20. WAN, M. J. Polym. Sci., Polym. Chem. 30, 543-549 (1992).

21. MONKMAN, A.P.; ADAMS, P. Synth. Met. 41-43, 891-896 (1991).

22. PHILLIPS, S. D.; YU, G.; CAO, Y.; HEEGER, A. J. Phys. Rev. B 39(15), 10702-707 (1989).

23. ZUO, F.; MCCALL, R. P.; GINDER, J. M.; ROE, M. G.; LENG, J. M.; EPSTEIN, A. J.; ASTURIAS, G. E.; ERMER, S. P.; RAY, A.; MACDIARMID, A. G. Synth. Met. 29, E445E450 (1989). 
24. CAO, Y.; SMITH, P.; HEEGER, A. J. Synth. Met. 32, 263-281 (1989).

25. STEJSKAL, J.; KRATOCHVÍL, P.; RADHAKRISHNAN, N. Synth. Met. 61(3), 225-231 (1993).

26. MCCALL, R. P.; GINDER, J. M.; LENG, J. M.; YE, H. J.; MANOHAR, S. K.; MASTERS, J. G.; ASTURIAS, G. E.; MACDIARMID, A. G.; EPSTEIN, A. J. Phys. Rev. B 41(8), 5202-13 (1990).

27. HUANG, W. S.; MACDIARMID, A. G. Polymer 34(9), 1833-45 (1993).

28. DUKE, C. B.; CONWELL, E. M.; PATON, A. Chem. Phys. Lett. 131, 82-86 (1986).

29. STAFSTRÖM, S.; SJÖGREN, B.; BRÉDAS, J. L. Synth. Met. 29, E219-E226 (1989).

30. KIM, Y. H.; FOSTER, C.; CHIANG, J.; HEEGER, A. J. Synth. Met. 26, 49-59 (1988).

31. KIM, Y. H.; FOSTER, C.; CHIANG, J.; HEEGER, A. J. Synth. Met. 29, E285-E290 (1989).

32. NOGUEIRA, J. S. Tese de Doutoramento, IQSC/USP, 1995.

33. MATTOSO, L. H. C. Tese de Doutoramento, UFSCar, 1993.

34. ASTURIAS, G. E.; MACDIARMID, A. G.; MCCALL, R. P.; EPSTEIN, A. J. Synth. Met. 29, E157-E162 (1989).

35. BAUMAN, R. P. Absorption Spectroscopy, John Wiley \& Sons, New York, 1962.

36. HARRIS, D. C.; BERTOLUCCI, M. D. Symmetry and Spectroscopy: An Introduction to Vibrational and Electronic Spectroscopy, Dover Publications, New York, 1978. 
37. KAPLAN, S.; CONWELL, E. M.; RICHTER, A. F.; MACDIARMID, A. G. Synth. Met. 29, E235-E242 (1989).

38. BARLTROP, J. Principles of Photochemistry, Ann Arbor, London, 1978.

39. CANTOR, C. R.; SCHIMMEL, P. R. Biophysical Chemistry, Part II: Techniques for the study of biological structure and function, W. H. Freeman and Company, New York, 1980.

40. MATTOSO, L. H. C.; MACDIARMID, A. G. "Polyanilines, Oxidation States", in: The Polymeric Materials Encyclopedia, ed. by SALAMONE, J. C.; CRC Press, Florida, 1996, em impressão.

41. ROSENCWAIG, A. Opt. Commun. 7(4), 305 (1973).

42. ROSENCWAIG, A. Anal. Chem. 47(60), 592A (1975).

43. ROSENCWAIG, A. Phys. Today 28(9), 23 (1975).

44. ROSENCWAIG, A.; GERSHO, A. Science 190, 556 (1975).

45. ROSENCWAIG, A.; GERSHO, A. J. Appl. Phys. 47 (1), 64 (1976).

46. ROSENCWAIG, A. Rev. Sci. Instrum. 48(9), 1133 (1977).

47. ROSENCWAIG, A. J. Appl. Phys. 49 (5), 2905 (1978).

48. ROSENCWAIG, A. "Solid State Photoacoustic Spectroscopy", in Optoacoustic Spectroscopy and Detection, ed. PAO, Y.-H.; Academic Press, New York, 1977, cap.8.

49. BLANK, R. E.; WAKEFIELD, T. Anal. Chem. 51(1), 50 (1979). 
50. ROSENCWAIG, A. Photoacoustics and Photoacoustic Spectroscopy, John Wiley \& Sons, New York, 1980.

51. COUFAL, H. Appl. Phys. Lett. 44(1), 59-61 (1984).

52. MANDELIS, A. Chem. Phys. Lett. 108(4), 388-92 (1984).

53. MANDELIS, A.; ZVER, M. M. J. Appl. Phys. 57(9), 4421-30 (1985).

54. MELO, W. L. B. Tese de Doutoramento, IFQSC/USP, 1992.

55. MELO, W. L. B.; PAWLICKA, A.; SANCHES, R.; MASCARENHAS, S.; FARIA, R. M. J. Appl. Phys. 74(2), 979-82 (1993).

56. CHRISTOFIDES, C. Crit. Rev. Sol. State Mat.Sci. 18 (2), 113-174 (1993).

57. CHRISTOFIDES, C.; MANDELIS, A.; GHANDI, K.; WAGNER, R. E. Rev. Sci. Instrum. 61 (9), 2360-67 (1990).

58. COUFAL, H.; MANDELIS, A. Ferroelectrics 118, 379-409 (1991).

59. CHRISTOFIDES, C.; ENGEL, A.; MANDELIS, A. Ferroelectrics 118, 411-424 (1991).

60. CHRISTOFIDES, C.; GHANDI, K.; MANDELIS, A. Meas. Sci. Technol. 1, 1363-70 (1990).

61. COUFAL, H.; MANDELIS, A. "Photopyroelectric Spectroscopy of Semiconductors", in: Photoacoustic and Thermal Wave Phenomena in Semiconductors, ed. by MANDELIS, A.; Elsevier Science Publishing Co., New York, 1987.

62. MASTERS, J. G.; MACDIARMID, A. G.; KIM, K.; GINDER, J. M.; EPSTEIN, A. J. Bull. Am. Phys. Soc. 36(3), 377 (1991). 
63. THORNE, J. R. G.; MASTERS, J. G.; WILLIAMS, S. A.; MACDIARMID, A. G.; HOCHSTRASSER, R. M. Synth. Met. 49-50, 159-165 (1992).

64. TOYODA, T.; NAKAMURA, H. Synth. Met. 69 (1-3), 227-228 (1995).

65. TOYODA, T.; NAKAMURA, H. Jap. J. Appl. Phys. Part 134 (5B), 2907-10 (1995).

66. GINDER, J. M.; RICHTER, A. F.; MACDIARMID, A. G.; EPSTEIN, A. J. Sol. State Commun. 63, 97 (1987).

67. WANG, Z. H.; RAY, A.; MACDIARMID, A. G.; EPSTEIN, A. J. Phys. Rev. B 43(5), 4373-84 (1991).

68. WANG, Z. H.; LI, C.; SCHERR, E. M.; MACDIARMID, A. G.; EPSTEIN, A. J. Phys. Rev. Lett. 66(13), 1745-48 (1991).

69 WANG, Z. H.; LI, C.; SCHERR, E. M.; MACDIARMID, A. G.; EPSTEIN, A. J. Phys. Rev. B 45(8), 4190-4202 (1992).

70. LEPIENSKI, C. M.; FERREIRA, G. F. L.; FARIA, R. M. submetido.

71. JEON, D.; KIM, J.; GALLAGHER, M. C.; WILLIS, R. F. Science 256, 1662 (1992). 


\section{APÊNDICE A}

O módulo da equação de Mandelis na região saturada, dada pela equação (16) do capítulo IV, é fornecida abaixo. Ela é dada em módulos, onde a intensidade do sinal Vn é o último termo escrito em função dos outros.

$$
\begin{aligned}
& a_{s}=\left(\frac{\pi f}{\alpha}\right)^{1 / 2} \\
& \mathrm{~A}=\left[\left(b_{g s}+1\right)\left(b_{p s}+1\right) e^{a_{s} L_{s}}-\left(b_{g s}-1\right)\left(b_{p s}-1\right) e^{-a_{s} L_{s}}\right] \cos \left(a_{s} L_{s}\right) \\
& \mathrm{B}=\left[\left(b_{g s}+1\right)\left(b_{p s}+1\right) e^{a_{s} L_{s}}+\left(b_{g s}-1\right)\left(b_{p s}-1\right) e^{-a_{s} L_{s}}\right] \operatorname{sen}\left(a_{s} L_{s}\right) \\
& \mathrm{Vn}=\frac{2 \eta_{s}\left(b_{g s}+b_{p s}\right)}{\sqrt{A^{2}+B^{2}}}
\end{aligned}
$$




\section{APÊNDICE B}

O módulo da equação de Mandelis, dada no capítulo IV, expressão (9), é fornecida abaixo para o caso dos filmes espessos de PANI. Ela está na forma apresentada pelo programa matemático "Maple V", sendo escrita em módulos, onde a intensidade do sinal Vn é o último termo, sendo dado em função dos outros. As três gaussianas são os termos C3, C4 e C5. Foi considerado que $b_{\mathrm{gs}}=2.769 \times \mathrm{b}_{\mathrm{ps}}$. A espessura da amostra é $\mathrm{L}$.

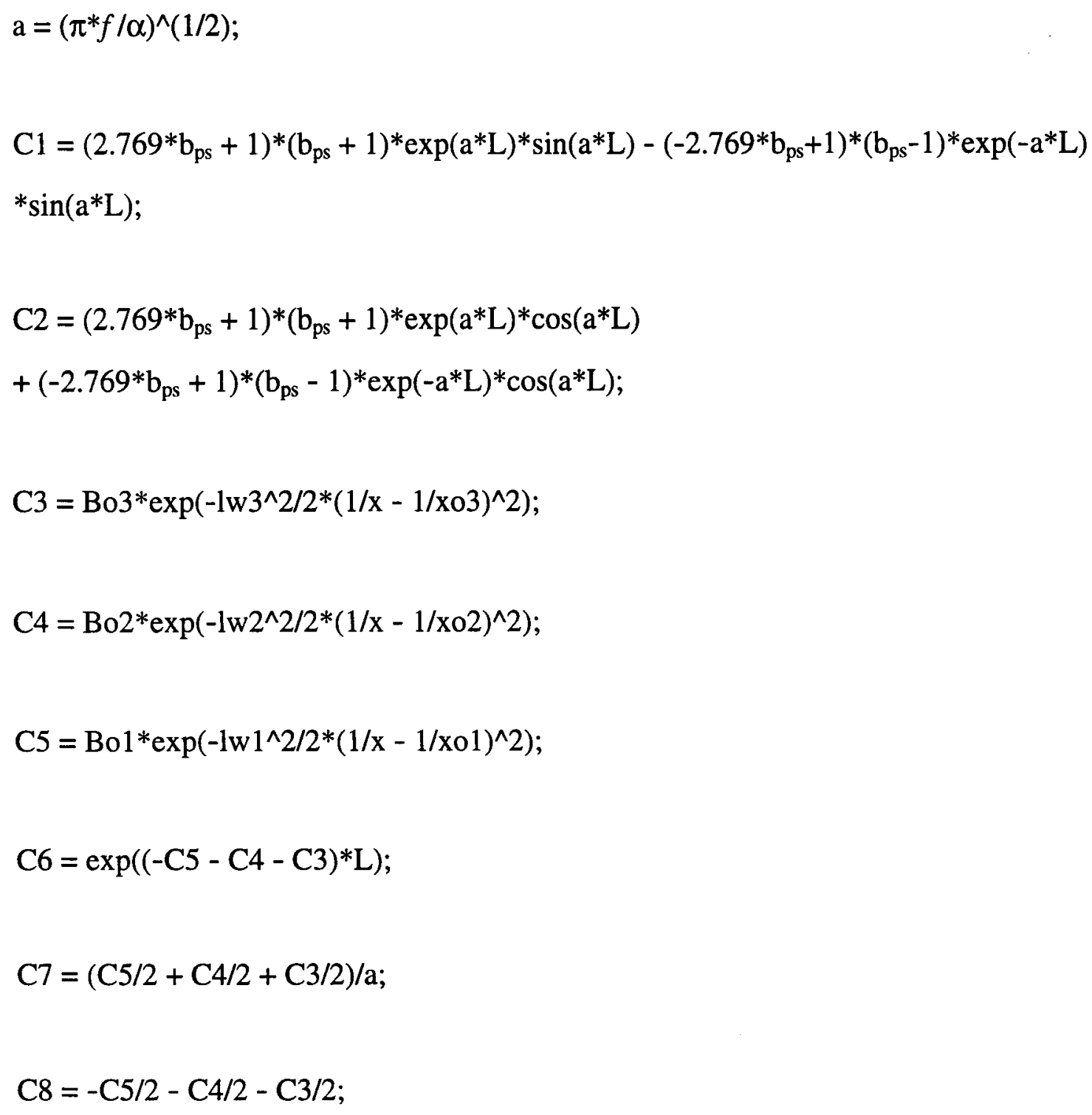




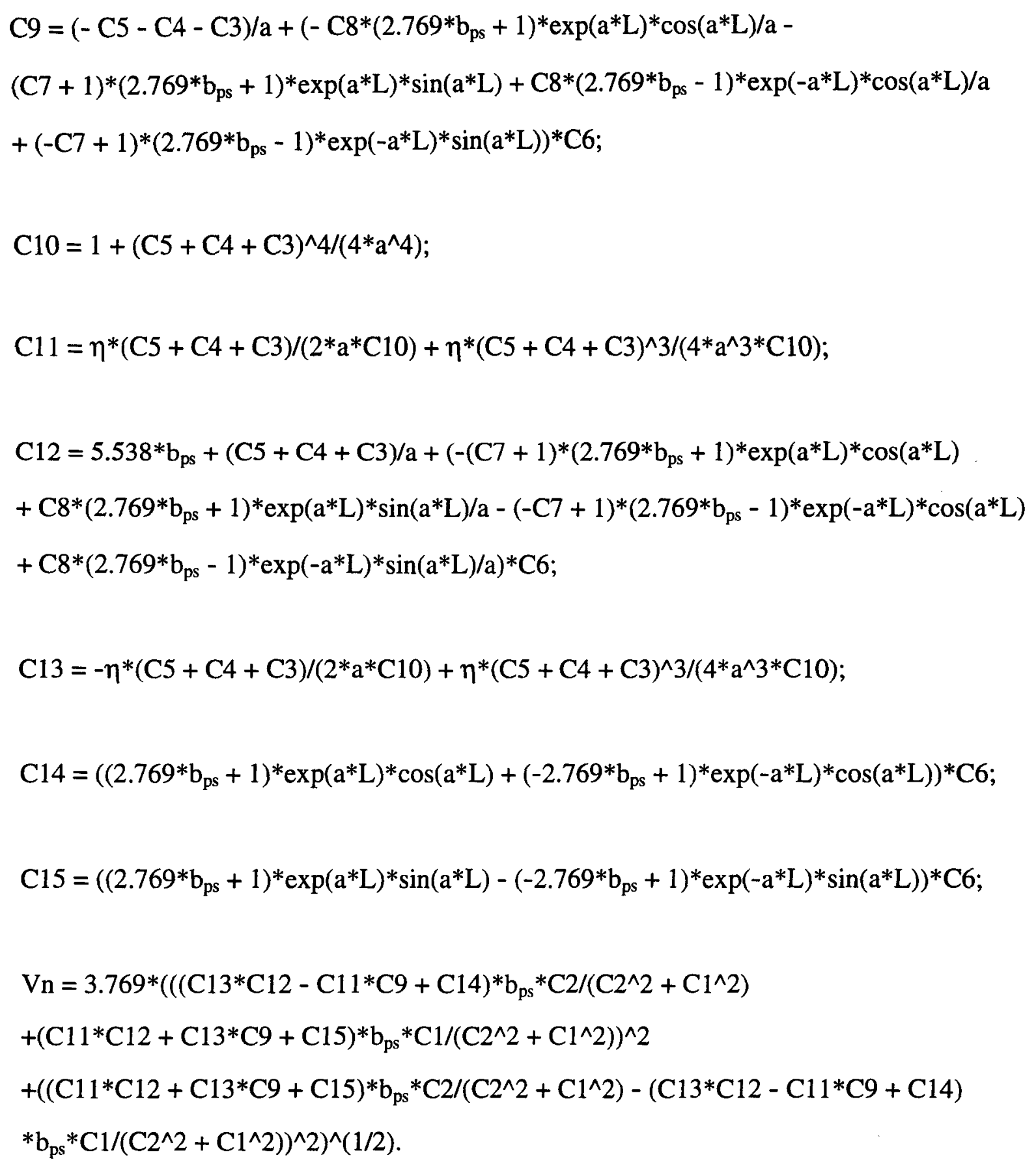




\section{ERRATA}

Na página 105 , na $12 .^{\mathrm{a}}$ linha, onde se lê:

“ As figuras III.5 e III.6 do capítulo anterior ..."

ie:

Is figuras III.7 e III.8 do capítulo anterior ...." 